\title{
Optimal Anchoring of a Urea-based Foldamer Inhibitor of ASF1 Histone Chaperone Through Backbone Plasticity
}

\author{
Johanne Mbianda, ${ }^{1 \dagger}$ May Bakail, ${ }^{2,3 \dagger}$ Christophe André, ${ }^{1}$ Gwenaëlle Moal,,${ }^{2,3}$ Marie E. Perrin,, 3 \\ Raphaël Guerois, ${ }^{2,3}$ François Becher, ${ }^{1}$ Pierre Legrand, ${ }^{4}$ Seydou Traoré,, 3 Céline Douat ${ }^{1+}$, Gilles \\ Guichard, ${ }^{1 *}$ Françoise Ochsenbein ${ }^{2,3 *}$ \\ ${ }^{1}$ Univ. Bordeaux, CNRS, Bordeaux INP, CBMN, UMR 5248, Institut Européen de Chimie et Biologie, 2 rue Robert \\ Escarpit, F-33607 Pessac (France) \\ ${ }^{2}$ Institute Joliot, Commissariat à l'énergie Atomique (CEA), Direction de la Recherche Fondamentale (DRF), CEA \\ Saclay, F91191 Gif-sur-Yvette, France \\ ${ }^{3}$ Institute for Integrative Biology of the Cell (I2BC), CEA, CNRS, Université Paris-Saclay, 91198, Gif-sur-Yvette \\ cedex, France \\ ${ }^{4}$ Synchrotron SOLEIL, L'Orme des Merisiers, F91190 Gif-sur-Yvette, France \\ $¥$ Present adress : Department of Pharmacy and Center for Integrated Protein Science ,Ludwig-Maximillians- \\ Universität, Butenandtstr. 5-13, 81377 München, Germany \\ $\dagger$ These authors contributed equally to this work \\ * corresponding authors : g.guichard@iecb.u-bordeaux.fr; francoise.ochsenbein@cea.fr
}

\begin{abstract}
Sequence-specific oligomers with predictable folding patterns, i.e. foldamers provide new opportunities to mimic $\alpha$-helical peptides and design inhibitors of protein-protein interactions. One major hurdle of this strategy is to retain the correct orientation of key side chains involved in protein surface recognition. Here, we show that the structural plasticity of a foldamer backbone may significantly contribute to the required spatial adjustment for optimal interaction with the protein surface. By using oligoureas as $\alpha$-helix mimics, we designed a foldamer/peptide hybrid inhibitor of histone chaperone ASF1, a key regulator of chromatin dynamics. The crystal structure of its complex with ASF1 reveals a striking plasticity of the urea backbone, which adapts to the ASF1 surface to maintain the same binding interface. One additional benefit of generating ASF1 ligands with non-peptide oligourea segments is the resistance to proteolysis in human plasma which was highly improved compared to the cognate $\alpha$-helical peptide.
\end{abstract}

\section{INTRODUCTION}

The synthesis of sequence-specific synthetic oligomers that fold into well-defined helical structures has opened up enticing opportunities for mimicking $\alpha$-helical peptides and addressing some of their limitations in biomedical applications.(1-5) The improved resistance to proteolysis demonstrated by a number of peptidomimetic foldamer backbones including peptoids, $(6) \beta$-and $\gamma$ peptides,(7-9) $\gamma$-AA-peptides,(10) N,N'-linked oligourea foldamers(11) and many others.(1-4) is a significant advantage that can translate into increased duration of action. Moreover, the use of artificial backbones as $\alpha$-helix mimics can lead to ligands with unusual receptor-activation profiles, $(12,13)$ inhibitors of protein-protein interactions with increased selectivity $(14)$ and cell permeability. $(10,15)$ However, one challenge associated with the use of foldamers for specific recognition of protein surface is to position the side chains at the surface of the foldamer with the correct spacing and orientation to maintain key contacts with the targeted protein surface. One emerging approach to elaborate such ligands consists in redesigning $\alpha$-helical peptides by combining $\alpha$-peptide and foldamer backbones in a single chain. This has been successfully achieved with $\alpha / \beta$ peptides by introducing regularly spaced $\beta$-amino acid residues to replace $\alpha$-amino acids along the 
sequence of interest to generate.(16-18) Similarly, we have recently shown that peptide-oligourea replacements can be used to produce analogues of class-B GPCR ligands with improved duration of action and to mimic protein tertiary folds. $(19,20)$ The choice of replacing a peptide segment with an oligourea insert is explained by the similarity and compatibility of the two helical folds and by the possibility to control the nature and the distribution of side chains at the surface of the oligourea helix.(21) In the work on GPCR ligands (incretins) we actually scanned the entire helical portion of the peptide by swapping four consecutive amino acids for three ureido residues ( $\mathrm{Ala}^{\mathrm{u}} \mathrm{Ala}^{\mathrm{u}} \mathrm{Ala}^{\mathrm{u}}$ scan) to identify the most effective positions for oligourea inserts.(19) However, the impact of replacing key anchor residues at sites that directly contact a protein surface by an oligourea foldamer has not yet been investigated in detail. This is particularly relevant if one aims to develop short oligourea/peptide hybrids that can disrupt protein-protein interactions. To address this question and investigate how to appropriately position side chains along the oligourea backbone while retaining recognition properties, we selected Anti-silencing function 1 (ASF1) histone chaperone as a protein target.

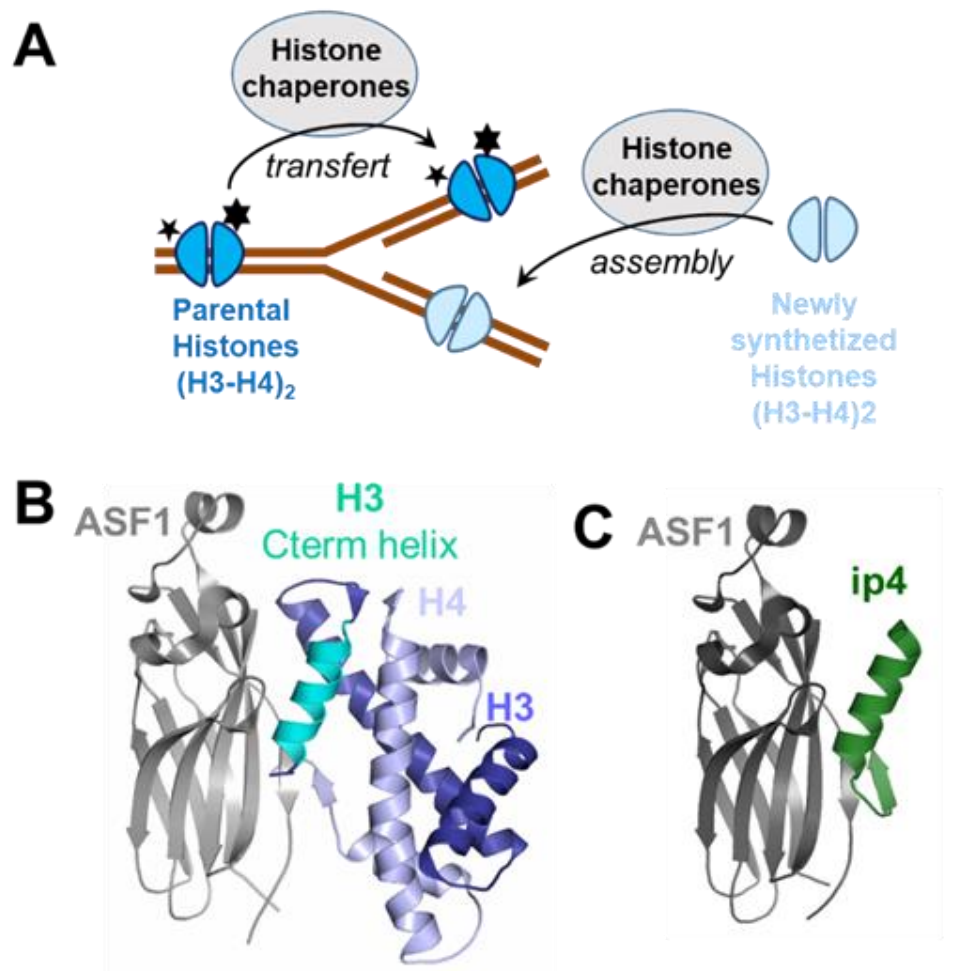

Fig. 1. The histone chaperone ASF1 target. (A) ASF1 belongs to the histone chaperone family whose members are involved in the transfer and assembly of parental histones (which are highly modified and carry essential epigenetic marks represented as stars) and newly synthetized histones during the process of DNA replication. (B) Structure of the ternary complex hASF1A(1-175)-H3-H4 (pdb 2io5). (C) Structure of the complex hASF1A(1-156)ip4 (pdb 6foh).(30)

Histone chaperones regulate histone dynamics within chromatin and the establishment of numerous epigenetic markers (Fig. 1A). Their dysfunction is associated with a number of pathologies including aging-related diseases, pathogen infections or cancer.(22) Anti-silencing function 1 (ASF1) histone $\mathrm{H} 3-\mathrm{H} 4$ chaperone is critically involved in nucleosome assembly/disassembly and regulation of gene expression. In human, two Asf1 paralogs exist, called Asf1A and Asf1B. They share 70\% of 
sequence identity and exhibit redundant and specific functions.(23) Depletion of ASF1A/ASF1B or ASF1A+ASF1B has been shown to block proliferation in various cancer cell lines and to sensitize cells to chemotherapeutic agents such as doxorubicin.(24) Over-expression of ASF1B in breast cancer patients is a marker of poor prognosis,(25) while ASF1A overexpression is observed in liver, prostate or gastric carcinoma. $(26,27)$ Altogether, these findings make ASF1A/ASF1B appealing biological targets for innovative anti-cancer treatments. Details of the interaction between ASF1 and its protein partners including $\mathrm{H} 3-\mathrm{H} 4$ have been gathered at atomic resolution and involve a binding surface fully identical for both paralogs (Fig. 1B). $(28,29)$ The specific recognition of the heterodimeric H3-H4 complex by ASF1 involves several shallow pockets distributed over a large surface area that renders the use of small molecule-based approaches highly challenging.

By using an iterative structure-guided approach, we recently designed 26-residues peptide called ip4, ASTEEKWARLARRIAGAGGVTLDGFG exhibiting an affinity for ASF1 in the low nanomolar-range. This peptide is composed of two parts, an $\alpha$-helical segment derived from histone $\mathrm{H} 3$-C-terminal helix covalently linked to a $\beta$-strand originating from histone $\mathrm{H} 4-\mathrm{C}$-terminus. The high resolution structure of ip4 in complex with ASF1 showed that its helical moiety interacts in a manner similar to histone $\mathrm{H} 3$ and arbors four of the five hot-spot residues of the interaction (Lys2, Leu6, Arg9 and Ile10) (Fig. 1C and Fig. S5A).(30) Upon conjugation to a cell-penetrating peptide (CPP), ip4 was able to translocate into cells, impair cell proliferation and perturb the cell cycle progression similarly to the silencing of ASF1.(30) Injection of this conjugate in mouse allografts reduced tumor growth. However, further exploration of its therapeutic potential was early compromised by its sensitivity to protease degradation.

To address this limitation, we developed a strategy based on rational design and foldamer chemistry to mimic the $\alpha$-helical part of ip4 and reproduce its binding mode. Herein, we report the identification of peptide/oligourea hydrids that recognize and bind to the surface of ASF1 as well as the first X-ray structure at atomic resolution of a foldamer ligand bound to this histone chaperone.

\section{RESULTS AND DISCUSSION}

Defining the minimal helical part required for ASF1 binding. At first, we synthesized the hexadecapeptide P1 corresponding to the $\alpha$-helical segment of ip4 as a reference of binding to ASF1. It contains the four anchor residues, Lys2, Leu6, Arg9 and Ile10 that are buried in specific pockets upon binding and mainly interact with Asp54, Asp88, Val94, Leu96, Tyr112 and Arg146 residues at the surface of ASF1 (Fig. 2, Fig. 4A). This peptide displays an affinity for the conserved domain of human ASF1A (hASF1A(1-156)) of $0.13 \pm 0.04 \mu \mathrm{M}$ as measured by isothermal titration microcalorimetry (ITC) (Table 1, Fig. S2) which is a 10-fold decrease in affinity with respect to ip4. This peptide possesses a N-terminal capping motif (Ala-Ser-Thr-Glu) and a C-terminal Gly residue, also known to favor helix capping.(31) Because our goal was to prepare minimal foldamer sequences, we next synthesized two derivatives of $\mathbf{P 1}$ missing the $\mathrm{N}$-terminal capping motif and bearing either the C-terminal Gly residue (P2) or not (P3) (Fig. 2). These two peptides exhibited an affinity for ASF1 in the submicromolar range with $\mathrm{K}_{\mathrm{D}}=0.44 \pm 0.02 \mu \mathrm{M}$ and $0.27 \pm 0.07 \mu \mathrm{M}$ for P2 and P3, respectively (Table 1, Fig. S2). P3 lacking both capping motifs showed a slight increase in affinity for ASF1 compared to $\mathbf{P 2}$. We thus decided to focus our design on sequences lacking the terminal Gly residue. As in ip4, peptides P1-P3 contain a Trp in position 3 whose indole side-chain enables favorable interactions with the apolar patch in ASF1 formed by Val92 and Tyr112. In our previous study, we showed that Trp3 combined with the ASTE motif led to a 10-fold increase in the affinity for ASF1.(30) With the aim to further improve apolar contacts with the surface of ASF1, we substituted Trp3 in $\mathbf{P 3}$ by a napthylalanine (Nal3 in P4) (Fig. 2). The binding affinity remained in the same range as that of $\mathbf{P 3}$ but the analysis of the thermodynamic parameters indicated a more favorable contribution to binding entropy (Table 1, Fig. S2). 


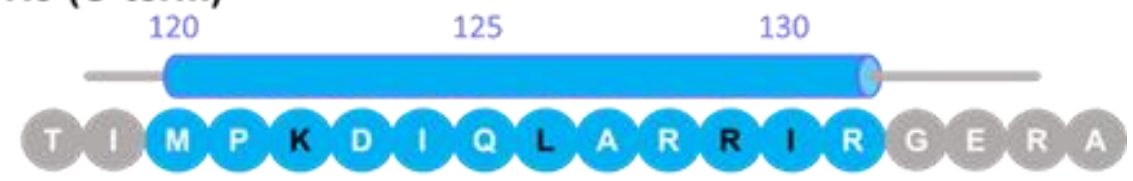

\section{H3-derived peptides $(P)$}

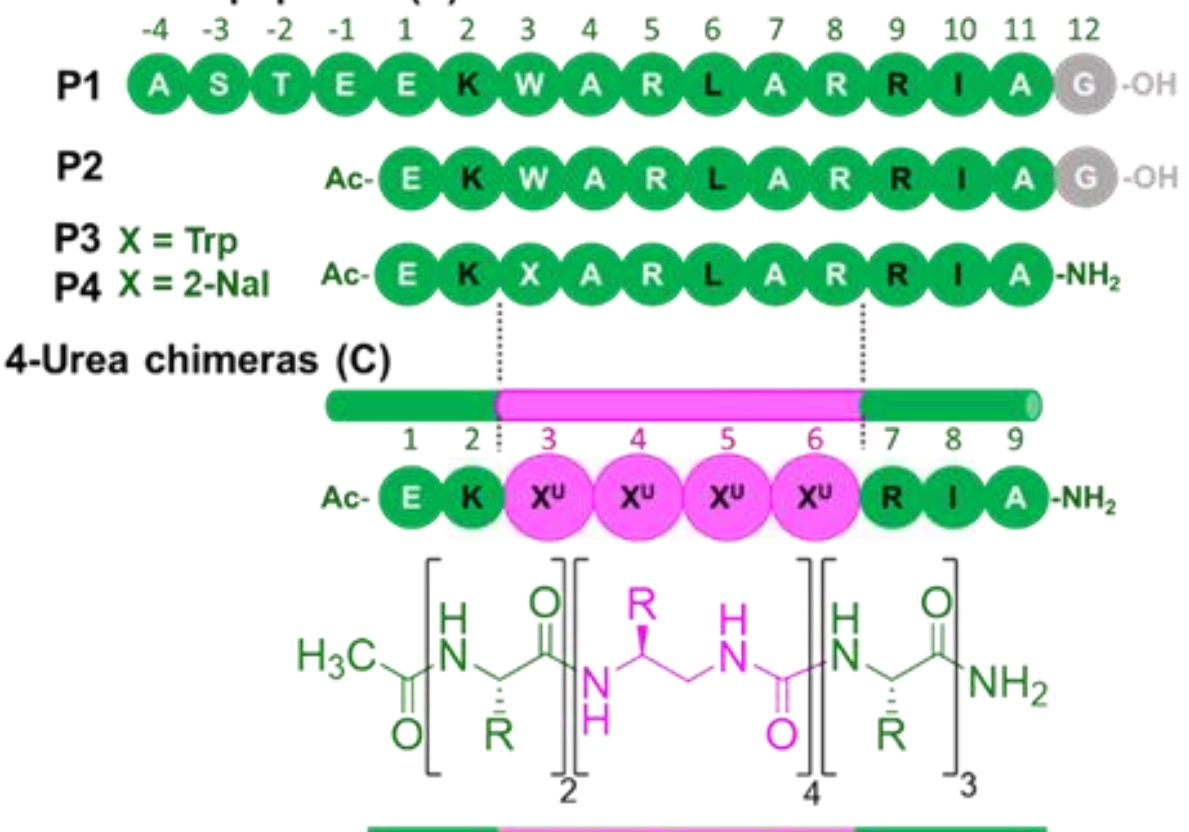

\begin{tabular}{|c|c|c|c|c|c|c|c|c|c|}
\hline C1 & $A C-E$ & K & $\operatorname{Trp}^{\prime}$ & $\operatorname{Arg}^{\circ}$ & Leu & GIn & $\mathbf{R}$ & 1 & A \\
\hline 2 & $A C-E$ & K & $\mathrm{Nal}^{3}$ & Argu & Leu" & Ginu & $\mathbf{R}$ & 1 & \\
\hline C3 & Ac- E & K & Fu & Argu & Leu & Ginu & $\mathbf{R}$ & I & \\
\hline C4 & $A C-E$ & K & $\mathrm{Ala}^{\mathrm{U}}$ & Argu & Leu & $\operatorname{Gln} U$ & $\mathbf{R}$ & 1 & \\
\hline 5 & $\mathrm{AC}-\mathrm{E}$ & $\mathrm{E}$ & $\mathrm{Nal}^{\mathrm{U}}$ & Argu & Leu" & $\operatorname{Gin}$ & $\mathbf{R}$ & 1 & \\
\hline 06 & $A C-E$ & K & $\mathrm{Nal}^{\mathrm{U}}$ & Argu & $\mathrm{Nlo}^{\mathrm{\nu}}$ & $\operatorname{Gin} U$ & $\mathbf{R}$ & 1 & \\
\hline C7 & & $E$ & Nalu & Argu & hPhel & Ginu & $\mathbf{R}$ & & \\
\hline & $A C-E$ & E & $\mathrm{Nal}^{4}$ & Argu & Nalo & GIn & $\mathbf{R}$ & 1 & \\
\hline & & $E$ & $\mathrm{Nal}^{4}$ & Argu & difu & GIn & $\mathbf{R}$ & 1 & \\
\hline & & E K & $\mathrm{Nal}^{\mathrm{U}}$ & Argu & Leu & GInU & $\mathbf{R}$ & 1 & A \\
\hline
\end{tabular}

P5

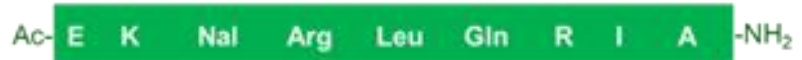

Fig. 2. List of peptides (P) and 4-Urea chimera (C) synthetized and analyzed in this study.

Design of a peptide-oligourea chimera C1-C2, mimicking the helical part of ip4. In a second round of design, we overlaid the X-ray crystal structure (pdb 6foh, Fig. 1C) of the Asf1-bound helical domain of ip4 (i.e. sequence P1) with representative oligourea X-ray crystal structures to identify the optimal location for oligourea segment insertion. $(21,32)$ We decided to replace the six central $\alpha$-residues in the sequence of $\mathbf{P 3}$ and $\mathbf{P 4}$ by four consecutive urea-type residues $\left(\mathrm{X}^{\mathrm{U}}\right.$ in Fig. 2). Models of the resulting 4-urea chimeras $\mathbf{C 1}$ and $\mathbf{C} 2$ were constructed assuming that the peptideurea-peptide helices are fully formed. $\mathbf{C} \mathbf{1}$ and $\mathbf{C} \mathbf{2}$ distinguish from one another solely by a Trp ${ }^{\mathrm{U}}$ or a $\mathrm{Nal}^{\mathrm{U}}$ residue at position 3 respectively. Both chimeras were properly docked to ASF1 surface without generating major clashes (Fig. S5A, middle panel). In this model, it was indeed possible to place three out of the four anchor residues very close to their respective position in the ip4/ASF1 X-ray crystal 
structure ( $\alpha$ carbons of Leu ${ }^{\mathrm{U}} 5$, Arg7 and Ile8, in C2 matching those of Leu6, Arg9 and Ile10 in P1 by less than $1.5 \AA$ respectively). However, the fourth anchor, Lys2, could not be properly aligned and lied away from the surface of ASF1, at more than $3 \AA$ from its position in the ip4/ASF1 X-ray crystal structure (Fig. 4E, middle panel, Fig. S5, middle panel).

The C1-C2 chimeras were prepared by solid phase synthesis using microwave assistance and appropriately protected succinimidyl carbamate building blocks for the construction of the oligourea segment (see supporting information for details, Table S1, Fig. S1).(33) The binding affinities of $\mathbf{C 1}$ and $\mathbf{C 2}$ for ASF1 were first measured by ITC (Table 1, Fig. S2). C2 exhibits a low micromolar affinity for the protein target $\left(\mathrm{K}_{\mathrm{D}}=2.7 \pm 0.6 \mu \mathrm{M}\right)$ while $\mathbf{C 1}$ has a 4-fold weaker affinity, showing the beneficial effect of $\mathrm{Nal}^{\mathrm{U}} 3$ residue over $\operatorname{Trp}^{\mathrm{U}} 3$. Overall, C1-C2 chimeras exhibit affinities 10 to 80 times lower than the P1-P4 peptide series, with a 13-fold affinity drop of C1 for ASF1 with respect to $\mathbf{P 4}$. In addition to binding affinities, microcalorimetry allowed us to measure the enthalpic and entropic contributions to the binding free energy for all peptides and chimeras (Table 1). Remarkably, binding of P1-P4 peptides to ASF1 is dominated by both a significant enthalpic contribution $(\Delta \mathrm{H}$ ranging from -9.2 to $-11.7 \mathrm{kCal} / \mathrm{Mol})$ and entropic cost $(-\mathrm{T} \Delta \mathrm{S}$ ranging from 0.7 to $2.9 \mathrm{kCal} / \mathrm{M}$ ). In contrast, the enthalpic contribution of ASF1 binding to chimeras C1-C2 (and also of all other chimeras analyzed in this study C1-C10) is much lower $(\Delta \mathrm{H}$ ranging from -3.6 to -1.7 $\mathrm{kCal} / \mathrm{M})$ but is associated with a favorable entropic contribution (-T $\Delta \mathrm{S}$ varying from -4.8 to -2.7 $\mathrm{kCal} / \mathrm{M})$. This entropy-driven binding mode of chimeras could likely reflect their favorable structural pre-organization with modest conformational entropy cost upon binding and/or favorable contribution of hydrophobic interactions to the binding free energy. The modest enthalpy gain of chimeras upon ASF1 binding may account for a less optimized interface in terms of packing, H-bond network and/or electrostatics.

Table 1. Binding affinities and thermodynamic parameters of peptides/chimeras for hASF1A determined by ITC measurements and NMR spectroscopy. [a] Not determined, [b] Binding curves are shown in Fig. S2, [c] Binding curves are shown in Fig. S4.

\begin{tabular}{llllll}
\hline $\begin{array}{l}\text { Peptide/ } \\
\text { Chimera }\end{array}$ & $\begin{array}{l}K_{\mathrm{D}}(\mu \mathrm{M}) \\
{[\mathrm{a}, \mathrm{b}]}\end{array}(\mathrm{ITC})$ & $\mathrm{N}^{[\mathrm{a}]}$ & $\begin{array}{l}\Delta \mathrm{H}^{[\mathrm{a}]} \\
(\mathrm{kCal} / \mathrm{M})\end{array}$ & $\begin{array}{l}-\mathrm{T} \Delta \mathrm{S} \\
(\mathrm{kCal} / \mathrm{M})\end{array}$ & $\begin{array}{l}K_{\mathrm{D}}(\mu \mathrm{M}){ }^{[\mathrm{c}]} \\
(\mathrm{NMR})\end{array}$ \\
\hline P1 & $0.13 \pm 0.04$ & $1.0 \pm 0.1$ & $-11.7 \pm 0.4$ & $2.9 \pm 0.4$ & $\mathrm{ND}$ \\
P2 & $0.44 \pm 0.02$ & $1.1 \pm 0.2$ & $-10.3 \pm 0.6$ & $2.2 \pm 0.6$ & $\mathrm{ND}$ \\
P3 & $0.27 \pm 0.07$ & $1.0 \pm 0.1$ & $-10.5 \pm 0.8$ & $2.2 \pm 0.9$ & $\mathrm{ND}$ \\
P4 & $0.20 \pm 0.09$ & $1.0 \pm 0.1$ & $-9.2 \pm 0.4$ & $0.7 \pm 0.6$ & $\mathrm{ND}$ \\
\hline C1 & $10.6 \pm 3.8$ & $1.2 \pm 0.2$ & $-3.6 \pm 0.5$ & $-2.7 \pm 0.7$ & $18 \pm 6$ \\
C2 & $2.7 \pm 0.6$ & $1.0 \pm 0.1$ & $-2.2 \pm 0.1$ & $-4.8 \pm 0.2$ & $4 \pm 1$ \\
C3 & $4.6 \pm 0.3$ & $1.0 \pm 0.1$ & $-3.3 \pm 0.1$ & $-3.5 \pm 0.7$ & $6 \pm 3$ \\
C4 & $13.3 \pm 3.5$ & $1.1 \pm 0.2$ & $-1.8 \pm 0.4$ & $-4.7 \pm 0.5$ & $15 \pm 7$ \\
C5 & $6.6 \pm 4.5$ & $1.1 \pm 0.1$ & $-3.5 \pm 1.4$ & $-3.1 \pm 0.2$ & $\mathrm{ND}$ \\
C6 & $4.3 \pm 1.4$ & $1.2 \pm 0.1$ & $-2.2 \pm 0.3$ & $-4.6 \pm 0.4$ & $8 \pm 3$ \\
C7 & $15.4 \pm 4.0$ & $1.4 \pm 0.2$ & $-1.7 \pm 0.2$ & $-4.4 \pm 0.4$ & $16 \pm 6$ \\
C8 & $\mathrm{ND}$ & $\mathrm{ND}$ & $\mathrm{ND}$ & $\mathrm{ND}$ & $152 \pm 90$ \\
C9 & $7.9 \pm 0.3$ & $1.2 \pm 0.3$ & $-3.5 \pm 0.6$ & $-3.0 \pm 0.5$ & $7 \pm 4$ \\
C10 & $13.1 \pm 4.1$ & $1.2 \pm 0.2$ & $-1.9 \pm 0.4$ & $-4.3 \pm 0.2$ & $18 \pm 4$ \\
\hline
\end{tabular}


NMR studies of chimera binding to ASF1. We next characterized the binding mode of C1 and $\mathbf{C 2}$ with ASF1 by nuclear magnetic resonance spectroscopy (NMR) and used P1 binding as a reference. Increasing amounts of $\mathbf{C 1}$ (or C2) were added to the N-terminal conserved domain of uniformly ${ }^{15} \mathrm{~N}$-labeled hASF1A(1-156) (hereafter referred as ${ }^{15} \mathrm{~N}$-hASF1A and see supporting information for ${ }^{15} \mathrm{~N}$-labeled protein production). Results are depicted in Fig. 3 and Fig. S3. The maximal chemical shift variations $(\Delta \delta)$ were measured for most ASF1 residues at saturation concentration of chimeras or P1 (Fig. S3) and mapped on ASF1 surface (Fig. 3C, right panels). The binding site on ASF1 of both $\mathbf{C 1}$ and $\mathbf{C 2}$ hybrid foldamers was found to match that of histone $\mathrm{H} 3$ helical domain, also highlighted upon addition of P1 (Fig. 3C, left panels and Fig. S3). Nonetheless, addition of $\mathbf{P 1}$ also led to chemical shift perturbations for some ASF1 residues from Val60 to Phe72, matching the B-domain binding site. (34) This corresponds to a nonspecific binding site for P1. Remarkably, $\mathbf{C 1}$ and $\mathbf{C 2}$ only interacted with the histone $\mathrm{H} 3$ binding site and did not give rise to such nonspecific binding (Fig. 3C, right panels, Fig. S3).

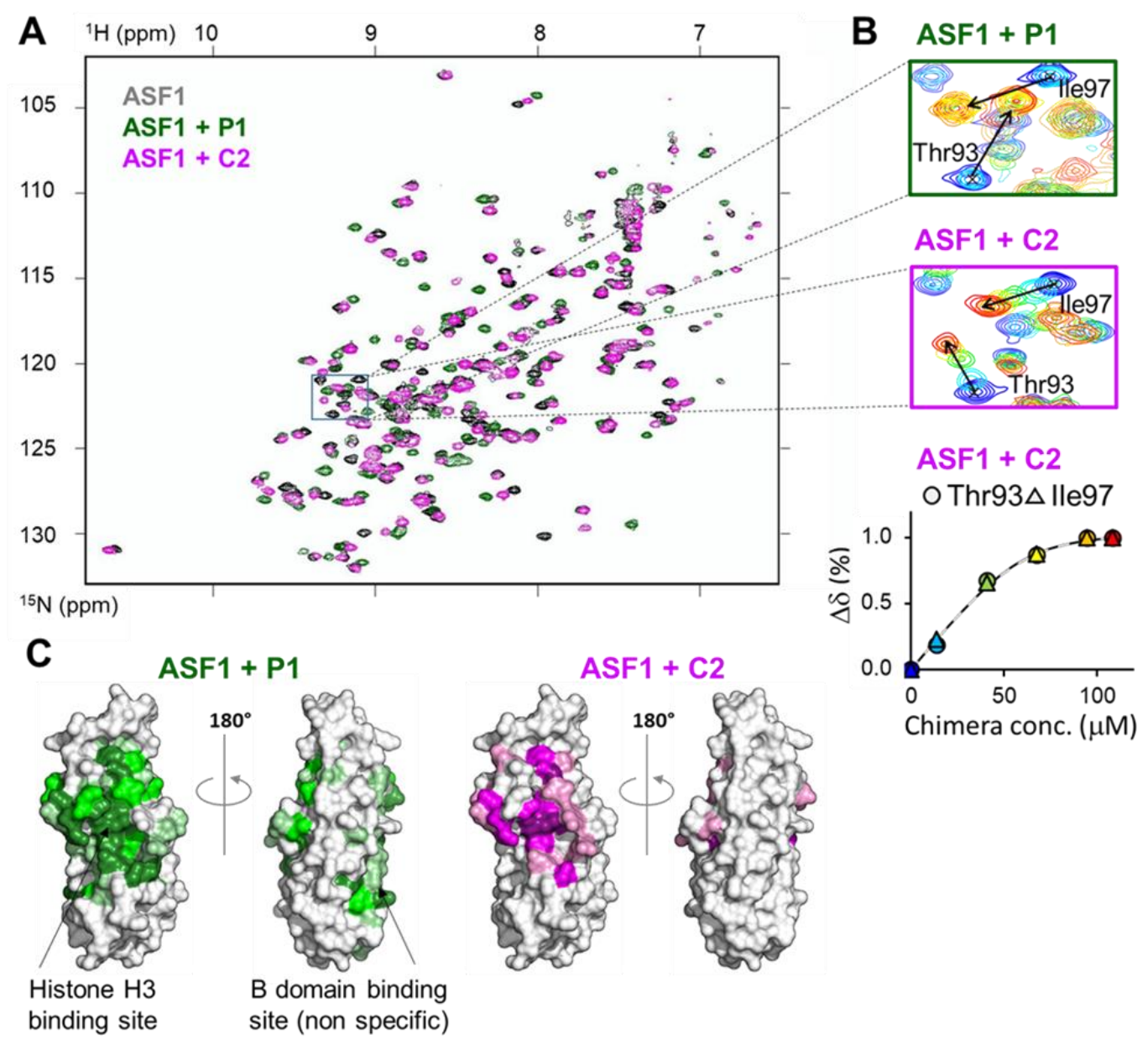

Fig. 3. NMR analysis of P1 and C2 binding to ASF1. (A) Overlay of the sofast HMQC spectra of ${ }^{15} \mathrm{~N}-\mathrm{hASF} 1 \mathrm{~A}$ alone and after addition of a twofold excess of $\mathbf{P 1}$ or $\mathbf{C 2}$ (in grey, green and magenta, respectively). The region indicated with a black box is magnified in panel B left and middle. (B) top and middle, overlay of 5 spectra measured at different concentrations of P1 and $\mathbf{C 2}$ respectively, with a rainbow color code from blue to red (in dark blue free hASF1A and in red, after addition of two fold excess of peptide/chimera), for the region boxed in panel A showing the modification signals of Thr93 and Ile97 upon titration. The position of the signal in the bound state is indicated by an arrow. Lower panel, representative titration curve for ASF1 residues Thr93 and Ile97 using the same color code. The fitted curve is depicted as a dashed line. (C) Chemical shift mapping on hASF1A surface after addition of a twofold 
excess of P1 or $\mathbf{C 2}$ as indicated. Increasing color scale corresponds to higher chemical shift variations as in Fig. S3.

Upon ${ }^{15} \mathrm{~N}$-ASF1 titration with $\mathbf{C 2}$ as ligand (and also with all other chimeras C1-C10 analyzed in this study), we observed a fast-exchange rate, as illustrated by the recorded chemical shift variation $(\Delta \delta)$ of some hASF1A residues ( $\Delta \delta$ of Thr93 and Ile97 displayed in Fig. 3B, central panel). In contrast, P1-P4 peptides showed a slow-exchange regime upon interaction with ASF1 surface (Fig. $3 \mathrm{~B}$, top panel for P1 titration). Although it is not possible to quantify the kinetic parameters from these NMR experiments, the fast exchange regime could reflect faster association/dissociation rates of the ASF1-chimera complexes compared to the ASF1-peptide ones. This hypothesis is compatible with a less optimized interface of the chimeras with respect to the peptides and consistent with the ITC results discussed above.

The fast exchange regime observed during the NMR titration experiments with the chimera C1-C2 allowed us to plot titration curves for several ASF1 residues interacting with each chimera (see the methods section in the support-ing information, Fig. 3B, right panel and Fig. S4). The fitted affinity values are in good agreement with those measured by ITC (Table 1, last column).

As additional proof of the relevancy of our foldamer de-sign, we synthesized the $\alpha$-peptide P5 having the exact side-chain composition of C2 (Fig. 2). No binding to ASF1 was detected with this peptide by ITC (Fig. S2). The chemical shift mapping presented in Fig. S3 shows that upon titration of ASF1 with P5 as ligand, we only observed small shifts of ASF1 residues in the B-domain nonspecific binding region. These results confirm that the binding of $\mathbf{C} 2$ in the $\mathrm{H} 3$ binding pocket of ASF1 corresponds to specific interactions.

High resolution structure of $\mathbf{C 2}$ bound to ASF1. With the aim of gaining additional structural information about the binding mode of the peptide-oligourea hybrids to ASF1, we solved the co-crystal structure of $\mathbf{C 2}$ bound to ASF1A conserved domain at $1.8 \AA$ resolution. The structure confirms that overall $\mathbf{C 2}$ binds ASF1 with the expected geometry (Fig. 4, Fig. S5A, right panel, Fig. S5B and Table S2). Interestingly, the four anchoring side chains are positioned in a similar way to their cognate residues in ASF1A-bound ip4 (Figure S5C). This finding was unexpected, since in the original design with a canonical straight hybrid helix, Lys2 side-chain was not oriented toward its anchoring position (Fig. 4E, middle panel). As regards the peptide/urea chimera backbone, it adopts a helical conformation. Yet, the urea helix is surprisingly distorted with respect to a regular 2.5-helix uniquely composed of urea-type units (Fig 4C and Fig. 4E, right panel).(35) The backbone hydrogenbond network is disrupted between $\mathrm{Nal}^{\mathrm{U}} 3$ carbonyl and the amides of the urea bond $\mathrm{Leu}^{\mathrm{U}} 5-\mathrm{Gln}^{\mathrm{U}} 6$, and a water molecule bridges Leu ${ }^{\mathrm{U}} 5$ carbonyl and Ile8 amide bond (Fig. 4C). It is unlikely that this distortion is an intrinsic consequence of the hybrid character of the oligomer sequence as previous structural investigations of model peptide-oligourea hybrids showed formation of homogeneous helices without disruption of the H-bond network between the two segments.(21) Alternatively, a mutual conformational adaptation between the protein and C2, together with the establishment of new specific contacts between the foldamer backbone and the protein, may account for this distortion. Several observations support this interpretation. First, a direct H-bond between the phenol group of Tyr112 and the main chain urea carbonyl of residue Leu ${ }_{5}$ is formed (Fig. 4C, 4D) and the intramolecular H-bond network of the chimeric helix is locally interrupted at this residue. This distortion can be further stabilized by the insertion of the Leu ${ }^{\mathrm{U}}$ 5-Ile8 water bridge (Fig. 4C, 4D). Overall, the orientation of several ASF1 side chains (such as Tyr 112 and Arg145) is modified upon C2 binding when compared to the ip4 binding (Fig. 4D). This side-chain conformational rearrangement is possibly taking place for shaping the surface to the slight modifications in Leu $\mathrm{U}_{5}$ and Ile8 geometry. Finally, the helix distortion induces a bending favorable for the anchor residue Lys2 to interact with the acid loop of ASF1. Moreover, the tilted conformation of the hybrid helix 
facilitates the interaction of Lys2 with Asp88 as for ip4 bound to ASF1 (Fig. 4E, Fig. S5C). Altogether, these observations highlight the remarkable plasticity of the urea chimeric helix, able to kink to adapt ASF1 surface and optimize interactions with the four anchoring residues.

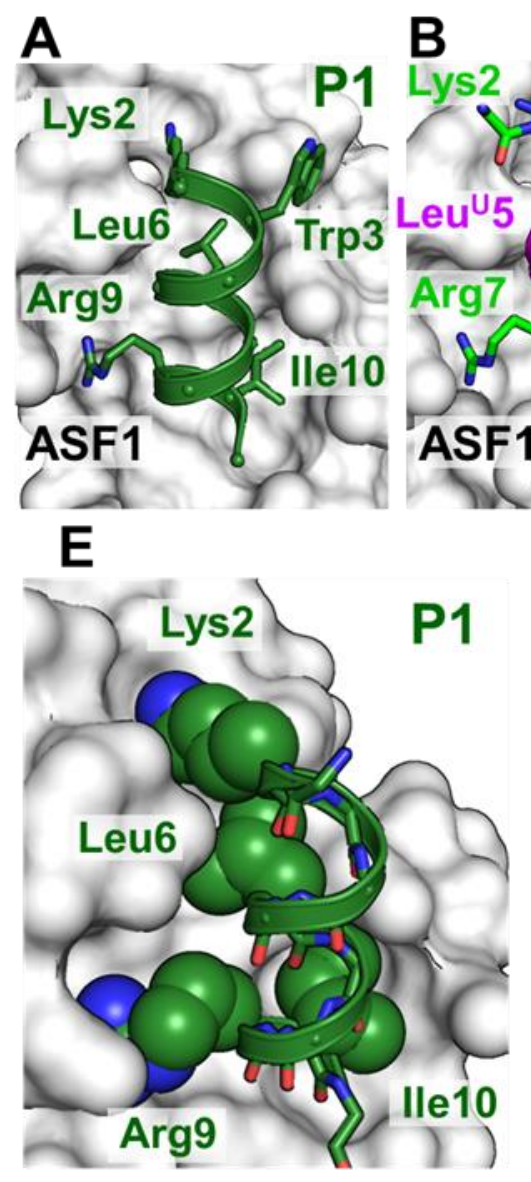

regular $\alpha$-helix
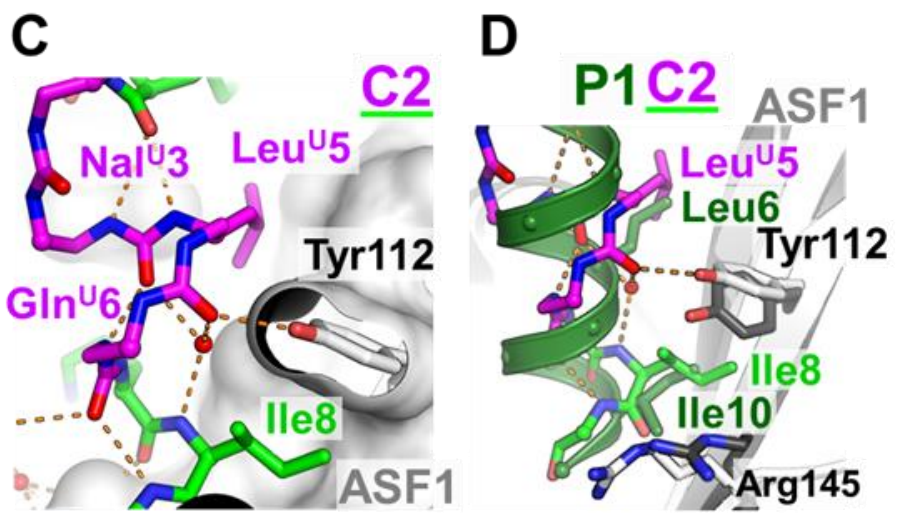

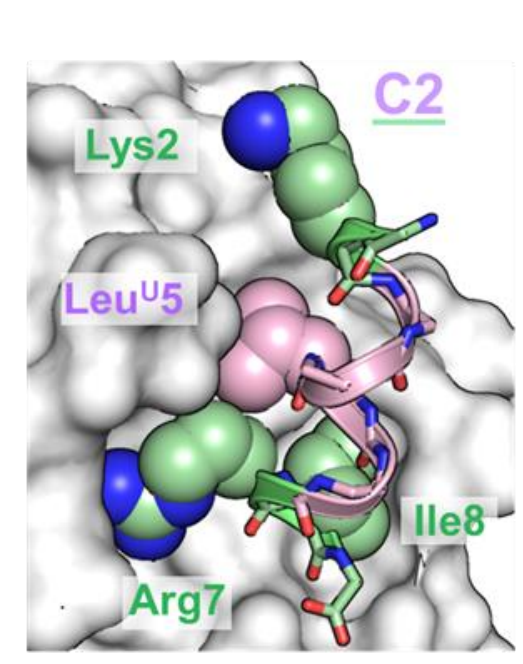

model of $\alpha-\mathrm{U}-\alpha$ helix

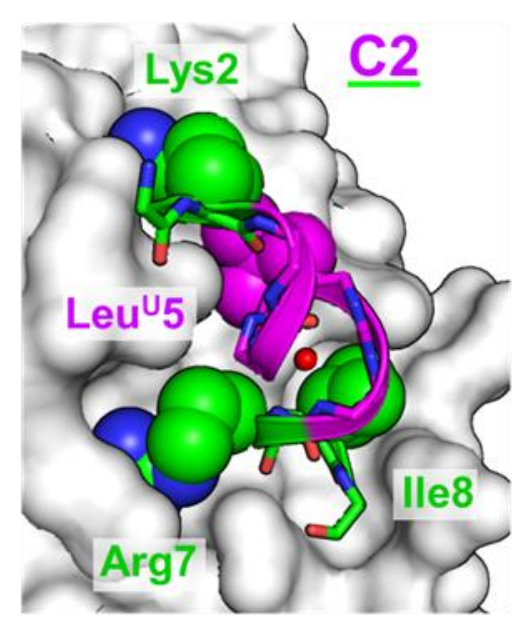

ASF1-bound $\alpha-\mathrm{U}-\alpha$ foldamer

Fig. 4. Crystal structure of chimera C2 in complex with ASF1 compared to the binding mode of P1. (A) Front view of ASF1 (gray surface) bound to the peptide P1 (green cartoon representation). Selected side chains of $\mathbf{P 1}$ residues contacting ASF1 surface are highlighted. (B) Crystal structure of C2 (sticks representation) bound to ASF1 (gray surface). C2 $\alpha$-amino acids are colored in green, and the four ureido-residues groups in pink. (C) Detailed view of the conformation of $\mathbf{C} 2$ in its central region with the same color code as in panel B. Hydrogen bonds are shown with orange dashed lines, selected water molecules with red spheres. (D) Overlay of P1 and C2 bound to ASF1. C2 and P1 backbones are shown with sticks or cartoon respectively. For the sake of clarity, only the side chain of the two ASF1 residues with the greatest structural variations between the two structures are shown (in light gray for C2-bound ASF1 and in black for P1-bound ASF1). Most side chains of the chimera/peptide are also omitted; only Leu ${ }^{\mathrm{U}} 5 / \mathrm{Leu} 6$ and Leu8/Leu10 of C2 and P1, respectively, are shown in sticks and labeled. (E) ASF1 bound to P1, modeled $\mathbf{C 2}$ and $\mathbf{C 2}$ in the crystal structure are depicted on the left, middle and right panels, respectively. ASF1 is displayed as a gray surface, peptides and chimera backbones as sticks with hydrogen bonds as orange dashed lines. The four anchor residues side chains are shown as spheres and labeled. The water molecule bridging Leu ${ }_{5}$ carbonyl and Ile8 amide bond is also shown as a red sphere. 
A second noticeable feature of bound-C2 in the crystal structure is that the $\mathrm{Nal}^{\mathrm{U}} 3$ residue does not interact with the expected ASF1 residues (Tyr112 and Val92). In contrast, the $\mathrm{Nal}^{\mathrm{U}} 3$ side chain associates with a symmetrical ASF1 molecule in a pocket of ASF1 containing the Val60-Phe72 stretch corresponding to the B-domain binding region (Fig. S5D). This interaction is most probably a crystallization artefact since this binding site was not highlighted in the NMR chemical shift mapping in solution upon addition of $\mathbf{C 2}$ to ${ }^{15} \mathrm{~N}$-hASF1 in solution as already mentioned (Fig. 3C, Fig. S3). To further validate this hypothesis, we synthetized two additional variants of $\mathbf{C 2}$ equipped either with a smaller (hPhe $\mathrm{U}_{3}$ in C3) or no aromatic ring (Ala $\mathrm{U}_{3}$ in C4) (Fig. 2). We next measured their respective affinity for ASF1 by ITC and NMR (Table 1, Fig S2). A slight decrease in affinity (2-fold) was observed for C3 whereas a more pronounced effect on binding was measured with C4. These data support the conclusion that the naphtyl ring of $\mathrm{Nal}^{\mathrm{U}} 3$ participates in the interaction, despite the absence of direct contact in the X-ray crystal structure of the ASF1/C2 complex. We thus conclude that the chimera $\mathbf{C 2}$ at the $\mathrm{Nal}^{\mathrm{U}} 3$ residue could adopt a different rotamer in solution than the one selected in the crystal, but this conformation might be rather dynamic due to sparse packing. Altogether, structural data reported here validate the mode of interaction of $\mathbf{C 2}$ with ASF1 as well as our general design approach.

We next attempted to modulate the recognition of ASF1 by hybrid foldamers through sequence manipulations. As already discussed in the X-ray crystal structure of ASF1/C2 complex, Lys 2 is properly oriented and establishes electrostatic interactions with ASF1-Asp88 (Fig. S5C). We evaluated if additional contacts could be established by replacing Lys2 by an Arg residue (C5, Fig. 2). However, the binding affinity of $\mathbf{C 5}$ measured by ITC was not improved (Table 1). We also explored the possibility to increase the binding affinity by varying $\mathrm{Leu}^{\mathrm{U}} 5$ side chain. Four additional chimeras were synthetized with several alkyl and aryl side chains at position $5, \mathrm{Nle}^{\mathrm{U}}, \mathrm{hPhe}^{\mathrm{U}}, \mathrm{Nal}^{\mathrm{U}}$ and $\mathrm{diF}^{\mathrm{U}}$ in the chimera $\mathbf{C 6}$ to $\mathbf{C 9}$, respectively (Fig. 2). Although some were equally tolerated (Nle in $\mathbf{C 6}$ and $\operatorname{diF}^{\mathrm{U}}$ in $\mathbf{C 9}$ ), none of these modifications improved the binding affinity of $\mathbf{C 2}$ (Table 1, Fig. S2 and S4). We finally evaluated the consequence of extending the N-terminus of $\mathbf{C} 2$ with a cappingbox and synthesized C10 terminated by the Ala-Ser-Thr-Glu tetrad (Fig. 2, Table 1, Fig. S2 and S4). In contrast to P1, this modification did not lead to a tighter binding. This result can in part be explained by the fact that the helix in ASF1-bound C2 is tilted compared to the cognate $\alpha$-helix in ip4, so the extension of the helix may potentially induce a clash with ASF1-Ala48 and Glu49 residues.

The chimera $\mathbf{C} 2$ is protected from proteolysis. We have previously shown that the oligourea backbone is far less susceptible to proteolysis than $\alpha$-peptides and can be used as molecular insert to increase the stability of bioactive peptides. $(11,19)$ To evaluate whether $\alpha$ to urea replacement in the sequence of ASF1 ligands provide compounds with improved resistance to proteolytic degradation, we quantified the degradation rate of $\mathbf{C 2}$ in human plasma and compared it to that of P4 (Fig 5). The half time of $\mathbf{P 4}$ in human plasma was determined by following the decay of the intact molecule by LCMS. In these conditions, $\mathbf{P 4}$ had a lifetime of about one hour. In contrast, $\mathbf{C 2}$ was largely resistant to protease degradation even after 8 hours in human plasma, and that despite the presence of flanking $\alpha$-amino acid residues at both termini of its sequence. We thus conclude that replacing about half of $\alpha$-amino acid residues by ureido residues in $\mathbf{P 4}$ is enough to protect the peptide hybrid against serum proteases. 


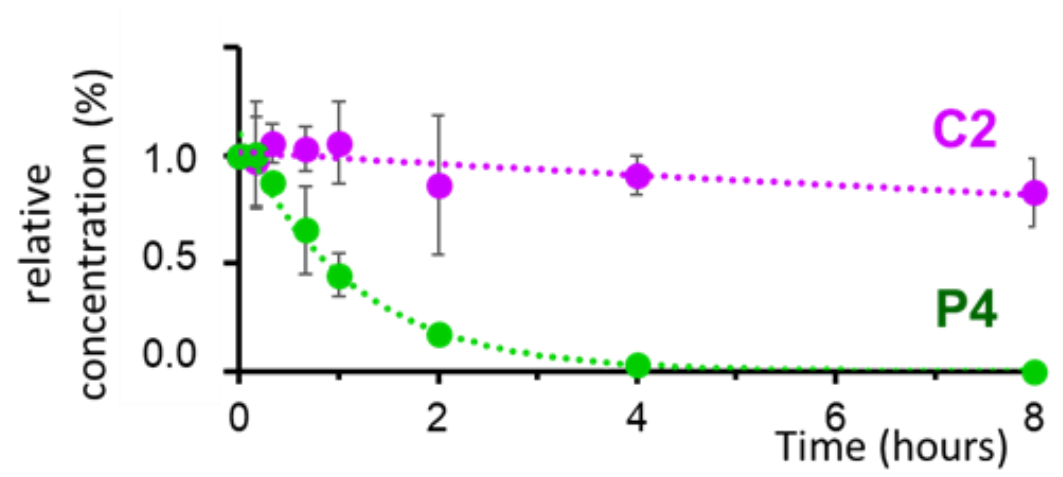

Fig. 5. Stability against protease degradation in human plasma. Stability against protease degradation in human plasma. The percentage of peptide $\mathbf{P 4}$ or chimera $\mathbf{C 2}$ detected by LCMS is reported as a function of time. Error bars represent standard deviation from three independent experiments.

\section{CONCLUSION}

In conclusion, we have designed the first generation of ASF1 ligands with a central foldamer backbone by engineering peptide sequences derived from the C-terminus of histone $\mathrm{H} 3$ and introducing oligourea inserts. We demonstrate that these sequence specific peptide-foldamer hybrids bind their biological target with $K_{\mathrm{D}}$ in the low micromolar range. We also report a unique X-ray crystal structure of a complex between ASF1 and the most potent compound in the series. In good agreement with biomolecular NMR studies, this structure shows that the helical bound conformation and the binding mode of the cognate peptide domain is retained. Strikingly, the crystal structure also shows mutual plasticity of the two partners upon binding and the formation of a non-canonical bent helical structure resulting from a modification of the typical intramolecular three-center H-bond pattern of oligoureas by a protein side-chain (Tyr112). This alteration allows helix bending favorable for the four anchor residues to interact simultaneously. Despite this mutual adaptation of the chimera and the protein, the low enthalpic contribution to the binding free energy measured by microcalorimetry gives room for further optimization of the packing at the complex interface. We also demonstrate that inserting four ureido residues in the center of the helix was sufficient to considerably protect against proteolysis in particularly stringent conditions. This increased stability of foldamers in biological fluids bodes well for the development of ASF1 ligands with prolonged duration of action in vivo. Yet, the affinity for ASF1 of this first generation of foldamer-based ligands still needs some improvement. The strategy reported previously for peptide ip4 consisting in connecting a central binding element to a distant anchor point via a tailored spacer has recently been applied to foldamer-peptide hybrids (36) and is likely to apply to chimera $\mathbf{C 2}$ to eventually conceive potent second generation ASF1 ligands.(30)

\section{MATERIALS AND METHODS}

\section{Chemistry}

Foldamer/peptide hybrids were synthesized on solid support using succinimidyl (2azidoethyl)carbamate as activated monomers for the elongation of oligourea segments, as previously reported. $(19,32,33)$ Full details on chemical synthesis and purification of peptides and foldamers C1-C10 are given in the Supplementary Materials.

\section{Information.Expression and Purification of ASF1}


Recombinant human ASF1 (hASF1A(1-156)) was purified as already described from expression in E. coli of a (His)6-GST-Tev site-Asf1 fusion protein using the pETM30 plasmid.(37) Briefly, soluble (His)6-tagged GST fusion protein was purified on reduced glutathione (GSH) agarose beads (Sigma). After cleavage with recombinant (His)6-TEV protease at room temperature overnight, the (His)6-GST tag and the protease were trapped in a Ni-NTA agarose column (Macherey Nagel). The flow-through fraction containing ASF1 protein was further purified by anion exchange chromatography using a Resource Q 6mL column (GE Healthcare). ASF1 was then concentrated using an Amicon device (Millipore) and the buffer was replaced with a 50mM Tris-HCl (pH7.5). Unlabled ASF1 used for ITC experiments was purified from pellets of bacteria grown in LB medium, and uniformly labeled ASF1 from bacteria gown in M9 minimal media supplemented with $\left({ }^{15} \mathrm{NH}_{4}\right) \mathrm{Cl}$ (Eurisotop, $0.5 \mathrm{~g} / \mathrm{L}$ ) as the sole nitrogen source and or ${ }^{13} \mathrm{C}$ glucose (Eurisotop, $2 \mathrm{~g} / \mathrm{L}$ ).

\section{Isothermal Titration Calorimetry}

All IsoThermal Calorimetry (ITC) experiments were performed in a VP-ITC titration calorimeter (Microcal/Malvern) at $20^{\circ} \mathrm{C}$, in a $50 \mathrm{mM}$ Tris- $\mathrm{HCl} \mathrm{pH} 7.5$ buffer. Protein and peptides concentrations were set to values of $10 \mu \mathrm{M}$ and $200 \mu \mathrm{M}$, respectively. Protein and peptide samples were prepared in the same buffer and degassed (ThermoVac, Malvern). After equilibrating the cell at $298^{\circ} \mathrm{K}$, the rotating syringe $(310 \mathrm{rpm})$ injected at intervals of $280 \mathrm{~s}, 6 \mu \mathrm{L}$ aliquots of peptide solution into the Asf1 solution previously introduced in the sample cell, until saturation was observed. Raw ITC data were processed with the Origin 7.0 Software (OriginLab, Malvern) using the One-Set of Sites fitting model. All ITC experiments were performed at least in duplicate. One representative curve for each peptide/chimera is shown in Figure S2.

\section{NMR studies $-{ }^{1} \mathrm{H}-{ }^{15} \mathrm{~N}$ HSQC}

The binding mode of the constrained peptides was assessed using NMR spectroscopy. NMR experiments were performed at $293^{\circ} \mathrm{K}$ or $298^{\circ} \mathrm{K}$ on Bruker Avance II $600 \mathrm{MHz}$ spectrometer equipped with a TCI cryoprobe. Purified uniformly labeled ${ }^{15} \mathrm{~N}$ hASF1A(1-156) was concentrated to $40 \mu \mathrm{M}$ and exchanged in NMR buffer [50 mM Tris-HCl pH7.5, $0.1 \mathrm{mM}$ EDTA, 0.1 mM DSS, $0.1 \mathrm{mM} \mathrm{NaN}_{3}$, protease inhibitor cocktail (at the concentration recommended by the provider, Roche), $10 \% \mathrm{D}_{2} \mathrm{O}$ ]. Proton chemical shifts (in ppm) were referenced relative to internal DSS and ${ }^{15} \mathrm{~N}$ reference was set indirectly relative to DSS using frequency ratios.(38) NMR data were processed using Topspin (Bruker) and analyzed using Sparky (T.D. Goddard and D.G. Kneller, UCSF). Amide assignment were taken from (37). The titration experiments were done by adding increasing amounts of concentrated peptide or chimera to the ASF1 sample. At each ASF1:peptide ratio, a two dimensional ${ }^{1} \mathrm{H}-{ }^{15} \mathrm{~N}$ sofast HMQC spectrum was recorded. Changes in chemical shift were measured for all resonances for all recorded spectra. Assignments were obtained by following progressive variations of chemical shifts upon titration or with a standard triple resonance method using a uniformly ${ }^{15} \mathrm{~N}$ ${ }^{13} \mathrm{C}$ labeled ASF1 sample complexed with an excess of peptide or chimera. Chemical shift variation was calculated with the following formula $\sqrt{\left(\delta_{H N}^{b}-\delta_{H N}^{f}\right)^{2}+\left(0.17\left(\delta_{N}^{b}-\delta_{N}^{f}\right)\right)^{2}}$, where $\delta$ represents measured chemical shift value. $\mathrm{b}$ or $\mathrm{f}$ refer to the bound or free form respectively, $\mathrm{HN}$ or $\mathrm{N}$ to the amide proton or nitrogen respectively. The factor 0.17 corresponds to the scaling factors used to normalize the magnitude of the proton and nitrogen chemical shift changes (in ppm).(39) At saturation of the peptide or chimera, the maximal chemical shift variation was plotted as a function of the residue number for 138 residues of the 156 residues of hASF1A(1-156) (Figure S3). This corresponds to $96 \%$ of the expected values, considering the 12 prolines.

The exchange rate between bound and free forms was rapid upon addition of the chimera $\mathrm{C} 1$ to $\mathrm{C} 11$ (Fig. 3A, lower central panel for C2). The dissociation constant of the complex was fitted from the plot of the normalized chemical shift variation in function of total chimera concentration (as shown for two residues in Fig. $3 \mathrm{~A}$, lower right panel) using the following equation: $\Delta \delta_{N}=$ 
$\left[\left(c_{A}+c_{C}+K_{D}\right)-\sqrt{\left(c_{A}+c_{C}+K_{D}\right)^{2}-4 c_{A} c_{C}}\right] / 2$, where $c_{A}$ represents the total concentration of $\mathrm{ASF} 1, c_{C}$, the total concentration od added chimera, and $K_{D}$, the dissociation constant. $\Delta \delta_{N}$ is the chemical shift variation normalized with the maximal chemical shift variation measured at saturating concentration of chimera. For each chimera, the fit was performed independently ASF1 residues belonging to the three main regions showing significant chemical shift changes: A48, E49, E51, V90, T93, I97, R108, V109, Y111. These residues were chosen because i) they show significant chemical shift variation (more than $0.07 \mathrm{ppm}$ ), and ii) the signals allowed a precise measure of the chemical shift at all chimera concentrations (no suppositions, no slow-intermediate exchange rate). Value of the dissociation constant reported in Table 1 corresponds to the mean $K_{D}$ value and standard deviation fitted for these residues. Curves and fits are shown in Figure S4.

\section{Crystallization, data collection and structure determination}

hASF1A(1-156) and $\mathbf{C 2}$ were mixed and the complex was concentrated to $8.6 \mathrm{mg} / \mathrm{mL}$ in a buffer 50mM Tris-HCl pH7.4. Crystals of the complex were grown by sitting drop vapor diffusion at $20^{\circ} \mathrm{C}$ against reservoir solution containing $100 \mathrm{mM}$ Sodium Citrate pH4.2, $300 \mathrm{mM} \mathrm{LiSO} 4,26 \%$ PEG3350. Crystals were soaked in a 100 mM Sodium Citrate pH4.2, 300 mM LiSO4, 26\% PEG3350, $20 \%$ Glycerol cryo-protectant solution before being flash-frozen in liquid nitrogen. Diffraction data were collected on the PROXIMA-1 beamline at the synchrotron SOLEIL (Saint Aubin, France) at a temperature of $100^{\circ} \mathrm{K}$ with a X-ray wavelength of $0.97857 \AA$. Diffraction images recorded with PILATUS 6M detector were processed using the XDS package (40). Best data sets were obtained from two crystals of hASF1A(1-156)-C2 belonging to space group P1 which diffracted up to $1.8 \AA$ resolution. The two data sets were merged and scaled and the structure of ASF1A(1-156)-C2 complex was determined by molecular replacement using MOLREP (41) with the human ASF1A structure (chain A of PDB entry 2i32) as model probe. Best solution contained two complexes per asymmetric unit. Model building was performed with the Coot software (42) and structure refinement was achieved with BUSTER version 2.10.(43, 44) Final refinement statistics are presented in Table S2. Structure representations presented in all figures were drawn with PYMOL software (Schrödinger).

\section{Proteolysis assay}

Stock solutions of the peptide $\mathbf{P 4}$ and the chimera $\mathbf{C 2}$ were prepared at a concentration of 250 $\mu \mathrm{M}$ in water. Stock solution of human plasma was prepared in water as aliquots. Each aliquot was diluted 1/4 with a solution of PBS $0.1 \mathrm{M} \mathrm{pH7.4} \mathrm{buffer} \mathrm{before} \mathrm{use.} \mathrm{Stability} \mathrm{of} \mathrm{these} \mathrm{molecules} \mathrm{in}$ human plasma was assessed by conducting protease reaction at $37{ }^{\circ} \mathrm{C}$. $392 \mu \mathrm{L}$ of the solution of human plasma in PBS, was first incubated for $15 \mathrm{~min}$ at $37^{\circ} \mathrm{C}$. To this pre-activated enzymatic solution was added $8 \mu \mathrm{L}$ of the solution of the tested compound (final concentration $5 \mu \mathrm{M}$ ). At the indicated time $(0,10,20,40,60,120,240$, and $480 \mathrm{~min})$ an aliquot of $45 \mu \mathrm{L}$ was collected and added to $150 \mu \mathrm{L}$ of acetonitrile to quench the reaction. The samples were frozen at $-80{ }^{\circ} \mathrm{C}$ before analysis. The frozen samples were defrosted, stirred with a vortex $(2 \mathrm{~min})$ and finally centrifuged $\left(16^{\circ} \mathrm{C}, 5 \mathrm{~min}\right.$, $18000 \mathrm{~g}$ ). A portion of the resulting supernatant was submitted to concentration under high vacuum to remove ACN excess, then resuspended in a solution of water+0.1 formic acid/ACN $+0.1 \%$ formic acid (95:5). Reaction progress over time was quantified by UPLC-MS analysis. The time course of inhibitor degradation was determined by integrating the area of the peak from the extracted ion chromatogram. All experiments were carried out in triplicates for both compounds. Column: Phenomenex $@$ Aeris PEPTIDE $1.7 \mu \mathrm{m}$ XB-C18, 150 x $2.1 \mathrm{~mm}$; Mobile phase: A = water with $0.1 \%$ formic acid, $B=$ acetonitrile with $0.1 \%$ formic acid; Gradient: A/B (95:5) for 1.0 min to A/B (60:40) over $5 \mathrm{~min}$ to $\mathrm{A} / \mathrm{B}(90: 10)$ for $1.5 \mathrm{~min}$ to $\mathrm{A} / \mathrm{B}(95: 5)$ for $2.5 \mathrm{~min}$; Flow rate: $0.5 \mathrm{~mL} / \mathrm{min}$; Temperature: $60^{\circ} \mathrm{C}$; Instrument: Dionex $(\mathrm{C}$ Ultimate 3000 (Thermo Fisher Scientific); Detection: ESI-FTMS in positive mode [150 - $2000 \mathrm{~m} / \mathrm{z}]$ on a QExactive instrument (Thermo Fisher Scientific). 


\section{SUPPLEMENTARY MATERIALS}

Materials and Methods

Table S1. ${ }^{1} \mathrm{H}$ NMR chemical shifts (in ppm) of $\mathbf{C 2}$ in $\mathrm{CD}_{3} \mathrm{OH}(400 \mathrm{MHz})$ at $25^{\circ} \mathrm{C}$.

Fig. S1. 1H NMR amide aliphatic region of a TOCSY spectrum of C2 in $\mathrm{CD} 3 \mathrm{OH}$ (400 $\mathrm{MHz}$ ) at $25^{\circ} \mathrm{C}$.

Fig. S2. ITC thermograms and data fitting for the indicated peptides/chimera with hASF1A(1-156)

Fig. S3. Chemical shift variation after addition of an excess of the indicated peptide/chimera

Fig. S4. NMR titration curves upon addition of the indicated chimera.

Table S2. Data collection and statistical refinement of the crystal structures of ASF1A(1156) in complex with the inhibitory chimer C2. Title of the first supplementary table.

Fig. S5. X-ray structure of the complex ASF1-C2.

\section{REFERENCES AND NOTES}

1. M. Pasco, G. Dolain, G. Guichard, in Comprehensive Supramolecular Chemistry II, J. L. Atwood, G. W. Gokel, L. J. Barbour, Eds. (Elsevier, 2017), vol. 5, chap. 5.05, pp. 89-125.

2. R. Gopalakrishnan, A. I. Frolov, L. Knerr, W. J. Drury, 3rd, E. Valeur, Therapeutic Potential of Foldamers: From Chemical Biology Tools To Drug Candidates? J Med Chem 59, 95999621 (2016).

3. E. Valeur et al., New Modalities for Challenging Targets in Drug Discovery. Angew Chem Int Ed Engl 56, 10294-10323 (2017).

4. V. Azzarito, K. Long, N. S. Murphy, A. J. Wilson, Inhibition of alpha-helix-mediated protein-protein interactions using designed molecules. Nat Chem 5, 161-173 (2013).

5. W. S. Horne, T. N. Grossmann, Proteomimetics as protein-inspired scaffolds with defined tertiary folding patterns. Nat Chem 12, 331-337 (2020).

6. R. J. Simon et al., Peptoids: a modular approach to drug discovery. Proceedings of the National Academy of Sciences of the United States of America 89, 9367-9371 (1992).

7. J. Frackenpohl, P. I. Arvidsson, J. V. Schreiber, D. Seebach, The outstanding biological stability of beta- and gamma-peptides toward proteolytic enzymes: an in vitro investigation with fifteen peptidases. Chembiochem 2, 445-455 (2001).

8. D. Seebach, A. K. Beck, D. J. Bierbaum, The world of beta- and gamma-peptides comprised of homologated proteinogenic amino acids and other components. Chem Biodivers 1, 11111239 (2004).

9. C. M. Grison, J. A. Miles, S. Robin, A. J. Wilson, D. J. Aitken, An alpha-Helix-Mimicking 12,13-Helix: Designed alpha/beta/gamma-Foldamers as Selective Inhibitors of ProteinProtein Interactions. Angew Chem Int Ed Engl 55, 11096-11100 (2016).

10. P. Sang et al., Inhibition of beta-catenin/B cell lymphoma 9 protein-protein interaction using alpha-helix-mimicking sulfono-gamma-AApeptide inhibitors. Proceedings of the National Academy of Sciences of the United States of America 116, 10757-10762 (2019).

11. E. Teyssieres et al., Proteolytically Stable Foldamer Mimics of Host-Defense Peptides with Protective Activities in a Murine Model of Bacterial Infection. J Med Chem 59, 8221-8232 (2016).

12. S. Liu, R. W. Cheloha, T. Watanabe, T. J. Gardella, S. H. Gellman, Receptor selectivity from minimal backbone modification of a polypeptide agonist. Proceedings of the National Academy of Sciences of the United States of America 115, 12383-12388 (2018). 
13. M. V. Hager, L. M. Johnson, D. Wootten, P. M. Sexton, S. H. Gellman, beta-ArrestinBiased Agonists of the GLP-1 Receptor from beta-Amino Acid Residue Incorporation into GLP-1 Analogues. J Am Chem Soc 138, 14970-14979 (2016).

14. K. J. Peterson-Kaufman et al., Residue-Based Preorganization of BH3-Derived alpha/betaPeptides: Modulating Affinity, Selectivity and Proteolytic Susceptibility in alpha-Helix Mimics. ACS Chem Biol 10, 1667-1675 (2015).

15. S. Kumar et al., Foldamer-mediated manipulation of a pre-amyloid toxin. Nat Commun 7, 11412 (2016).

16. L. M. Johnson, S. H. Gellman, alpha-Helix mimicry with alpha/beta-peptides. Methods Enzymol 523, 407-429 (2013).

17. W. S. Horne et al., Structural and biological mimicry of protein surface recognition by alpha/beta-peptide foldamers. Proceedings of the National Academy of Sciences of the United States of America 106, 14751-14756 (2009).

18. R. W. Cheloha, A. Maeda, T. Dean, T. J. Gardella, S. H. Gellman, Backbone modification of a polypeptide drug alters duration of action in vivo. Nat Biotechnol 32, 653-655 (2014).

19. J. Fremaux et al., Peptide-oligourea hybrids analogue of GLP-1 with improved action in vivo. Nat Commun 10, 924 (2019).

20. C. M. Lombardo et al., Design and Structure Determination of a Composite Zinc Finger Containing a Nonpeptide Foldamer Helical Domain. J Am Chem Soc 141, 2516-2525 (2019).

21. J. Fremaux et al., alpha-Peptide-Oligourea Chimeras: Stabilization of Short alpha-Helices by Non-Peptide Helical Foldamers. Angew Chem Int Ed Engl 54, 9816-9820 (2015).

22. R. J. Burgess, Z. Zhang, Histone chaperones in nucleosome assembly and human disease. Nature structural \& molecular biology 20, 14-22 (2013).

23. F. Abascal et al., Subfunctionalization via adaptive evolution influenced by genomic context: the case of histone chaperones ASF1a and ASF1b. Molecular biology and evolution 30, 1853-1866 (2013).

24. J. S. Im et al., ATR checkpoint kinase and CRL1betaTRCP collaborate to degrade ASF1a and thus repress genes overlapping with clusters of stalled replication forks. Genes Dev $\mathbf{2 8}$, 875-887 (2014).

25. A. Corpet et al., Asf1b, the necessary Asf1 isoform for proliferation, is predictive of outcome in breast cancer. EMBO J 30, 480-493 (2011).

26. X. Liang et al., Histone Chaperone ASF1A Predicts Poor Outcomes for Patients With Gastrointestinal Cancer and Drives Cancer Progression by Stimulating Transcription of beta-Catenin Target Genes. EBioMedicine 21, 104-116 (2017).

27. Y. Wu, X. Li, J. Yu, M. Bjorkholm, D. Xu, ASF1a inhibition induces p53-dependent growth arrest and senescence of cancer cells. Cell Death Dis 10, 76 (2019).

28. F. Mousson et al., Structural basis for the interaction of Asf1 with histone H3 and its functional implications. Proceedings of the National Academy of Sciences of the United States of America 102, 5975-5980 (2005).

29. C. M. English, M. W. Adkins, J. J. Carson, M. E. Churchill, J. K. Tyler, Structural basis for the histone chaperone activity of Asf1. Cell 127, 495-508 (2006).

30. M. Bakail et al., Design on a Rational Basis of High-Affinity Peptides Inhibiting the Histone Chaperone ASF1. Cell Chem Biol, (2019).

31. R. Aurora, G. D. Rose, Helix capping. Protein science : a publication of the Protein Society 7, 21-38 (1998).

32. G. W. Collie et al., Shaping quaternary assemblies of water-soluble non-peptide helical foldamers by sequence manipulation. Nat Chem 7, 871-878 (2015). 
33. C. Douat-Casassus, K. Pulka, P. Claudon, G. Guichard, Microwave-enhanced solid-phase synthesis of N,N'-linked aliphatic oligoureas and related hybrids. Org Lett 14, 3130-3133 (2012).

34. Y. Tang et al., Structure of a human ASF1a-HIRA complex and insights into specificity of histone chaperone complex assembly. Nature structural \& molecular biology 13, 921-929 (2006).

35. L. Fischer et al., The canonical helix of urea oligomers at atomic resolution: insights into folding-induced axial organization. Angew Chem Int Ed Engl 49, 1067-1070 (2010).

36. G. M. Burslem et al., Towards "bionic" proteins: replacement of continuous sequences from HIF-1alpha with proteomimetics to create functional p300 binding HIF-1alpha mimics. Chem Commun (Camb) 52, 5421-5424 (2016).

37. F. Mousson et al., $1 \mathrm{H}, 13 \mathrm{C}$ and $15 \mathrm{~N}$ resonance assignments of the conserved core of hAsf1 A. Journal of biomolecular NMR 29, 413-414 (2004).

38. D. S. Wishart et al., 1H, 13C and $15 \mathrm{~N}$ chemical shift referencing in biomolecular NMR. Journal of biomolecular NMR 6, 135-140 (1995).

39. B. T. Farmer, 2nd et al., Localizing the NADP+ binding site on the MurB enzyme by NMR. Nat Struct Biol 3, 995-997 (1996).

40. W. Kabsch, Integration, scaling, space-group assignment and post-refinement. Acta Crystallogr D Biol Crystallogr 66, 133-144 (2010).

41. A. Vagin, A. Teplyakov, Molecular replacement with MOLREP. Acta Crystallogr D Biol Crystallogr 66, 22-25 (2010).

42. P. Emsley, K. Cowtan, Coot: model-building tools for molecular graphics. Acta Crystallogr D Biol Crystallogr 60, 2126-2132 (2004).

43. G. Bricogne et al., BUSTER version 2.10. Cambridge, United Kingdom: Global Phasing Ltd., (2017).

44. O. S. Smart et al., Exploiting structure similarity in refinement: automated NCS and targetstructure restraints in BUSTER. Acta Crystallogr D Biol Crystallogr 68, 368-380 (2012).

\section{Acknowledgments}

General: We thank the Synchrotron Soleil, the European Synchrotron Radiation Facility (ESRF) and the French Infrastructure for Integrated Structural Biology (FRISBI) ANR-10INBS-05.

Funding: Research was funded by the French Centre National de Recherche Scientifique (CNRS), the Commissariat à l'Energie Atomique (CEA), University of Bordeaux, University Paris-Saclay, the Synchrothron Soleil. The project was supported by the ANR 2007 BREAKABOUND, 2011 BIPBIP, 2012 CHAPINHIB, 2015 CHIPSET, 2015 CHIMPP2I and the program labeled by the ARC foundation 2016. M.B. was supported by Canceropole (Paris, France), and a grant for young researchers from La Ligue contre le Cancer. J.B. was supported by La Ligue contre le Cancer.

Author contributions: The manuscript was written through contributions of all authors. / All authors have given approval to the final version of the manuscript.

Competing interests: Authors declare no competing interests.

Data and materials availability: The accession number of the structure in the PDB is D_1292109544. 
Supplementary data 


\section{Experimental procedures for peptide and oligourea-peptide hybrids synthesis}

A. Synthesis of activated azido monomers A (Scheme S1)

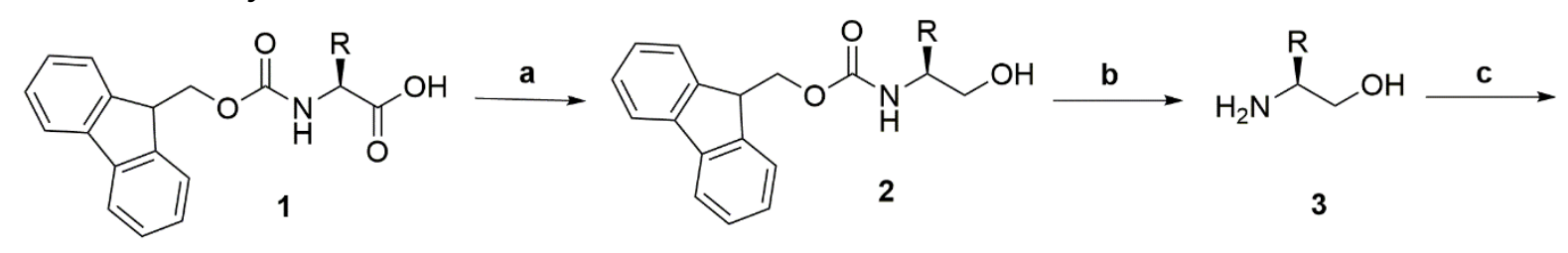

$1 \mathrm{a}=\left(\mathrm{CH}_{2}\right)_{3}-\mathrm{NH}-\mathrm{C}(=\mathrm{NH}) \mathrm{NH}-\mathrm{Pbf}$

$1 \mathrm{~b}=\mathrm{CH}_{2}$-Indol(Boc)

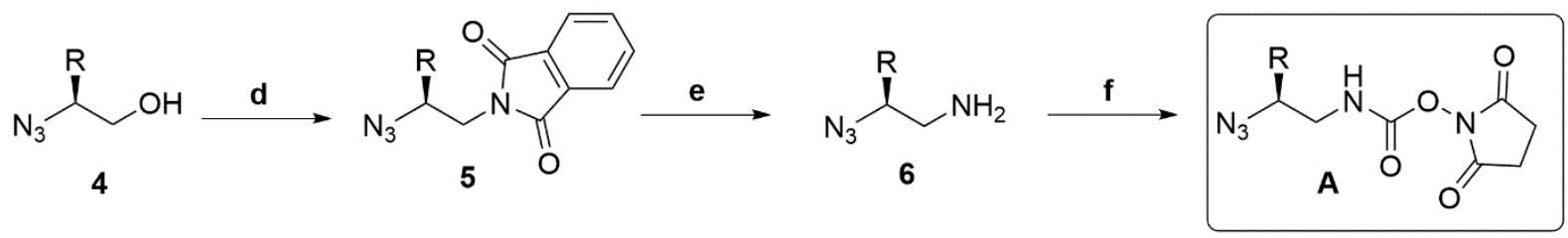

Scheme S1. a: 1) NMM, IBCF, THF, $-10^{\circ} \mathrm{C}$; 2) $\mathrm{NaBH}_{4}, \mathrm{H}_{2} \mathrm{O}$; b: DBU, EtOAc; c: $\mathrm{N}_{3} \mathrm{SO}_{2} \mathrm{Im} . \mathrm{HCl}, \mathrm{K}_{2} \mathrm{CO}_{3}$, $\mathrm{CuSO}_{4}: 5 \mathrm{H}_{2} \mathrm{O}, \mathrm{CH}_{3} \mathrm{CN}: \mathrm{H}_{2} \mathrm{O}$ (1:1), r.t.; d: $\mathrm{PPh}_{3}$, Phthalimide, DIAD, THF; e: $\mathrm{N}_{2} \mathrm{H}_{4} \cdot \mathrm{H}_{2} \mathrm{O}, \mathrm{MeOH}, 70^{\circ} \mathrm{C}$; f: DSC, $\mathrm{CH}_{2} \mathrm{Cl}_{2}$

\section{General procedure for N-Fmoc amino alcohol (2) formation}

$N$-Fmoc $\alpha$-amino acids (1) were converted to their corresponding primary alcohol (2) according to recently reported procedure. \{ Douat-Casassus, $2012 \# 2528\}$

Fmoc-Arg(Pbf)-ol 2a: solid, 93\%; ${ }^{1} \mathrm{H}$ NMR (300 MHz, $\left.\mathrm{CDCl}_{3}\right): \delta=7.75(\mathrm{t}, \mathrm{J}=7.1 \mathrm{~Hz}, 2 \mathrm{H}), 7.65-7.54$ $(\mathrm{m}, 2 \mathrm{H}), 7.48-7.32(\mathrm{~m}, 4 \mathrm{H}), 6.24(\mathrm{~s}, 1 \mathrm{H}), 5.29(\mathrm{t}, \mathrm{J}=14.5 \mathrm{~Hz}, 1 \mathrm{H}), 4.42$ (d, J = 6.1 Hz, 2H), 4.20 (d, $\mathrm{J}=5.9 \mathrm{~Hz}, 2 \mathrm{H}), 3.63(\mathrm{dd}, \mathrm{J}=21.4,10.6 \mathrm{~Hz}, 2 \mathrm{H}), 3.23(\mathrm{~d}, \mathrm{~J}=21.9 \mathrm{~Hz}, 2 \mathrm{H}), 2.95(\mathrm{~d}, \mathrm{~J}=7.0 \mathrm{~Hz}, 3 \mathrm{H})$, $2.54(\mathrm{dd}, \mathrm{J}=20.5,9.1 \mathrm{~Hz}, 6 \mathrm{H}), 2.27(\mathrm{~d}, \mathrm{~J}=20.3 \mathrm{~Hz}, 1 \mathrm{H}), 2.10(\mathrm{~d}, \mathrm{~J}=5.3 \mathrm{~Hz}, 3 \mathrm{H}), 1.48-1.40$ (m, 6H).

Fmoc-Trp(Boc)-ol 2b: Solid, 90\%; ${ }^{1} \mathrm{H}$ NMR (300 MHz, $\left.\mathrm{CDCl}_{3}\right): \delta=8.13(\mathrm{~d}, \mathrm{~J}=8.0 \mathrm{~Hz}, 1 \mathrm{H}), 7.79(\mathrm{~d}$, $\mathrm{J}=7.5 \mathrm{~Hz}, 2 \mathrm{H}), 7.69-7.25(\mathrm{~m}, 10 \mathrm{H}), 5.21(\mathrm{~d}, \mathrm{~J}=6.6 \mathrm{~Hz}, 1 \mathrm{H}), 4.45(\mathrm{~d}, \mathrm{~J}=6.9 \mathrm{~Hz}, 2 \mathrm{H}), 4.23(\mathrm{t}, \mathrm{J}=6.8$ Hz, 1H), 4.10 (brs,1H), 3.72 (d, J = 4.7 Hz, 2H), 3.02 (d, J = 6.0 Hz, 2H), 2.05 (brs, 1H), 1.67 (s, 9H).

\section{General procedure for Fmoc deprotection, amine and conversion to azido alcohol (4)}

$N$-Fmoc protected amino alcohol (2) was dissolved in THF and DBU (1 equiv.) was added. The reaction mixture was left to react at r.t. for $30 \mathrm{~min}$. THF was removed under reduced pressure and the resulting amine was dried overnight under vacuum line and engaged in the next step without any further purification. The conversion of amino alcohol (3) into azido alcohol (4) was carried out following previously reported procedure. \{Douat-Casassus, 2012 \#2528;Goddard-Borger, 2007 \#4768\}

4a: white solid, 76\%; ${ }^{1} \mathrm{H}$ NMR $\left(300 \mathrm{MHz} \mathrm{CDCl}_{3}\right): \delta=6.27(\mathrm{~s}, 1 \mathrm{H}), 6.11(\mathrm{~s}, 1 \mathrm{H}), 5.30(\mathrm{~s}, 1 \mathrm{H}), 3.75-$ $3.52(\mathrm{~m}, 2 \mathrm{H}), 3.52-3.38(\mathrm{~m}, 1 \mathrm{H}), 3.34-3.13(\mathrm{~m}, 2 \mathrm{H}), 2.96(\mathrm{~s}, 3 \mathrm{H}), 2.53(\mathrm{~d}, \mathrm{~J}=20.4 \mathrm{~Hz}, 6 \mathrm{H}), 2.15-$ $2.07(\mathrm{~m}, 3 \mathrm{H}), 1.61(\mathrm{tt}, \mathrm{J}=16.7,8.5 \mathrm{~Hz}, 3 \mathrm{H}), 1.44(\mathrm{~d}, \mathrm{~J}=10.9 \mathrm{~Hz}, 6 \mathrm{H})$.

4b: oil, 82\%; ${ }^{1} \mathrm{H}$ NMR (300 MHz, $\left.\mathrm{CDCl}_{3}\right): \delta=8.13(\mathrm{~d}, \mathrm{~J}=8.0 \mathrm{~Hz}, 1 \mathrm{H}), 7.69-7.25(\mathrm{~m}, 4 \mathrm{H}), 3.95-3.62$ $(\mathrm{m}, 3 \mathrm{H}), 3.02(\mathrm{~m}, 2 \mathrm{H}), 1.72(\mathrm{~s}, 9 \mathrm{H})$.

\section{From azido alcohol 4 to succinimidyl azido-2-substituted-ethyl-carbamate $A$}


The Mitsunobu's reaction to form the phthalimide intermediate (5), followed by the release of the azido amine (6) in the presence of hydrazine hydrate and subsequent activation with $N, N^{\prime}$-disuccinimidyl carbonate (DSC) to give succinimidyl azido carbamates of type A were carried out according to the recently published procedure depicted in Scheme S1. \{Douat-Casassus, 2012 \#2528\}

Aa: solid, 72\%; ${ }^{1} \mathrm{H}$ NMR (300 MHz, $\left.\mathrm{CDCl}_{3}\right): \delta=6.12(\mathrm{~s}, 2 \mathrm{H}), 5.91(\mathrm{~s}, 1 \mathrm{H}), 5.15-5.01(\mathrm{~m}, 1 \mathrm{H}), 3.65$ (s, 2H), $3.44(\mathrm{~d}, \mathrm{~J}=6.9 \mathrm{~Hz}, 1 \mathrm{H}), 3.37-3.27(\mathrm{~m}, 2$ ), $2.96(\mathrm{~s}, 2 \mathrm{H}), 2.85$ (s, 4H), 2.57 (d, J = $20.3 \mathrm{~Hz}$, $6 \mathrm{H}), 2.10(\mathrm{~s}, 3 \mathrm{H}), 1.63(\mathrm{~m}, 2 \mathrm{H}), 1.46(\mathrm{~s}, 6 \mathrm{H}), 1.32-1.24(\mathrm{~m}, 2 \mathrm{H}) \cdot{ }^{13} \mathrm{C} \mathrm{NMR}\left(75 \mathrm{MHz}, \mathrm{CDCl}_{3}\right): \delta=170.45$, 156.19, 152.28, 138.67, 132.61, 132.39, 132.28, 128.80, 124.92, 117.78, 86.69, 77.58, 77.36, 77.16, $76.74,60.95,44.60,44.14,43.33,28.74,28.14,25.67,25.28,19.43,18.10,12.61$. HRMS (ESITOFMS) $\mathrm{m} / \mathrm{z}$ calcd. for $\mathrm{C}_{24} \mathrm{H}_{35} \mathrm{~N}_{8} \mathrm{O}_{7} \mathrm{~S}[\mathrm{M}+\mathrm{H}]^{+}$579.2349; found 579.2327

Ab: solid, 76\%; ${ }^{1} \mathrm{H}$ NMR (300 MHz, $\left.\mathrm{CDCl}_{3}\right): \delta(\mathrm{ppm})=8.13(\mathrm{~s}, 1 \mathrm{H}), 7.62-7.49(\mathrm{~m}, 2 \mathrm{H}), 7.46-7.31$ $(\mathrm{m}, 2 \mathrm{H}), 6.33(\mathrm{~d}, \mathrm{~J}=28.6 \mathrm{~Hz}, 1 \mathrm{H}), 3.70-3.53(\mathrm{~m}, 2 \mathrm{H}), 3.45(\mathrm{dt}, \mathrm{J}=45.8,23.1 \mathrm{~Hz}, 1 \mathrm{H}), 3.07-3.03$ (m, 2H), 2.80 (s, 4H), 1.67 (s, 9H). ${ }^{13} \mathrm{C}$ NMR $\left(75 \mathrm{MHz}, \mathrm{CDCl}_{3}\right): \delta=170.08,124.90,123.90,122.85$, $118.84,115.61,77.58,77.58,77.36,77.16,76.74,52.80,46.48,31.57,28.35,25.60$. HRMS (ESITOFMS) $\mathrm{m} / \mathrm{z}$ calcd for $\mathrm{C}_{21} \mathrm{H}_{24} \mathrm{~N}_{6} \mathrm{O}_{6} \mathrm{Na}[\mathrm{M}+\mathrm{Na}]^{+} 479.1649$; found 479.1643

\section{B. Synthesis of activated azido monomers B (Scheme S2)}

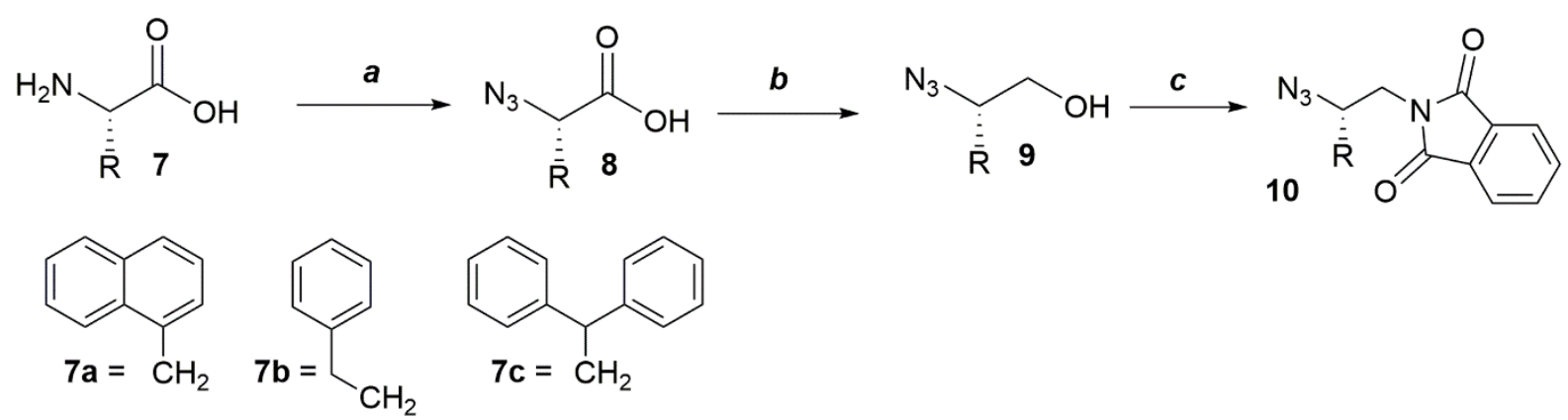

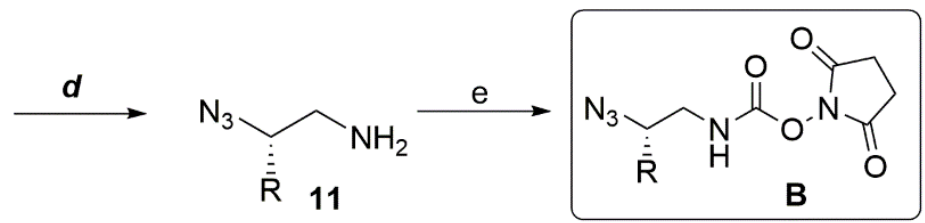

Scheme S2. a: $\mathrm{N}_{3} \mathrm{SO}_{2}-\mathrm{Im}, \mathrm{HCl}, \mathrm{K}_{2} \mathrm{CO}_{3}, \mathrm{CuSO}_{4}: 5 \mathrm{H} 2 \mathrm{O}, \mathrm{CH}_{3} \mathrm{CN}: \mathrm{H}_{2} \mathrm{O}$ (1:1); b:1) NMM, IBCF, THF, $\left.-10^{\circ} \mathrm{C} ; 2\right)$ $\mathrm{NaBH}_{4}, \mathrm{H}_{2} \mathrm{O} ; \mathrm{c}: \mathrm{PPh}_{3}$, phthalimide, DIAD, THF; d: $\mathrm{N}_{2} \mathrm{H}_{4} \cdot \mathrm{H}_{2} \mathrm{O}, \mathrm{MeOH}, 70^{\circ} \mathrm{C}$; e: DSC, $\mathrm{CH}_{2} \mathrm{Cl}_{2}$

\section{General procedure for conversion to azido acid 8}

To a solution containing $N$-amino acid ( $10 \mathrm{mmol}$ ) in $\mathrm{CH}_{3} \mathrm{CN} / \mathrm{H}_{2} \mathrm{O}(1: 1)$, were successively added $\mathrm{K}_{2} \mathrm{CO}_{3}$ $(2.04 \mathrm{~g}, 12.84 \mathrm{mmol}), \mathrm{N}_{3} \mathrm{SO}_{2}-\mathrm{Im} . \mathrm{HCl}(2.46 \mathrm{~g}, 11.77 \mathrm{mmol})$ and $\mathrm{CuSO}_{4} .5 \mathrm{H}_{2} \mathrm{O}$ (15 mg, $\left.0.1 \mathrm{mmol}\right)$. The mixture was stirred at RT overnight. The reaction mixture was then filtered off to remove the remaining $\mathrm{K}_{2} \mathrm{CO}_{3}$. After concentration of the crude reaction mixture under reduced pressure, EtOAc was added. The organic phase was washed two times with $1 \mathrm{M}$ solution of $\mathrm{KHSO}_{4}$ solution, once with brine, dried over $\mathrm{MgSO}_{4}$ and concentrated under reduced pressure. After silica gel flash chromatography, the desired product was recovered as pure compound.

8a brown oil; 87\% yield; ${ }^{1} \mathrm{H}$ NMR (300 MHz, $\mathrm{CDCl}_{3}$ ): $\delta=3.18$ (dd, J = 14.4, 9.5 Hz, 1H), 3.57-3.70 (m, $2 \mathrm{H}), 4.08-4.21(\mathrm{~m}, 2 \mathrm{H}), 7.28-7.87(\mathrm{~m}, 7 \mathrm{H})$

8b: yellow oil, 71\%; ${ }^{1} \mathrm{H}$ NMR (300 MHz, $\left.\mathrm{CDCl}_{3}\right)$ : $\delta=2.04-2.28 \mathrm{ppm}(\mathrm{m}, 2 \mathrm{H}), 2.68-2.90(\mathrm{~m}, 2 \mathrm{H}), 3.9$ ppm (dd, J=8.8, 4.9 Hz, 1H), 7.21-7.35 (m, 5H), $8.56(\mathrm{~s}, 1 \mathrm{H})$ 
8c: $97 \%$; ${ }^{1} \mathrm{H}$ NMR $\left(300 \mathrm{MHz}, \mathrm{CDCl}_{3}\right): \delta=7.67(\mathrm{dd}, \mathrm{J}=14.0,7.3 \mathrm{~Hz}, 5 \mathrm{H}), 7.35-7.15(\mathrm{~m}, 5 \mathrm{H}), 4.42(\mathrm{~d}$, $\mathrm{J}=9.3 \mathrm{~Hz}, 1 \mathrm{H}), 2.30(\mathrm{~s}, 1 \mathrm{H})$.

\section{General procedure for reduction to $\beta$-azido alcohol 9}

The $\alpha$-azido acid (8) ( $2 \mathrm{~g}, 1$ equiv.) was dissolved in THF under $\mathrm{N}_{2}$ and cooled down to $-10^{\circ} \mathrm{C}$. After addition of NMM (1.2 equiv.) and IBCF (1.2 equiv.) the mixture reaction was stirred at $-10^{\circ} \mathrm{C}$ for 30 min. The resulting white suspension was filtered off and a solution of $\mathrm{NaBH}_{4}(1.2$ equiv.) in water was added dropwise to the filtrate cooled to $-10^{\circ} \mathrm{C}$. The reaction was left to react for $30 \mathrm{~min}$. After the addition of water and THF removal under reduced pressure, the aqueous solution was extracted twice with EtOAc. The organic layers were combined and washed two times with $1 \mathrm{M} \mathrm{KHSO}_{4}$, two times with a solution of saturated $\mathrm{NaHCO}_{3}$, once with brine solution and dried over $\mathrm{MgSO}_{4}$. After concentration under vacuum, and silica gel flash chromatography, the desired product was recovered as pure compound.

9a: brown oil, $86 \%$; ${ }^{1} \mathrm{H}-\mathrm{NMR}\left(\mathrm{CDCl}_{3}, 300 \mathrm{MHz}\right)$ : $\delta=3.35$ (qd, J = 14.1, 7.1 Hz, 2H), 3.56-3.82 (m, 2H), 3.86-3.94 (m, 1H), 7.42-8.09 (m, 7H)

9b: yellow oil, 70\%; ${ }^{1} \mathrm{H}-\mathrm{NMR}\left(\mathrm{CDCl}_{3}, 300 \mathrm{MHz}\right)$ : $\delta=1.79-1.91(\mathrm{~m}, 2 \mathrm{H}), 2.63-2.94(\mathrm{~m}, 2 \mathrm{H}), 3.74$ (ddd, $\mathrm{J}=39.2,12.9,7.2 \mathrm{~Hz}, 2 \mathrm{H}), 3.96(\mathrm{~d}, \mathrm{~J}=6.7 \mathrm{~Hz}, 1 \mathrm{H}), 7.26-7.35(\mathrm{~m}, 5 \mathrm{H})$

9c: ${ }^{1} \mathrm{H}-\mathrm{NMR}\left(\mathrm{CDCl}_{3}, 300 \mathrm{MHz}\right): \delta=8.00-7.64(\mathrm{~m}, 10 \mathrm{H}), 4.94-4.77(\mathrm{~m}, 2 \mathrm{H}), 4.42(\mathrm{~d}, \mathrm{~J}=9.3 \mathrm{~Hz}$, $1 \mathrm{H}), 2.30(\mathrm{~s}, 1 \mathrm{H})$.

\section{General procedure for conversion to phthalimide intermediate $\mathbf{1 0}$}

To a solution of $\mathrm{PPh}_{3}$ (1.2 equiv.) and phthalimide (1.2 equiv.) in anhydrous $\mathrm{THF}$ at $0^{\circ} \mathrm{C}$ under a positive $\mathrm{N}_{2}$ atmosphere, was added DIAD (1.2 equiv.). Azido alcohol (1.5 g) dissolved in anhydrous THF (20 $\mathrm{mL}$ ) was next added dropwise and the reaction mixture was stirred and allowed to reach the RT. After 4 hours, TLC plate showed complete conversion of the alcohol into phthalimide. THF was removed under reduced pressure and the crude material was directly engaged to the next step.

\section{General procedure for $\beta$-azido amine synthesis (11)}

Hydrazine hydrate ( 3 equiv.) was added to a solution of azido phthalimide in $\mathrm{MeOH}(150 \mathrm{~mL})$. The reaction mixture was heated to reflux for 4 hours. The reaction mixture was filtered off, washed with $\mathrm{MeOH}$ and the filtrate was concentrated under reduced pressure. The crude material was dissolved in EtOAc and the organic layer was washed twice with $1 \mathrm{M} \mathrm{HCl}$ solution. The combined aqueous phases were again washed with EtOAc and were neutralized by addition of $\mathrm{K}_{2} \mathrm{CO}_{3}$ until $\mathrm{pH}$ 8. The aqueous phase was finally extracted with DCM and the combined organic layers were dried over $\mathrm{MgSO}_{4}$, concentrated under reduced pressure. The resulting azido amine was directly engaged for the final activation step without further purification.

\section{General procedure for the preparation of succinimidyl azido-2-substituted-ethyl- carbamates $\boldsymbol{B}$}

To a stirred suspension of DSC (1.2 equiv.) in anhydrous DCM, was added dropwise a solution of the azido amine (11) in DCM. The reaction mixture was stirred 4 hours and was concentrated under reduced pressure. The crude material was dissolved in EtOAc and the organic phase was washed twice with $1 \mathrm{M} \mathrm{KHSO}_{4}$, once with brine and dried over $\mathrm{MgSO}_{4}$ before to be concentrated under reduced pressure to furnish succinimidyl carbamate $\mathbf{B}$ as a white solid.

Ba: solid, 75\% yield; ${ }^{1} \mathrm{H}$ NMR (300 MHz, $\left.\mathrm{CDCl}_{3}\right)$ : $\delta=7.42-8.07(\mathrm{~m}, 7 \mathrm{H}), 5.52(\mathrm{~s}, 1 \mathrm{H}), 3.92-4.02(\mathrm{~m}$, $1 \mathrm{H}), 3.5(\mathrm{ddd}, \mathrm{J}=13.9,6.5,4.0 \mathrm{~Hz}, 2 \mathrm{H}), 3.30(\mathrm{~m}, 2 \mathrm{H}), 2.82(\mathrm{~s}, 4 \mathrm{H}) ;{ }^{13} \mathrm{C}$ NMR $\left(75 \mathrm{MHz}, \mathrm{CDCl}_{3}\right): \delta=$ $170,151.2,134,132.2,128,127.2,126.5,125.8,122.5,61.8,44.8,35,25.1 ;$ HRMS (ESI-TOFMS) m/z calcd for $\mathrm{C}_{18} \mathrm{H}_{17} \mathrm{~N}_{5} \mathrm{O}_{4} \mathrm{Na}[\mathrm{M}+\mathrm{Na}]^{+} 390.1173$; found 390.1178 . 
Bb: White solid, 79\%; ${ }^{1} \mathrm{H}$ NMR $\left(300 \mathrm{MHz}, \mathrm{CDCl}_{3}\right)$ : $\delta=7.18-7.34(\mathrm{~m}, 5 \mathrm{H}), 5.51(\mathrm{~s}, 1 \mathrm{H}), 3.39-3.58(\mathrm{~m}$, $2 \mathrm{H}), 3.17-3.28(\mathrm{~m}, 1 \mathrm{H}), 2.82(\mathrm{~s}, 4 \mathrm{H}), 2.73(\mathrm{dd}, \mathrm{J}=12.0,4.4 \mathrm{~Hz}, 2 \mathrm{H}), 1.87(\mathrm{dd}, \mathrm{J}=15.9,8.1 \mathrm{~Hz}, 2 \mathrm{H})$; ${ }^{13} \mathrm{C} \mathrm{NMR}\left(75 \mathrm{MHz}, \mathrm{CDCl}_{3}\right.$ ): $\delta=170.8,151.5,141.2,129,127.2,61.8,46,32.5,31.8,25.1$; HRMS (ESITOFMS) $\mathrm{m} / \mathrm{z}$ calcd for $\mathrm{C}_{15} \mathrm{H}_{17} \mathrm{~N}_{5} \mathrm{O}_{4} \mathrm{Na}[\mathrm{M}+\mathrm{Na}]^{+} 354.1173$; found 354.1180.

Bc: White solid, 57\% yield, ${ }^{1} \mathrm{H}$ NMR (300 MHz, $\left.\mathrm{CDCl}_{3}\right): \delta=7.47$ (dd, J = 14.0, 7.3 Hz, 4H), $7.35-7.15$ $(\mathrm{m}, 6 \mathrm{H}), 4.53(\mathrm{t}, \mathrm{J}=8.4 \mathrm{~Hz}, 1 \mathrm{H}), 4.11(\mathrm{~d}, \mathrm{~J}=10.7 \mathrm{~Hz}, 2 \mathrm{H}), 3.19(\mathrm{dd}, \mathrm{J}=10.5,2.8 \mathrm{~Hz}, 1 \mathrm{H}), 3.10-2.96$ $(\mathrm{m}, 1 \mathrm{H}), 2.77(\mathrm{~s}, 4 \mathrm{H}) ;{ }^{13} \mathrm{C}$ NMR $\left(75 \mathrm{MHz}, \mathrm{CDCl}_{3}\right): \delta=169.80,140.52,129.07,128.14,127.47,65.69$, $55.01,45.19,30.59,25.47$.

\section{Synthesis of Fmoc-protected monomer 14 (Scheme S3)}

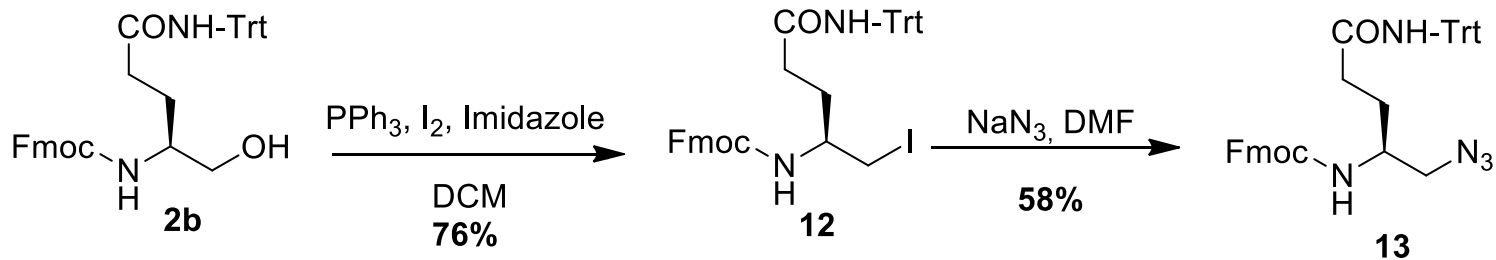

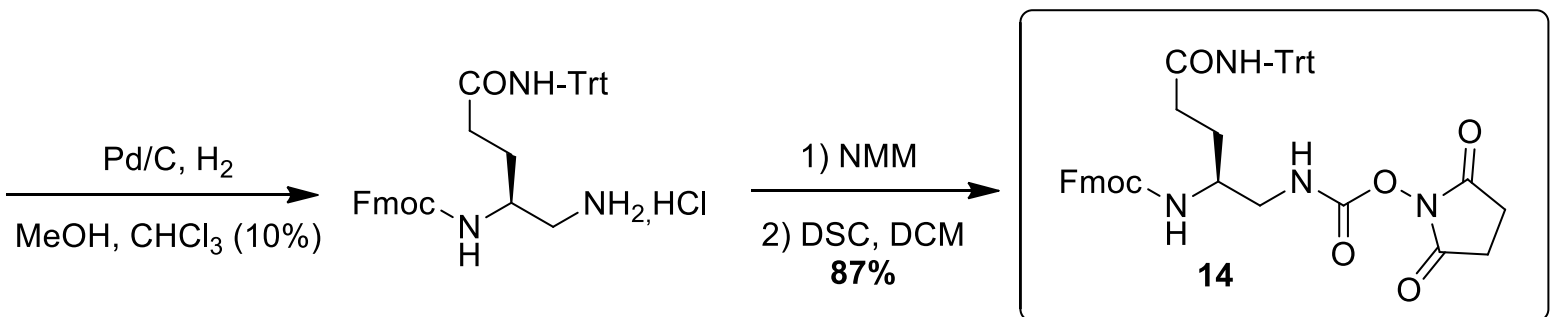

Scheme S3. Synthesis of N-Fmoc-protected monomer 14 from Fmoc-Gln(Trt)-OH

Compound 12. Fmoc-Gln(Trt)-ol was converted into iodine derivative 12 according to the procedure described by Sureshbabu et al. \{Sureshbabu, 2009 \#4771\} white solid, 76\% yield, ${ }^{1} \mathrm{H}$ NMR (300 MHz, $\left.\mathrm{CDCl}_{3}\right): \delta=7.76(\mathrm{~d}, \mathrm{~J}=7.6 \mathrm{~Hz}, 2 \mathrm{H}), 7.63-7.56(\mathrm{~m}, 2 \mathrm{H}), 7.48-7.28(\mathrm{~m}, 11 \mathrm{H}), 7.25-7.16(\mathrm{~m}, 8 \mathrm{H})$, $6.73(\mathrm{~s}, 1 \mathrm{H}), 5.04(\mathrm{~d}, \mathrm{~J}=8.0 \mathrm{~Hz}, 1 \mathrm{H}), 4.51(\mathrm{dd}, \mathrm{J}=10.5,6.9 \mathrm{~Hz}, 1 \mathrm{H}), 4.37(\mathrm{t}, \mathrm{J}=8.4 \mathrm{~Hz}, 1 \mathrm{H}), 4.20(\mathrm{dd}$, $\mathrm{J}=18.5,12.0 \mathrm{~Hz}, 1 \mathrm{H}), 3.47(\mathrm{~s}, 1 \mathrm{H}), 3.29(\mathrm{dt}, \mathrm{J}=10.3,7.7 \mathrm{~Hz}, 2 \mathrm{H}), 2.34(\mathrm{t}, \mathrm{J}=6.5 \mathrm{~Hz}, 2 \mathrm{H}), 1.87(\mathrm{~s}$, $2 \mathrm{H})$.

Compound 13. 12 was converted into azide $\mathbf{1 3}$ according to the procedure described by Antunes $e t$ al. $\left\{\right.$ Antunes, 2016 \#4773\} White solid, 58\% yield, ${ }^{1} \mathrm{H}$ NMR (300 MHz, $\left.\mathrm{CDCl}_{3}\right): \delta=7.74(\mathrm{~d}, \mathrm{~J}=7.5 \mathrm{~Hz}$, $2 \mathrm{H}), 7.62-7.51(\mathrm{~m}, 3 \mathrm{H}), 7.43-7.28(\mathrm{~m}, 9 \mathrm{H}), 7.23-7.12(\mathrm{~m}, 9 \mathrm{H}), 6.73(\mathrm{~s}, 1 \mathrm{H}), 4.99(\mathrm{~d}, \mathrm{~J}=8.9 \mathrm{~Hz}$, $1 \mathrm{H}), 4.54-4.33(\mathrm{~m}, 3 \mathrm{H}), 4.20(\mathrm{t}, \mathrm{J}=6.5 \mathrm{~Hz}, 1 \mathrm{H}), 3.73(\mathrm{~d}, \mathrm{~J}=4.7 \mathrm{~Hz}, 1 \mathrm{H}), 3.36(\mathrm{~s}, 2 \mathrm{H}), 2.30(\mathrm{dd}, \mathrm{J}=$ $14.8,7.9 \mathrm{~Hz}, 2 \mathrm{H}), 1.75(\mathrm{~d}, \mathrm{~J}=44.6 \mathrm{~Hz}, 2 \mathrm{H})$.

Compound 14. $N$-Fmoc protected azide $13(3 \mathrm{~g}, 4.83 \mathrm{mmol})$ was dissolved in a round bottom flask in $300 \mathrm{~mL}$ of $\mathrm{MeOH} / \mathrm{CHCl}_{3}(9: 1 ; \mathrm{v} / \mathrm{v})$ solvent mixture, $\mathrm{Pd} / \mathrm{C}(10 \%$ in mass, $300 \mathrm{mg})$ was gently added and under $\mathrm{N}_{2}$ pressure. The reaction mixture was next placed under $\mathrm{H}_{2}$ atmosphere and stirred overnight at room temperature. $\mathrm{Pd} / \mathrm{C}$ was filtered off carefully over Millipore paper filter and the filtrate was concentrated under reduced pressure. The product was precipitated in an ice bath with a solvent mixture composed of $\mathrm{EtOAc} / \mathrm{Et}_{2} \mathrm{O}(5: 5, \mathrm{v} / \mathrm{v})$. The precipitate was filtered off, dried under vacuum line and directly engaged to the final step without any purification. It was dissolved in anhydrous $\mathrm{CH}_{2} \mathrm{Cl}_{2}$, under $\mathrm{N}_{2}$ atmosphere, at $0^{\circ} \mathrm{C}$, and NMM (1.2 equiv.) was added. The reaction mixture was stirred for 5 min and then DSC (1 equiv.) dissolved in anhydrous $\mathrm{CH}_{2} \mathrm{Cl}_{2}$ was slowly added dropwise. The reaction mixture was stirred for 4 additional hours after which the crude mixture was quenched by adding a $1 \mathrm{M}$ aqueous solution of $\mathrm{KHSO}_{4}$. The aqueous solution was then extracted twice with EtOAc and the 
combined organic layers were finally washed twice with brine. After drying over magnesium sulfate, the organic phase was concentrated under reduced pressure and dried under vacuum line to give monomer 14 in $87 \%$ yield.

${ }^{1} \mathrm{H}$ NMR $\left(300 \mathrm{MHz}, \mathrm{CDCl}_{3}\right): \delta=7.74(\mathrm{~d}, \mathrm{~J}=7.7 \mathrm{~Hz}, 2 \mathrm{H}), 7.57(\mathrm{dd}, \mathrm{J}=16.0,8.8 \mathrm{~Hz}, 2 \mathrm{H}), 7.33(\mathrm{ddd}, \mathrm{J}=$ 11.0, 9.8, 4.5 Hz, 10H), 7.25 - 7.16 (m, 9H), $6.74(\mathrm{~s}, 1 \mathrm{H}), 5.78(\mathrm{~d}, \mathrm{~J}=24.7 \mathrm{~Hz}, 1 \mathrm{H}), 5.33-5.11(\mathrm{~m}$, $1 \mathrm{H}), 4.57-4.27(\mathrm{~m}, 3 \mathrm{H}), 3.66(\mathrm{~d}, \mathrm{~J}=13.4 \mathrm{~Hz}, 1 \mathrm{H}), 3.28(\mathrm{~d}, \mathrm{~J}=20.1 \mathrm{~Hz}, 1 \mathrm{H}), 3.08(\mathrm{~s}, 1 \mathrm{H}), 2.74(\mathrm{~s}$, $4 \mathrm{H}), 2.45(\mathrm{~d}, \mathrm{~J}=37.3 \mathrm{~Hz}, 2 \mathrm{H}), 1.96-1.65(\mathrm{~m}, 2 \mathrm{H}) .{ }^{13} \mathrm{C} \mathrm{NMR}\left(75 \mathrm{MHz}, \mathrm{CDCl}_{3}\right): \delta=169.67,144.45$, $141.34,128.64,128.01,127.69,127.12,119.95,71.65,69.70,67.74,65.78,52.53,50.35,47.33,46.13$, 45.00, 33.39, 26.94, 25.43.; HRMS (ESI-TOF-MS) m/z calcd for $\mathrm{C}_{44} \mathrm{H}_{40} \mathrm{~N}_{4} \mathrm{O}_{7}[\mathrm{M}+\mathrm{H}]^{+}$736.2897; found 737.2973.

\section{Oligomer Synthesis}

Commercially available reagents were used throughout without purification. Rink amide and Wang resins were purchased from Merck Millipore. $N, N$ '-diisopropylefthylamine (DIEA) was purchased from Sigma-Aldrich. $N$-Fmoc amino acids, $N, N^{\prime}$-Diisopropylcarbodiimide (DIC) and Ethyl cyano(hydroxyimino)acetate (Oxyma) were purchased from IRIS Biotech GMBH. Benzotriazole-1-yloxy-tris-(dimethylamino)-phosphonium hexa-fluorophosphate (BOP) reagent were purchased from PolyPeptide Laboratories France. Solid phase synthesis (SPS) grade organic solvents (DMF, DCM) were used for solid phase synthesis and were purchased from Carlo Erba. Dioxane, RP-HPLC-quality acetonitrile $\left(\mathrm{CH}_{3} \mathrm{CN}\right)$ were purchased from Sigma Aldrich. MilliQ water was used for RP-HPLC analyses and semi-preparative purifications. The synthesis of hybrid sequences was performed manually under microwave irradiation (vide infra) on a Discover Bio® System from CEM (CEM $\mu$ Waves S.A.S., Orsay, France). Solid phase peptide synthesis (SPPS) was performed automatically on a Liberty Blue peptide synthesizer (vide infra) (CEM $\mu$ Waves S.A.S., Orsay, France). RP-HPLC analyses were performed on a Dionex U3000SD using a Macherey-Nagel Nucleodur column $(4.6 \times 100$ $\mathrm{mm}, 3 \mu \mathrm{m})$ at a flow rate of $1 \mathrm{~mL} \cdot \mathrm{min}^{-1}$. The mobile phase was composed of $0.1 \%(\mathrm{v} / \mathrm{v}) \mathrm{TFA}-\mathrm{H}_{2} \mathrm{O}$ (Solvent A) and $0.1 \%$ TFA- $\mathrm{CH}_{3} \mathrm{CN}$ (Solvent B). Detection was performed at three different wavelengths (200, 214 and $254 \mathrm{~nm})$ and the column temperature in the oven was maintained at $50^{\circ} \mathrm{C}$. Semi-preparative purifications of oligoureas were performed on a Gilson GX-281 system using a Macherey-Nagel Nucleodure column $(20 \times 250 \mathrm{~mm}, 5 \mu \mathrm{m})$ at a flow rate of $20 \mathrm{~mL} \cdot \mathrm{min}^{-1}$. The mobile phase composition was similar to the one used for analytical injections. A solvent gradient elution (80\% to $40 \%$ A in $20 \mathrm{~min}$ ) was applied. Column effluent was monitored by UV detection at 200 and $214 \mathrm{~nm}$. The purity of the compounds was determined to be $\geq 95 \%$ by using the data processing application of Chromoleon7 software. ESI-HRMS analyses were carried out on a ThermoElectron LCQ Advantage spectrometer equipped with an ion trap mass analyzer and coupled with a ThermoElectron Surveyor HPLC system. LC/MS analyses were carried out on Agilent TOF LC/MS system 6230. 

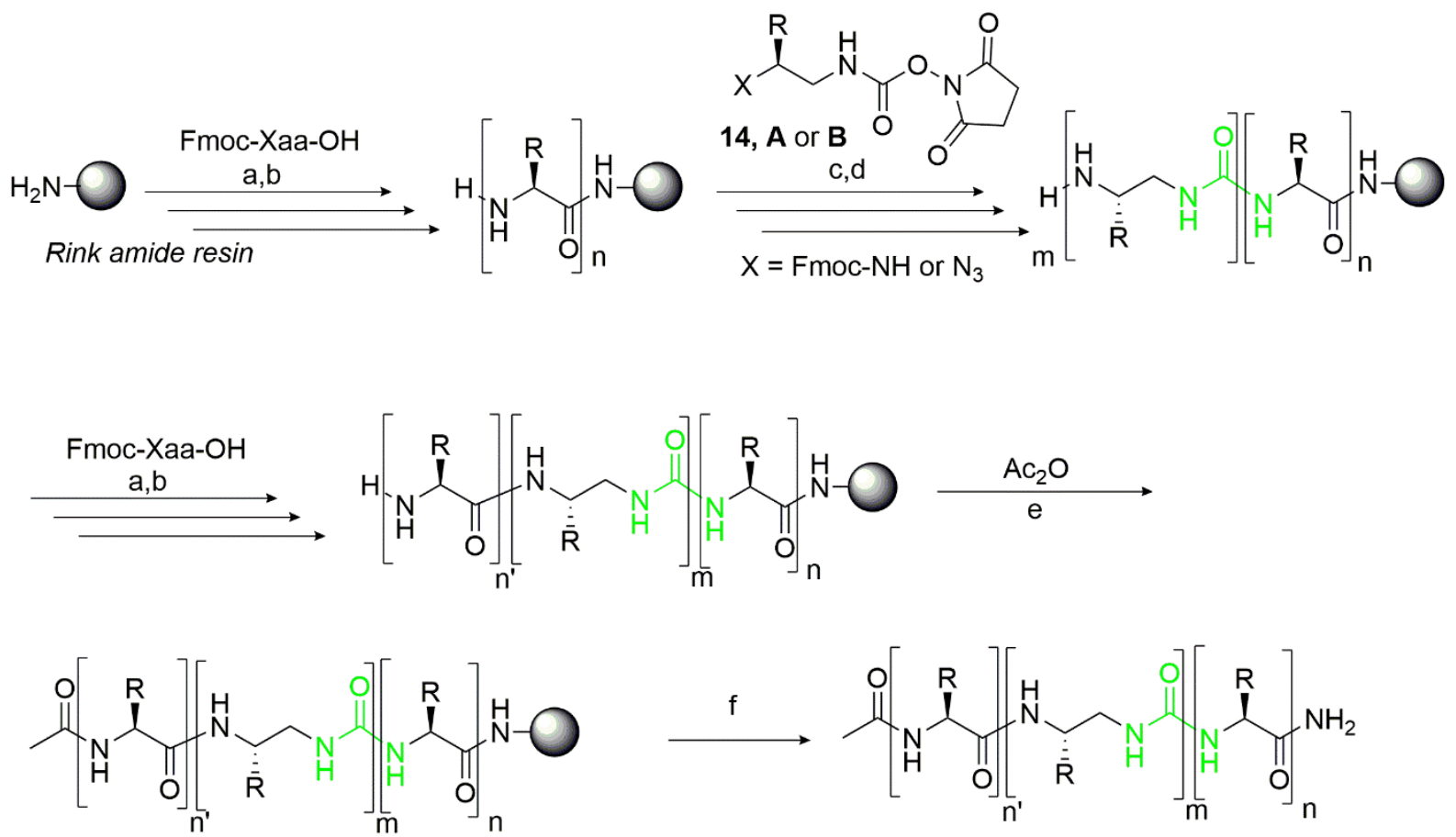

Scheme S4. a: $N$-Fmoc- $(\alpha)$-Xaa-OH (5 equiv. relative to the resin loading), DIC (5 equiv.) and Oxyma (5 equiv.) $75^{\circ} \mathrm{C}, 25 \mathrm{~W}, 5 \mathrm{~min}$; b: $20 \%$ piperidine, DMF $\left(90^{\circ} \mathrm{C} / 35 \mathrm{~W} / 50 \mathrm{sec}\right)$; c: $\mathbf{A}$ or $\mathbf{B}$ (1.5 equiv. relative to the resin loading ), DIEA (3 equiv.), $50^{\circ} \mathrm{C}, 50 \mathrm{~W} 2 \times 15$ min; d: PMe3 in THF (1M) (10 equiv.), Dioxane $/ \mathrm{H}_{2} \mathrm{O}$ (7:3; v,v), $50^{\circ} \mathrm{C}$, 50W, 2 x 15min; e: Acetic anhydride/DCM (1:1; v,v) (15 min, R.T.); f: TFA/TIS/H ${ }_{2} \mathrm{O} / \mathrm{EDT}$ (92.5:2.5:2.5:2.5; $\mathrm{v}, \mathrm{v}, \mathrm{v}, \mathrm{v})$

$\alpha /$ urea_hybrid foldamers were synthesized on a 50 to $100 \mu$ mol scale. Polystyrene Rink amide resin (loading $0.76 \mathrm{mmol} / \mathrm{g}$ ) was placed in the reaction vessel, and pre-swollen with DMF for 1-2 hours. All steps were performed under inert atmosphere $\left(\mathrm{N}_{2}\right)$ and microwave irradiation on either the Discover Liberty Blue or Bio system (CEM). The vessel was then placed inside the microwave oven. The temperature was maintained by modulation of power and controlled with a fiber optic sensor. $N$-Fmoc$(\alpha)$-Xaa-OH (5 equiv. relative to the resin loading), DIC ( 5 equiv.) and Oxyma (5 equiv.) were added to the reaction vessel $(\mathrm{RV})$ and the $\mathrm{RV}$ was irradiated $\left(75^{\circ} \mathrm{C}, 25 \mathrm{~W}, 5 \mathrm{~min}\right)$ for all amino acids at exception of Fmoc-Arg(pbf)-OH, for which the coupling reaction was performed at RT and time was extended to $45 \mathrm{~min}$ and repeated once. The resin was then filtered off and washed with DMF $(3 \times 3$ $\mathrm{mL})$. Fmoc removal was carried out with $20 \%$ of piperidine in $\mathrm{DMF}(2 \mathrm{~mL})$ under microwave irradiation $\left(75^{\circ} \mathrm{C}, 155 \mathrm{~W}, 15 \mathrm{sec}\right)+\left(90^{\circ} \mathrm{C}, 35 \mathrm{~W}, 50 \mathrm{sec}\right)$.

Next, the first urea residue (Fmoc-Gln $\left.(\mathrm{Trt})^{\mathrm{U}}-\mathrm{OSu}, \mathrm{14}\right)$ was introduced as a Fmoc protected derivative (5 equiv.) in the presence of DIEA ( 7 equiv.) at r.t. for $2 \mathrm{~h}$ and this step was repeated once. Fmoc removal was performed as described above. The three remaining urea residues were introduced using azido protected monomers activated as succinimidyl carbamate (A or $\mathbf{B}, 1.5$ equiv.) dissolved into DMF (2 $\mathrm{mL}$ ). After addition to the reaction vessel (CEM) DIEA (3 equiv.) was added. The reaction vessel was then irradiated under microwave $\left(50^{\circ} \mathrm{C}, 50 \mathrm{~W}, 15 \mathrm{~min}\right)$. A double coupling was performed systematically. The resin was filtered and washed with DMF $(3 \times 3 \mathrm{~mL})$. The resin was then filtered off, washed with DMF $(3 \times 3 \mathrm{~mL})$ and with a mixture of 1,4-dioxane/ $\mathrm{H}_{2} \mathrm{O}(7: 3, \mathrm{v} / \mathrm{v}, 3 \times 3 \mathrm{~mL})$. The Staudinger reduction reaction was performed under microwave irradiation $\left(50^{\circ} \mathrm{C}, 50 \mathrm{~W}, 15 \mathrm{~min}\right)$ by swelling the resin in 1,4-dioxane $/ \mathrm{H}_{2} \mathrm{O}$ solvent mixture $(1.5 \mathrm{~mL})$ and adding $1 \mathrm{M} \mathrm{PMe}_{3}$ solution in THF (10 equiv.). The reduction step was systematically performed twice. The resin was then filtered off and 
washed with DMF $(4 \times 3 \mathrm{~mL})$. These coupling and reduction steps were monitored with the chloranil test. The two last $\alpha$-amino acid residue were introduced as described above. Final acetylation was performed with a mixture acetic anhydride/DCM $(1: 1, \mathrm{v} / \mathrm{v}, 2 \mathrm{~mL})$. The resin was next swelled in a mixture TFA/TIS/ $\mathrm{H}_{2} \mathrm{O} /(95: 2.5: 2.5, \mathrm{v} / \mathrm{v} / \mathrm{v})$ and left to react for $4 \mathrm{hrs}$ under slight shaking, then filtered off, washed with TFA $(2 \times 2 \mathrm{~mL})$ and $\mathrm{CH}_{2} \mathrm{Cl}_{2}(2 \times 2 \mathrm{~mL})$. The filtrate was evaporated under reduced pressure and precipitated in cold $\mathrm{Et}_{2} \mathrm{O}$. The crude oligomer was lyophilized, analyzed on RP-HPLC before to be purified by preparative or semi-preparative RP-HPLC using the appropriate gradient to a final purity $\geq 95 \%$.

\section{General procedure for peptide synthesis}

Peptides were prepared on a $50 \mu \mathrm{mol}$ scale. Polystyrene Rink amide resin (loading $0.45 \mathrm{mmol} / \mathrm{g}$ ) was placed in the reaction vessel, and pre-swelled with DMF for 1-2h. The vessel was then placed inside the microwave reactor of the Liberty Blue. The temperature was maintained by modulation of power and controlled with a fiber optic sensor. $N$-Fmoc- $(\alpha)-\mathrm{Xaa}-\mathrm{OH}$ (5 equiv. relative to the resin loading), DIC (5 equiv.) and Oxyma (5 equiv.), were dissolved in DMF. The vessel was then irradiated $\left(75^{\circ} \mathrm{C}\right.$, $170 \mathrm{~W}, 15 \mathrm{sec})+\left(90^{\circ} \mathrm{C}, 35 \mathrm{~W}, 110 \mathrm{sec}\right)$. The resin was then filtered off and washed with DMF $(3 \times 3$ $\mathrm{mL})$. Fmoc removal was carried out with $20 \%$ of piperidine in DMF $(2 \mathrm{~mL})$ under microwave irradiation $\left(75^{\circ} \mathrm{C}, 155 \mathrm{~W}, 15 \mathrm{sec}\right)+\left(90^{\circ} \mathrm{C}, 35 \mathrm{~W}, 50 \mathrm{sec}\right)$. When Acetyl $N$-cap was needed, an additional step was performed manually with a mixture acetic anhydride/DCM (1:1, v/v). Finally, the resin was swelled in a mixture TFA/TIS $/ \mathrm{H}_{2} \mathrm{O} /(95: 2.5: 2.5, \mathrm{v} / \mathrm{v} / \mathrm{v})$ and left to react for $4 \mathrm{hrs}$ under slight shaking. Then, the resin was filtered off, washed with TFA $(2 \times 2 \mathrm{~mL})$ and $\mathrm{CH}_{2} \mathrm{Cl}_{2}(2 \times 2 \mathrm{~mL})$ and the filtrate was evaporated under reduced pressure. After precipitation in cold $\mathrm{Et}_{2} \mathrm{O}$, the crude oligomer was lyophilized then analyzed by RP-HPLC before to be purified by preparative RP-HPLC using the appropriate gradient to a final purity $\geq 95 \%$.

Nomenclature: The one letter / three letter code is used for natural $\alpha$-amino acids and the same letter code is also employed for ethylene diamine residue with a $U$ in superscript corresponding to the urea linkage.

Peptides P1 Ac-ASTEEKWARLARRIAG-NH ${ }_{2}$ and $\underline{\text { P2 Ac-EKWARLARRIAG-NH }} 2$ were purchased from custom synthesis service (GeneCust) (> 98\% purity).

\section{P3: Ac-EKWARLARRIA-NH ${ }_{2}$}

Peptide P3 was automatically synthesized on $50 \mu \mathrm{mol}$ scale following the general SPPS procedure described above. The desired peptide was purified by preparative RP-HPLC with a gradient 20 to $50 \%$ of B in 20 min at a flow of $20 \mathrm{~mL} / \mathrm{min}$. $\mathbf{P 3}$ was recovered with an overall yield of $49 \%$.

ESI-MS (ESI+): $\mathrm{m} / \mathrm{z} \mathrm{m} / \mathrm{z}$ calculated for $\mathrm{C}_{63} \mathrm{H}_{108} \mathrm{~N}_{23} \mathrm{O}_{14}: 705.84[\mathrm{M}+2 \mathrm{H}]^{2+}$ found $705.8[\mathrm{M}+2 \mathrm{H}]^{2+}, 470.8$ $[\mathrm{M}+3 \mathrm{H}]^{3+}, 353.4[\mathrm{M}+4 \mathrm{H}]^{4+} ; \mathrm{RP}-\mathrm{HPLC} t_{\mathrm{R}}=3.88 \mathrm{~min}$ (gradient $20-100 \% \mathrm{~B}, 10 \mathrm{~min}$ ) 


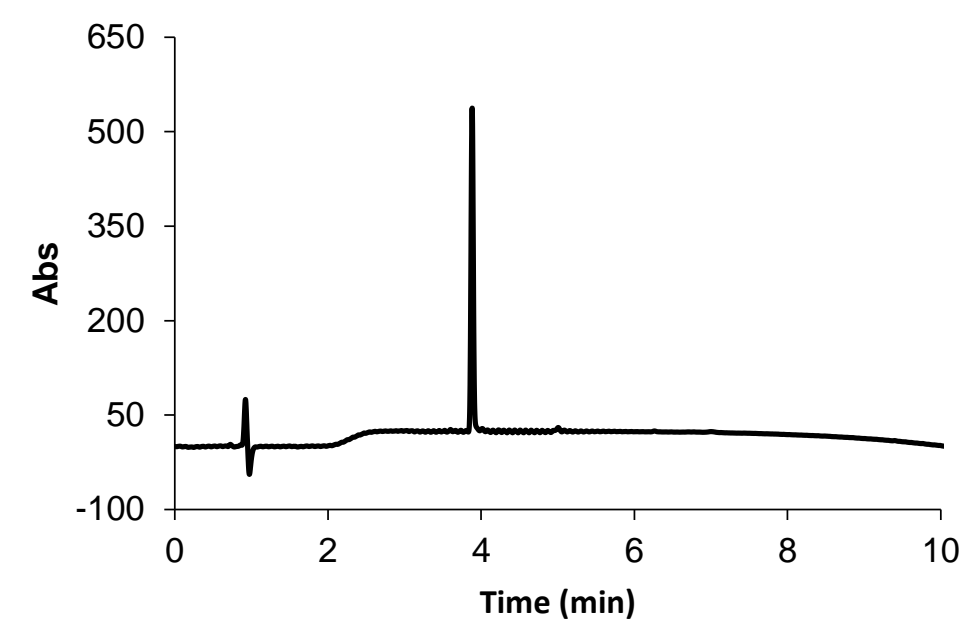

\section{P4: Ac-EK-Nal-ARLARRIA-NH}

Peptide P4 was automatically synthesized on $50 \mu \mathrm{mol}$ scale following the general SPPS procedure described above. The desired peptide was purified by preparative RP-HPLC with a gradient 20 to $50 \%$ of $\mathrm{B}$ in $20 \mathrm{~min}$ at a flow of $20 \mathrm{~mL} / \mathrm{min}$. $\mathbf{P 4}$ was recovered with an overall yield of $55 \%$.

ESI-MS (ESI+): $m / z$ calculated for $\mathrm{C}_{65} \mathrm{H}_{108} \mathrm{~N}_{22} \mathrm{O}_{14}: 711.35[\mathrm{M}+2 \mathrm{H}]^{2+}$ found $711.6[\mathrm{M}+2 \mathrm{H}]^{2+}, 474.7$ $[\mathrm{M}+3 \mathrm{H}]^{3+}, 366.3[\mathrm{M}+4 \mathrm{H}]^{4+}$; RP-HPLC $t_{\mathrm{R}}=4.22 \mathrm{~min}$ (gradient $20-100 \% \mathrm{~B}, 10 \mathrm{~min}$ )

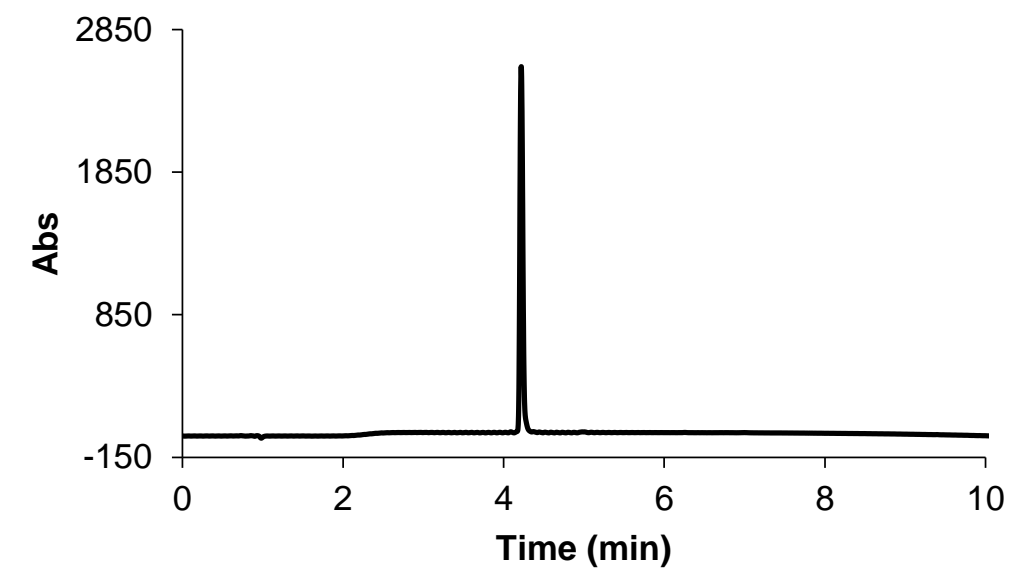

\section{P5: Ac-EK-Nal-RLQRIA-NH 2}

Peptide P5 was automatically synthesized on $100 \mu$ mol scale following the general SPPS procedure described above. The desired peptide was purified by preparative RP-HPLC with a gradient 20 to $50 \%$ of B in $20 \mathrm{~min}$ at a flow of $20 \mathrm{~mL} / \mathrm{min}$. P5 was recovered with an overall yield of $65 \%$.

ESI-MS (ESI+): $m / z$ calculated for $\mathrm{C}_{58} \mathrm{H}_{95} \mathrm{~N}_{18} \mathrm{O}_{13}: 626.36[\mathrm{M}+2 \mathrm{H}]^{2+}$ found $626.33[\mathrm{M}+2 \mathrm{H}]^{2+}, 417.93$ $[\mathrm{M}+3 \mathrm{H}]^{3+} ;$ RP-HPLC $t_{\mathrm{R}}=4.17$ min (linear gradient $20-100 \% \mathrm{~B}, 10 \mathrm{~min}$ ) 


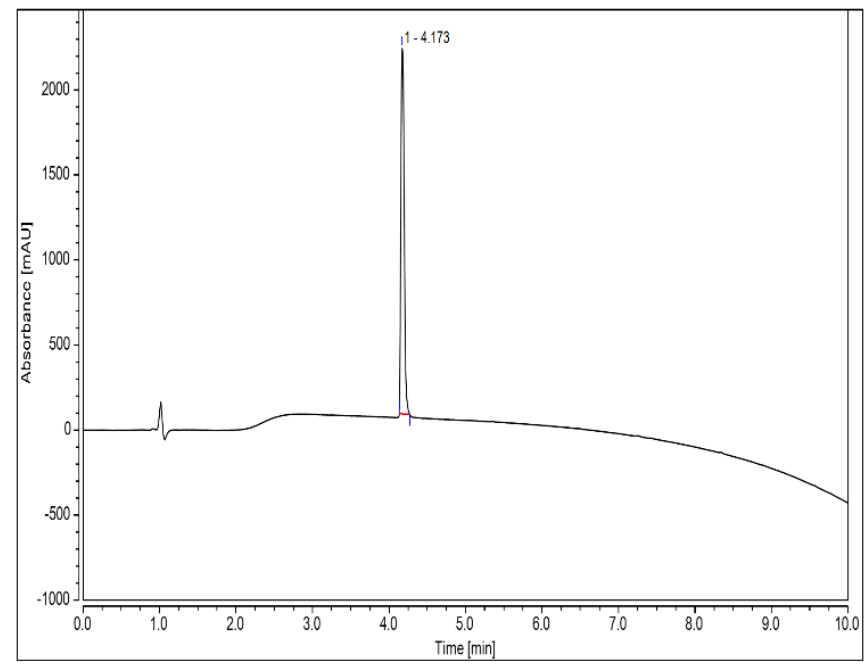

\section{C1: Ac-E-K-W ${ }^{\mathrm{u}}-\mathrm{R}^{\mathrm{u}}-\mathrm{L}^{\mathrm{u}}-\mathrm{Q}^{\mathrm{u}}-\mathrm{R}-\mathrm{I}-\mathrm{A}-\mathrm{NH}_{2}$}

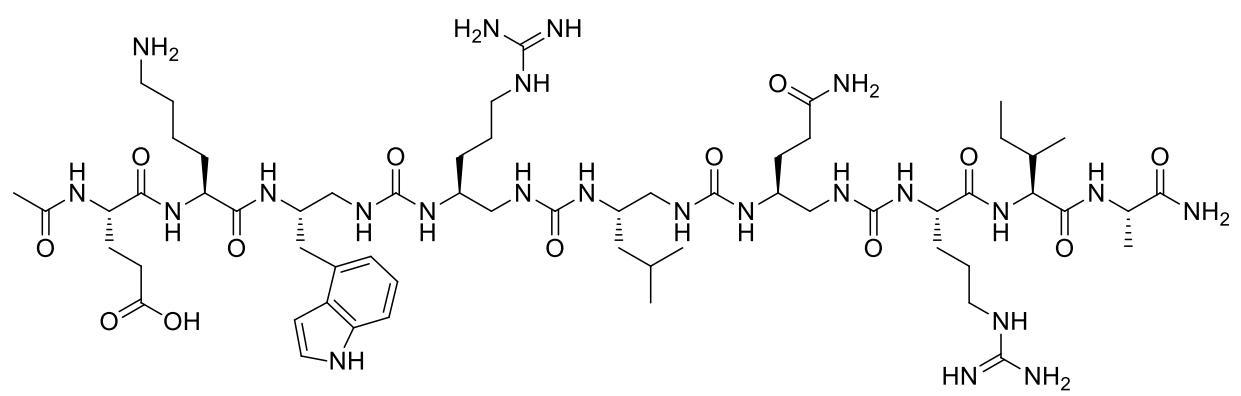

Overall yield after RP-HPLC purification: $4 \%$

ESI-MS $\left(\mathrm{ESI}^{+}\right): \mathrm{m} / z$ calculated for $\mathrm{C}_{60} \mathrm{H}_{106} \mathrm{~N}_{23} \mathrm{O}_{13}: 678.92[\mathrm{M}+2 \mathrm{H}]^{2+}$ found $678.82[\mathrm{M}+2 \mathrm{H}]^{2+}, 452.8698$ $[\mathrm{M}+3 \mathrm{H}]^{3+}$; RP-HPLC $t_{\mathrm{R}} 5.3 \mathrm{~min}$ (linear gradient, 10-100\% B, $10 \mathrm{~min}$ ).
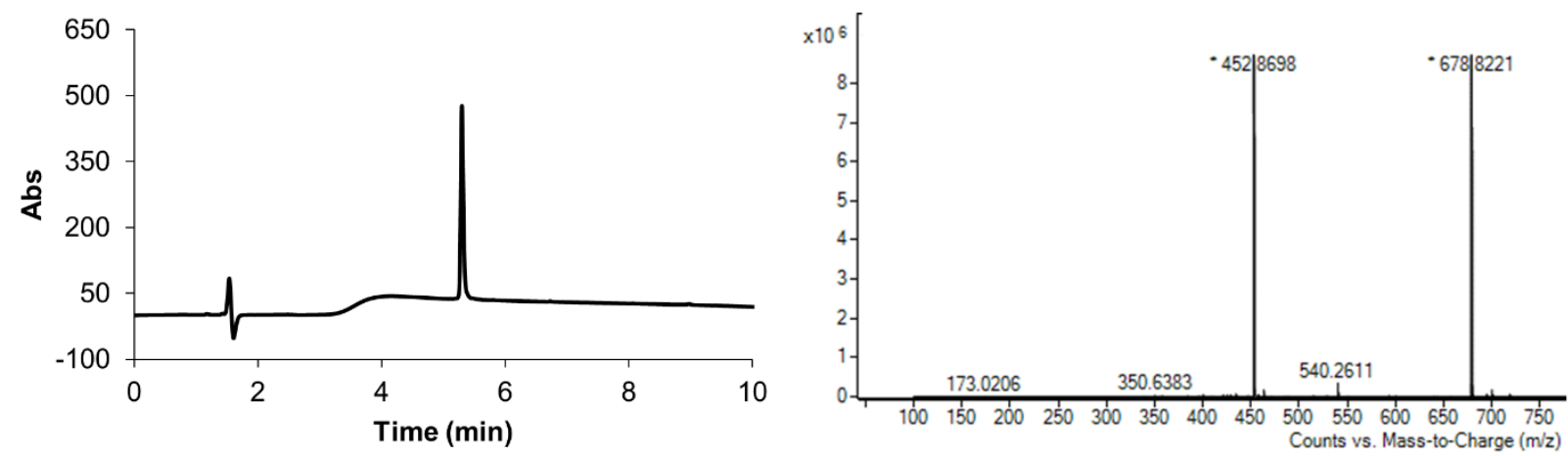
$\underline{\text { C2 : Ac-E-K-Nal }{ }^{\mathrm{u}}-\mathrm{R}^{\mathrm{u}}-\mathrm{L}^{\mathrm{u}}-\mathrm{Q}^{\mathrm{u}}-\mathrm{R}-\mathrm{I}-\mathrm{A}-\mathrm{NH}_{2}}$

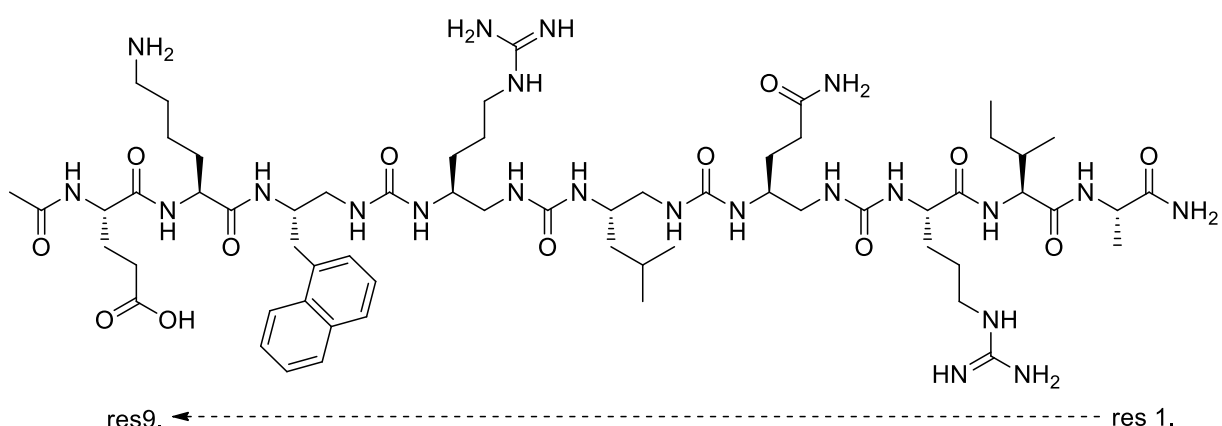

Overall yield after RP-HPLC purification: 7\%

ESI-MS $\left(\mathrm{ESI}^{+}\right): \mathrm{m} / z$ calculated for $\mathrm{C}_{62} \mathrm{H}_{103} \mathrm{~N}_{22} \mathrm{O}_{13}: 1367.83[\mathrm{M}+\mathrm{H}]^{+}$found 1367.67, $684.53[\mathrm{M}+2 \mathrm{H}]^{2+}$, $456.60[\mathrm{M}+3 \mathrm{H}]^{3+}$; RP-HPLC $t_{\mathrm{R}} 4.54 \mathrm{~min}$; (linear gradient, 10-100\% B, $10 \mathrm{~min}$ ).
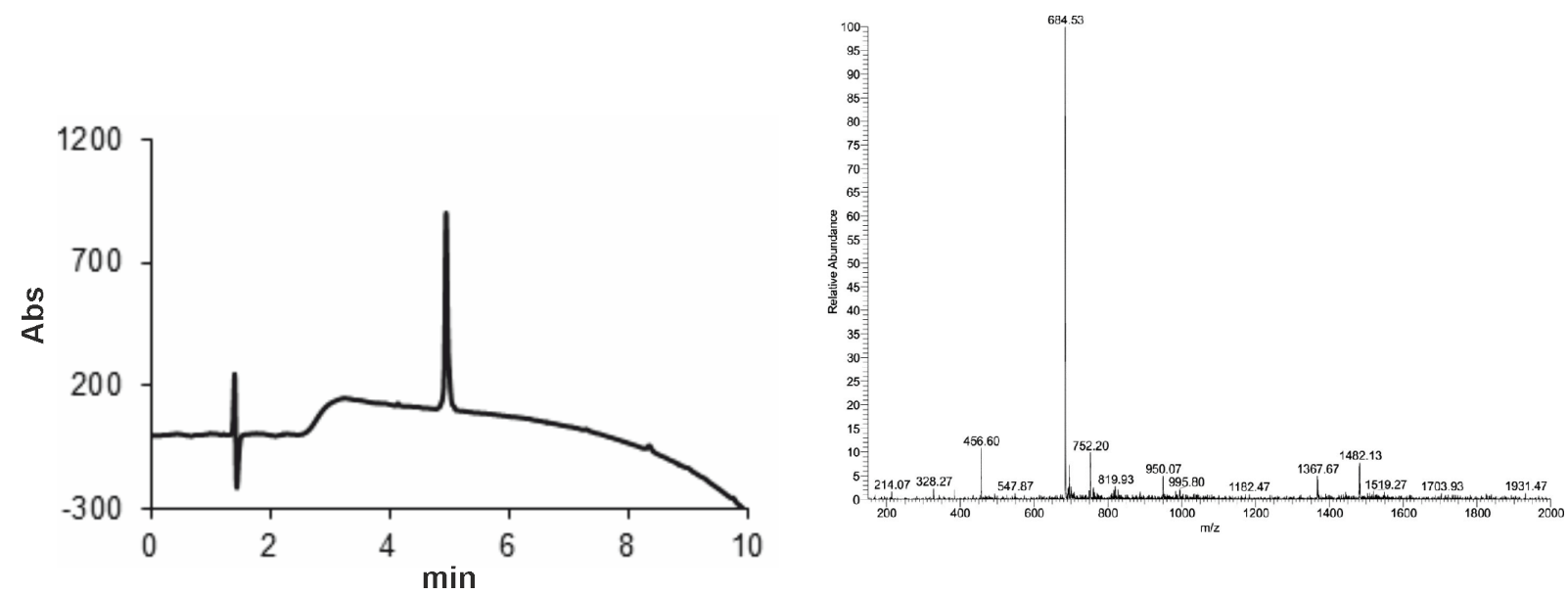

Table S1. ${ }^{1} \mathrm{H}$ NMR chemical shifts (in ppm) of $\mathbf{C 2}$ in $\mathrm{CD}_{3} \mathrm{OH}(400 \mathrm{MHz})$ at $25^{\circ} \mathrm{C}$.

\begin{tabular}{|c|c|c|c|c|c|c|c|c|c|c|c|c|}
\hline \multicolumn{2}{|c|}{ Residue } & \multirow{2}{*}{$\frac{\mathbf{N H}}{8.32}$} & \multirow[t]{2}{*}{$\mathbf{N}^{\prime} \mathbf{H}$} & \multirow{2}{*}{$\frac{{ }^{\alpha} \mathbf{C H}^{1}}{4.42}$} & \multirow{2}{*}{$\frac{{ }^{\alpha} \mathbf{C H}^{2}}{-}$} & \multirow{2}{*}{$\frac{{ }^{\boldsymbol{B}} \mathbf{C H}}{1.45}$} & \multirow[t]{2}{*}{${ }^{\gamma} \mathbf{C H}$} & \multirow[t]{2}{*}{${ }^{\delta} \mathrm{CH}$} & \multirow[t]{2}{*}{${ }^{\varepsilon} \mathbf{C H}$} & \multirow[t]{2}{*}{$\mathbf{N H}_{2}$} & \multirow[t]{2}{*}{ Arom } & \multirow[t]{2}{*}{$\Delta \delta\left({ }^{\alpha} \mathrm{CH}\right)$} \\
\hline Ala & 1 & & & & & & & & & & & \\
\hline Ile & 2 & 8.39 & & 4.26 & - & 2.10 & $\begin{array}{l}1.05 / \\
1.32, \\
1.58\end{array}$ & 0.96 & & & & \\
\hline Arg & 3 & 5.80 & & 4.03 & - & 1.69 & 1.86 & 3.17 & & $7.49 /$ & & \\
\hline Gln $^{u}$ & 4 & 6.70 & 6.13 & 3.59 & & 3.79 & $\begin{array}{l}1.72 / \\
1.59\end{array}$ & $\begin{array}{l}2.43 / \\
2.28\end{array}$ & & & & \\
\hline Leu $^{u}$ & 5 & 5.70 & 6.06 & 3.20 & 2.49 & 3.84 & 1.63 & 1.87 & 0.86 & & & \\
\hline $\operatorname{Arg}^{u}$ & 6 & 5.81 & 6.08 & 3.56 & 2.52 & 3.73 & 1.31 & 1.72 & 3.18 & $7.47 / 8.17$ & & \\
\hline $\mathrm{Nal}^{\mathrm{u}}$ & 7 & 7.60 & 6.11 & 3.75 & 2.99 & 4.57 & $\begin{array}{l}3.32 / \\
3.11\end{array}$ & & & & & \\
\hline Lys & 8 & 8.36 & & 4.03 & - & 1.57 & 1.57 & 1.57 & 2.84 & & & \\
\hline Glu & 9 & 8.51 & & 4.23 & - & 2.48 & 2.03 & & & & & \\
\hline \multicolumn{2}{|c|}{ Ac } & 2.11 & & & & & & & & & & \\
\hline
\end{tabular}




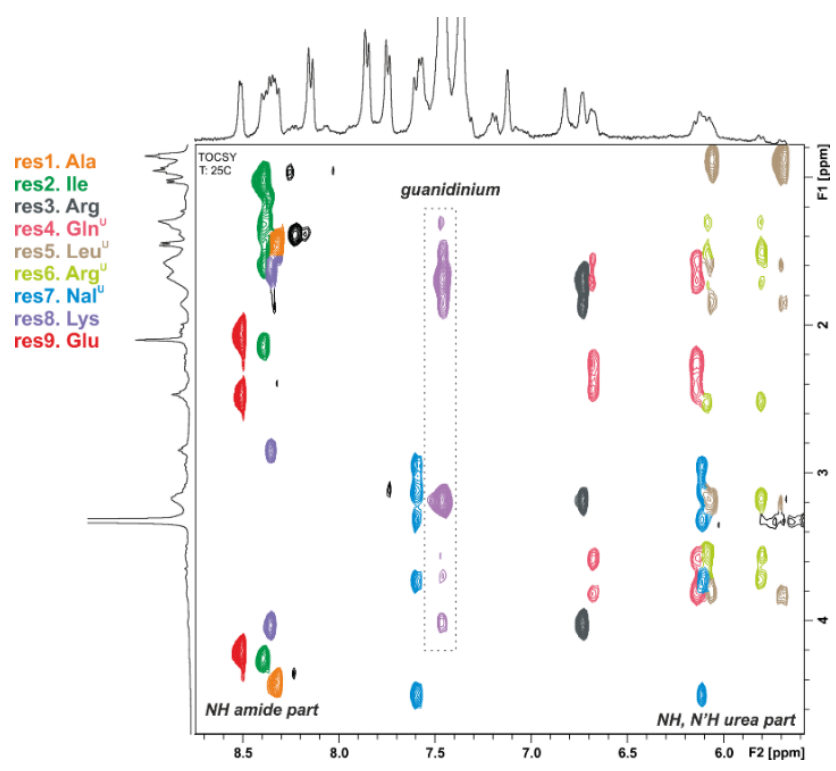

Figure S1. ${ }^{1} \mathrm{H}$ NMR amide aliphatic region of a TOCSY spectrum of $\mathbf{C 2}$ in $\mathrm{CD}_{3} \mathrm{OH}(400 \mathrm{MHz})$ at $25^{\circ} \mathrm{C}$. Signal corresponding to the different monomers are coloured as indicated on the left.

\section{C3: Ac-E-K-hF $\mathbf{H}^{\mathrm{u}}-\mathbf{R}^{\mathrm{u}}-\mathrm{L}^{\mathrm{u}}-\mathrm{Q}^{\mathrm{u}}-\mathrm{R}-\mathrm{I}-\mathrm{A}-\mathrm{NH}_{2}$}

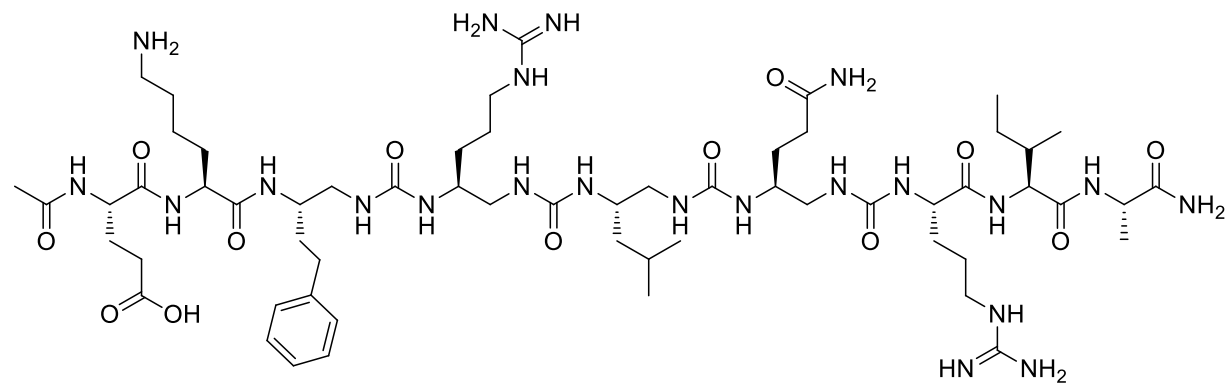

Overall yield after RP-HPLC purification: $2 \%$

ESI-MS (ESI+): $m / z$ calculated for $\mathrm{C}_{59} \mathrm{H}_{106} \mathrm{~N}_{22} \mathrm{O}_{13}: 1331.84[\mathrm{M}+\mathrm{H}]^{+}$found 1331.60; $[\mathrm{M}+\mathrm{H}]^{+}, 666.40$; $[\mathrm{M}+2 \mathrm{H}]^{2+}, 444.87$; $[\mathrm{M}+3 \mathrm{H}]^{3+}$; RP-HPLC $t_{\mathrm{R}} 4.82 \mathrm{~min}$; (linear gradient, $10-100 \% \mathrm{~B}, 10 \mathrm{~min}$ )
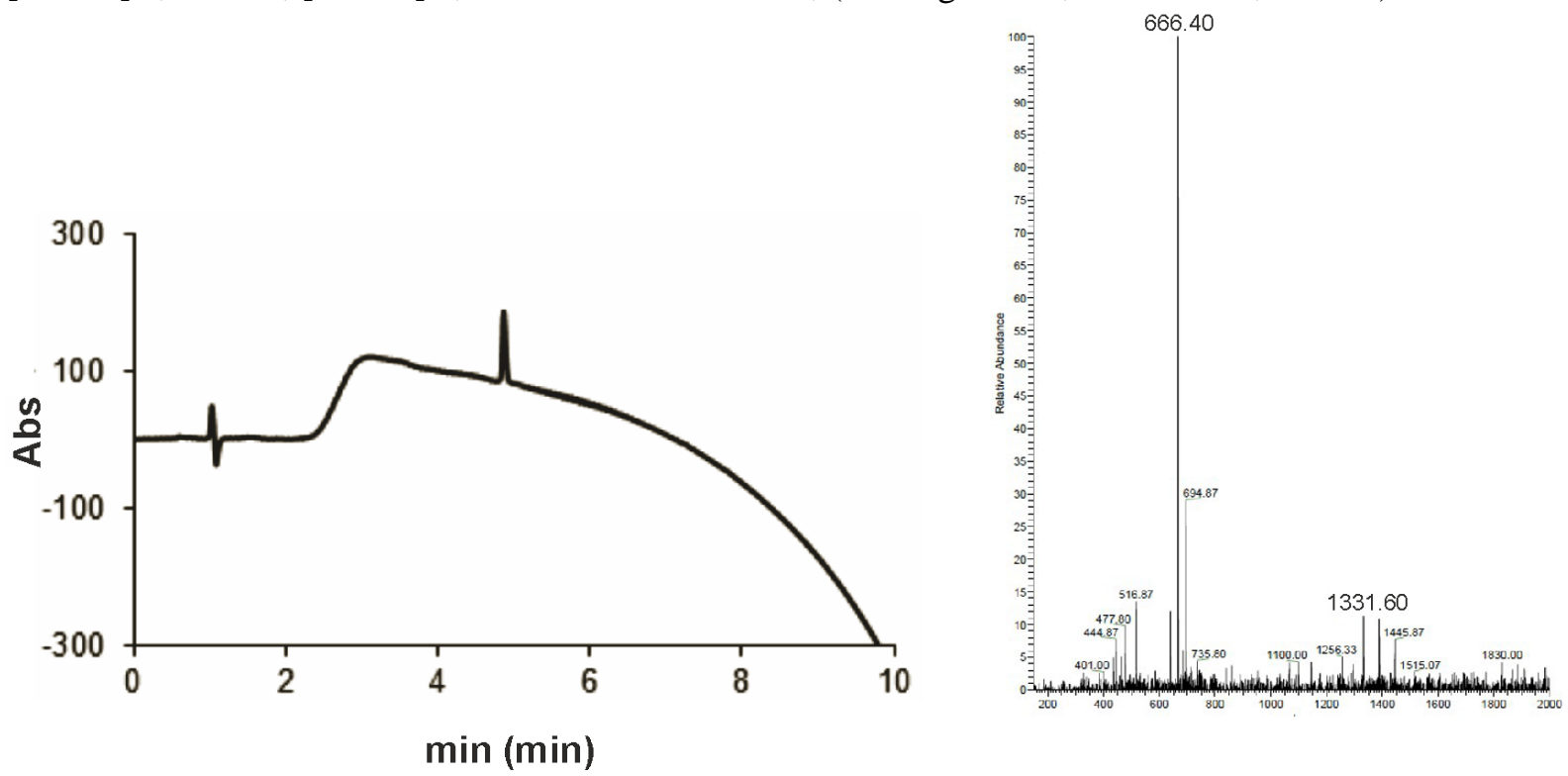
C4: Ac-E-K-A ${ }^{\mathrm{u}}-\mathrm{R}^{\mathrm{u}}-\mathrm{L}^{\mathrm{u}}-\mathrm{Q}^{\mathrm{u}}-\mathrm{R}-\mathrm{I}-\mathrm{A}-\mathrm{NH}_{2}$<smiles>CCC(C)C(NC(=O)C(CCCNC(=N)N)NC(=O)NCC(CCC(N)=O)NC(=O)NCC(CC(C)C)NC(=O)NCC(CCCNC(=N)N)NC(=O)NCCNC(=O)C(CCCCN)NC(=O)C(CCC(=O)O)NC(C)=O)C(=O)NC(C)C(N)=O</smiles>

Overall yield after RP-HPLC purification: $3 \%$

ESI-MS (ESI+): $m / z$ calculated for $\mathrm{C}_{52} \mathrm{H}_{100} \mathrm{~N}_{22} \mathrm{O}_{13}: 1241.79[\mathrm{M}+\mathrm{H}]^{+}$found $1241.60[\mathrm{M}+\mathrm{H}]^{+}, 621.4$ $[\mathrm{M}+2 \mathrm{H}]^{2+}$; RP-HPLC $t_{\mathrm{R}} 3.69 \mathrm{~min}$; (linear gradient, $10-100 \% \mathrm{~B}, 10 \mathrm{~min}$ )

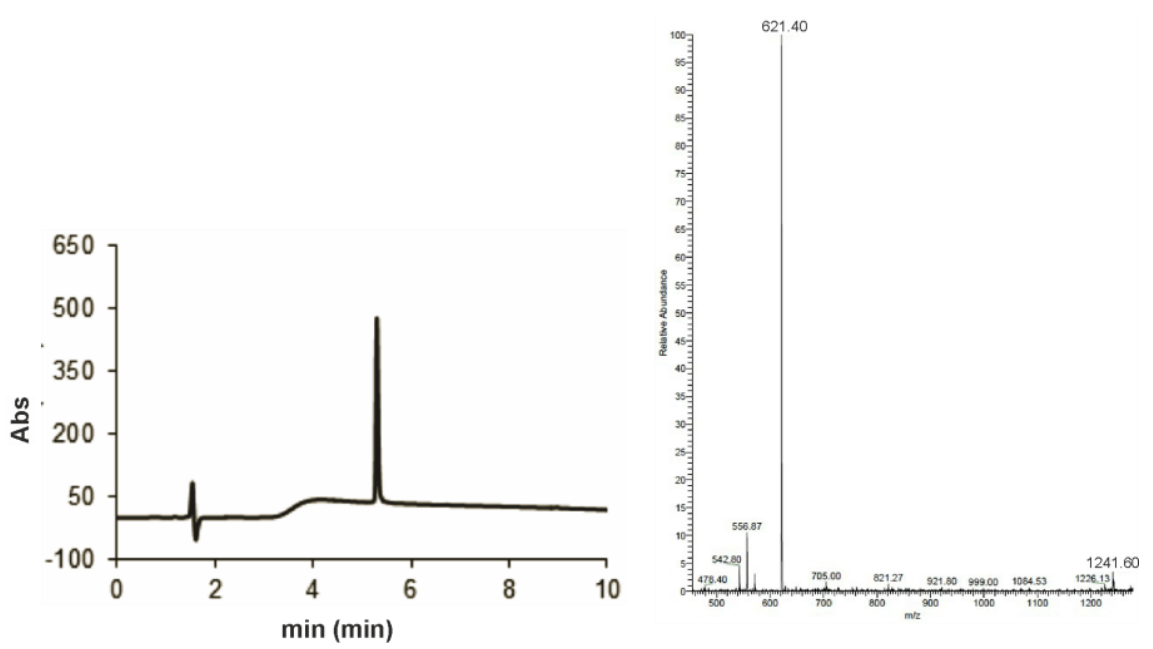

\section{C5 :Ac-E-R-Nal" ${ }^{\mathrm{u}} \mathbf{R}^{\mathrm{u}}-\mathrm{L}^{\mathrm{u}}-\mathrm{Q}^{\mathrm{u}}-\mathrm{R}-\mathrm{I}-\mathrm{A}-\mathrm{NH}_{2}$}

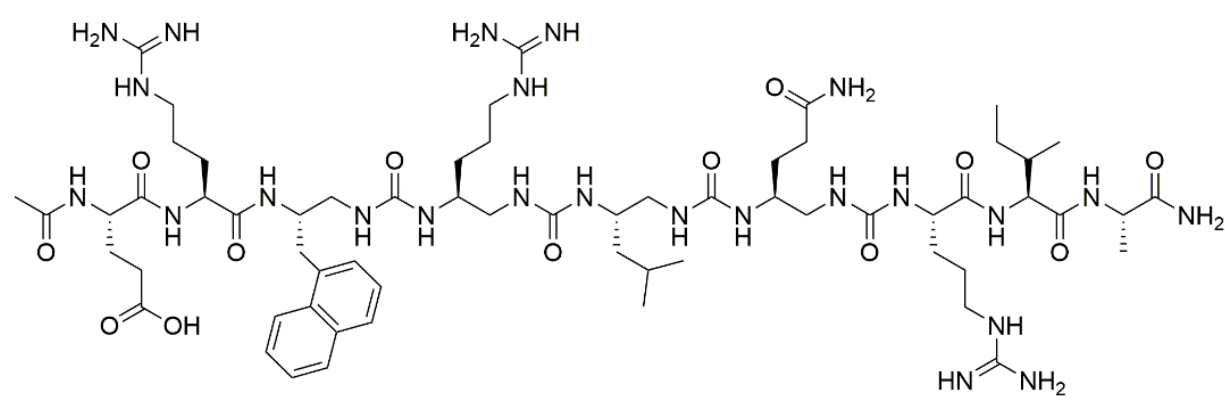

Overall yield after HPLC purification: $10 \%$

ESI-MS: $m / z$ calculated for $\mathrm{C}_{62} \mathrm{H}_{106} \mathrm{~N}_{24} \mathrm{O}_{13} 698.33[\mathrm{M}+2 \mathrm{H}]^{2+}$, found $698.71[\mathrm{M}+2 \mathrm{H}]^{2+}$; RP-HPLC $t_{\mathrm{R}}$ $5.03 \mathrm{~min}$ (linear gradient $10-100 \% \mathrm{~B}, 10 \mathrm{~min}$ ) 

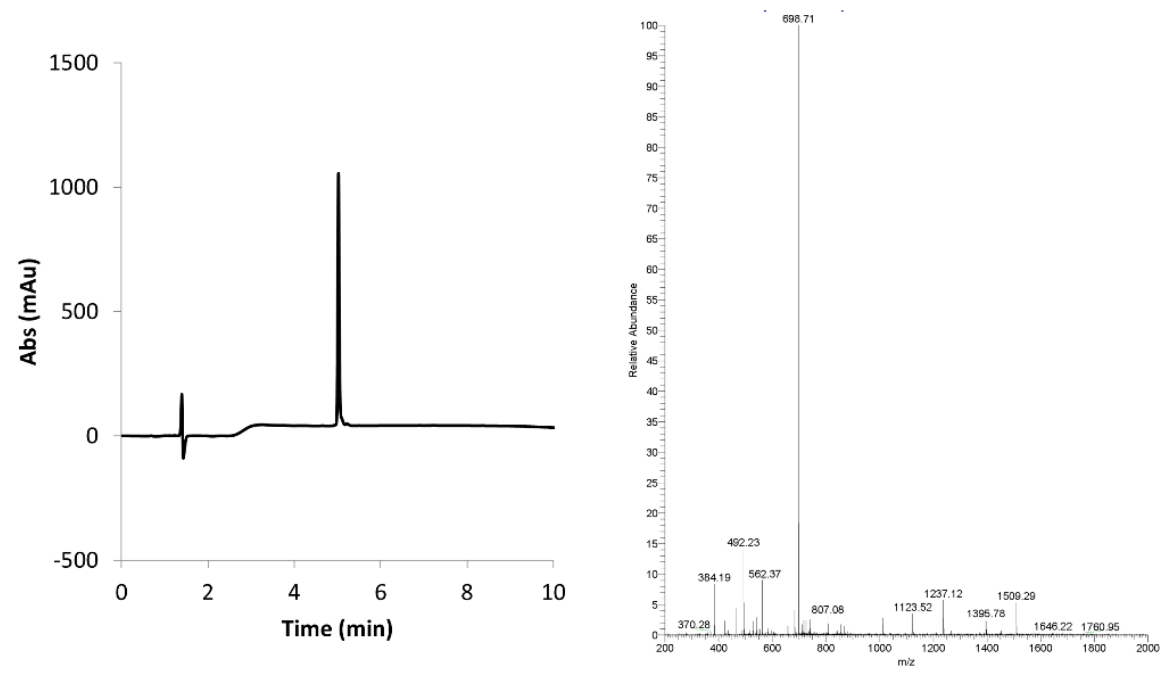

C6: Ac-E-K-Nal" - R $^{\mathrm{u}}-\mathrm{Nle}^{\mathrm{u}}-\mathrm{Q}^{\mathrm{u}}-\mathrm{R}-\mathrm{I}-\mathrm{A}-\mathrm{NH}_{2}$

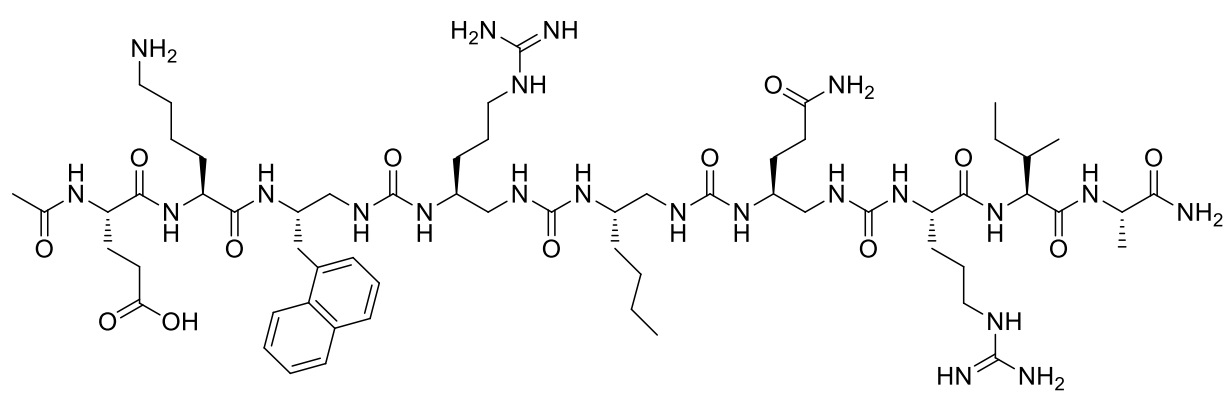

Overall yield after RP-HPLC purification: $27 \%$

ESI-MS (ESI+): $\mathrm{m} / z$ calculated for $\mathrm{C}_{62} \mathrm{H}_{106} \mathrm{~N}_{22} \mathrm{O}_{13}[\mathrm{M}+\mathrm{H}]^{+} 1367.84$ found $1367.91[\mathrm{M}+\mathrm{H}]^{+} ; 684.4716$ $[\mathrm{M}+2 \mathrm{H}]^{2+}$, RP-HPLC $t_{\mathrm{R}} 3.89 \mathrm{~min}$; (linear gradient, 10-100\% B, $10 \mathrm{~min}$ )
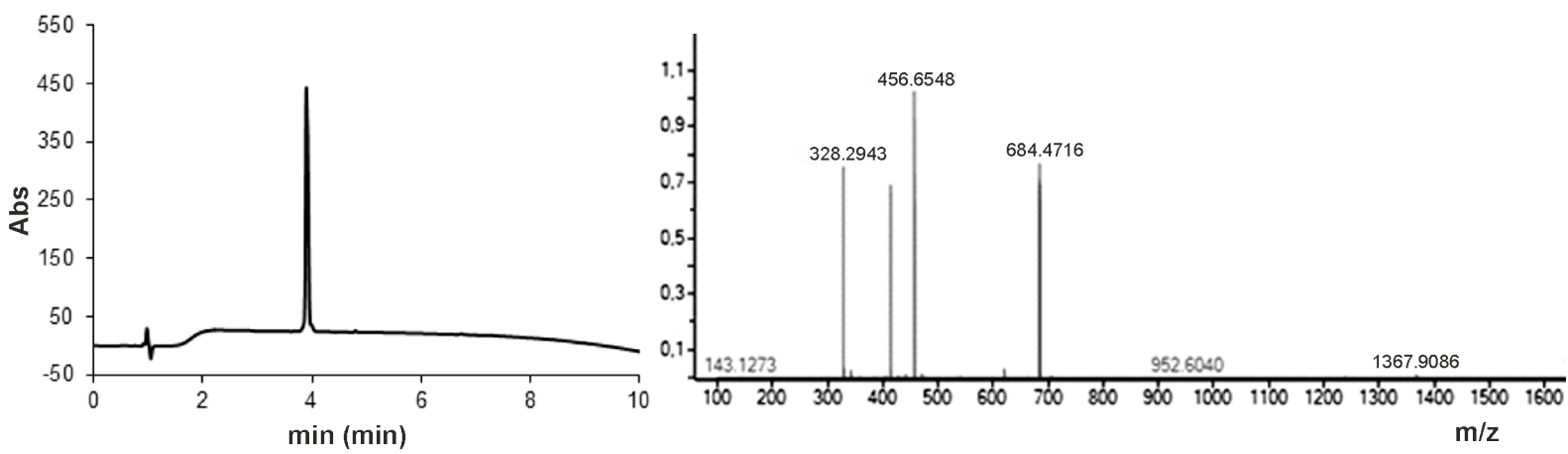

\section{C7: Ac-E-K-Nal'- ${ }^{\mathrm{u}}{ }^{\mathrm{u}}-\mathbf{h F}{ }^{\mathrm{u}}-\mathbf{Q}^{\mathrm{u}}-\mathrm{R}-\mathrm{I}-\mathrm{A}-\mathrm{NH}_{2}$}




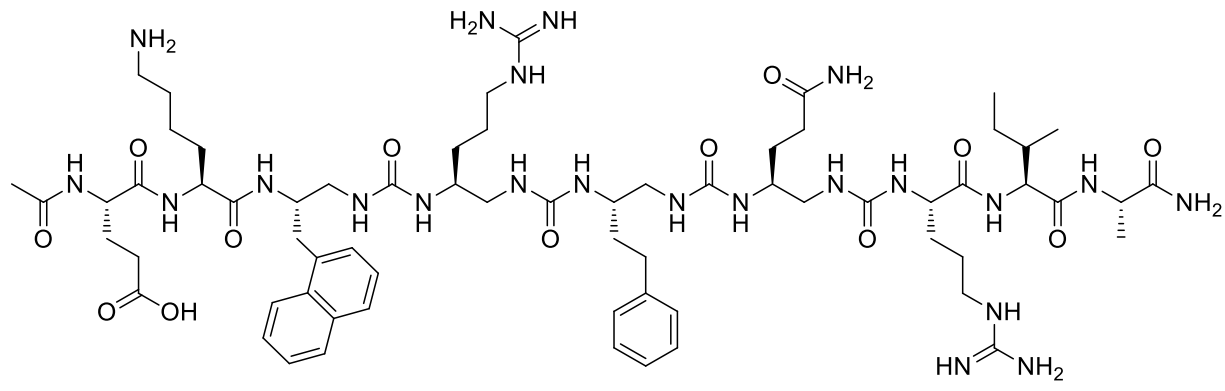

Overall yield after RP-HPLC purification: $12 \%$

ESI-MS (ESI+): $m / z$ calculated for $\mathrm{C}_{66} \mathrm{H}_{107} \mathrm{~N}_{22} \mathrm{O}_{13}[\mathrm{M}+\mathrm{H}]^{+} 1416.84$ found $1416.69[\mathrm{M}+\mathrm{H}]^{+} ; 708.33$

$[\mathrm{M}+2 \mathrm{H}]^{2+}, 472.54[\mathrm{M}+3 \mathrm{H}]^{3+} ;$ RP-HPLC $t_{\mathrm{R}} 3.60 \mathrm{~min}$; (linear gradient, 10-100\% B, $10 \mathrm{~min}$ )
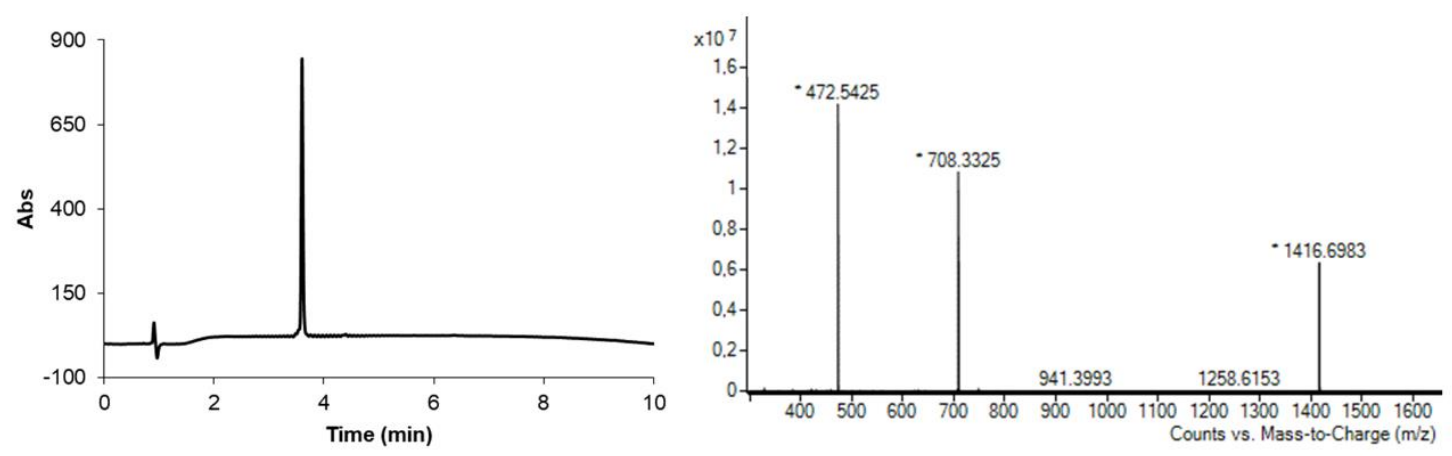

\section{C8: Ac-E-K-Nal ${ }^{\mathrm{u}}-\mathrm{R}^{\mathrm{u}}-\mathrm{Nal}^{\mathrm{u}}-\mathrm{Q}^{\mathrm{u}}-\mathrm{R}-\mathrm{I}-\mathrm{A}-\mathrm{NH}_{2}$}

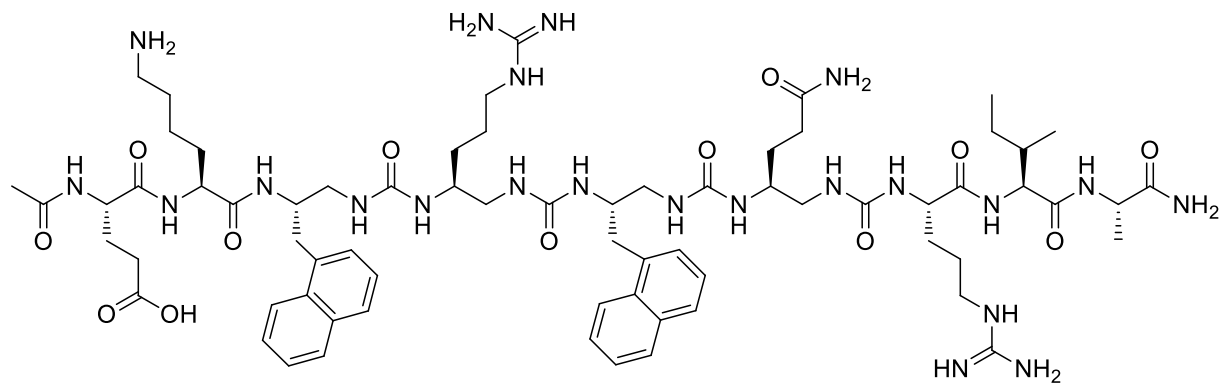

Overall yield after RP-HPLC purification: $12 \%$

ESI-MS (ESI+): $m / z$ calculated for $\mathrm{C}_{69} \mathrm{H}_{106} \mathrm{~N}_{22} \mathrm{O}_{13} 1451.83[\mathrm{M}+\mathrm{H}]^{+}$found $1451.7[\mathrm{M}+\mathrm{H}]^{+}, 725.5$ $[\mathrm{M}+2 \mathrm{H}]^{2+}$; RP-HPLC $t_{\mathrm{R}} 4.21 \mathrm{~min}$; (linear gradient, 20-100\% B, $50 \mathrm{~min}$ )

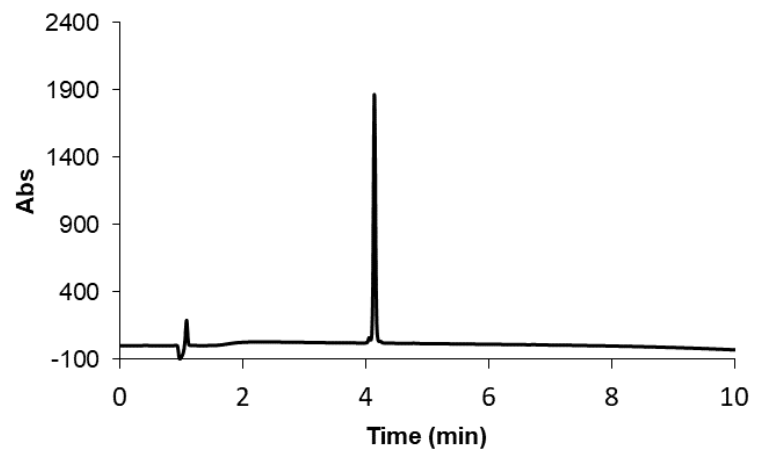




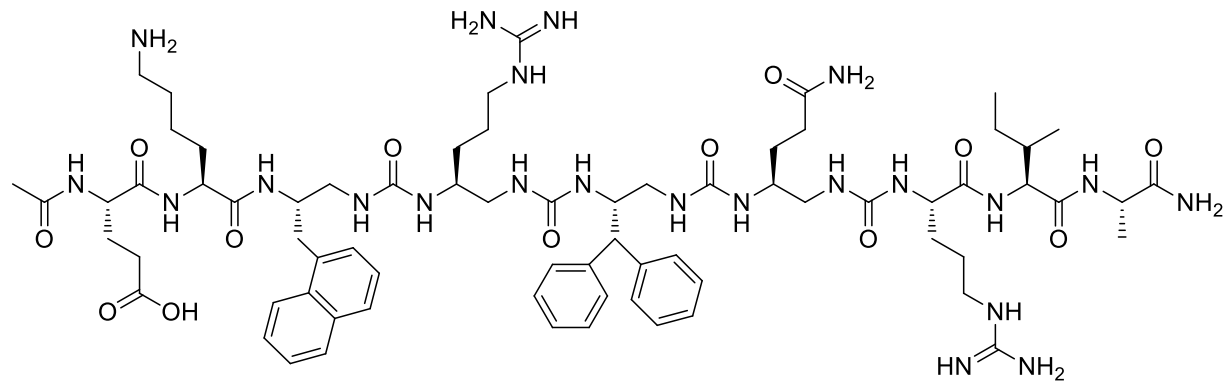

Overall yield after RP-HPLC purification: $15 \%$

ESI-MS (ESI+): $m / z$ calculated for $\mathrm{C}_{71} \mathrm{H}_{108} \mathrm{~N}_{22} \mathrm{O}_{13} 739.38[\mathrm{M}+2 \mathrm{H}]^{2+}$ found $739.27[\mathrm{M}+2 \mathrm{H}]^{2+}, 493.16$ $[\mathrm{M}+3 \mathrm{H}]^{3+}$; RP-HPLC $t_{\mathrm{R}} 4.19 \mathrm{~min}$; (linear gradient, $10-100 \% \mathrm{~B}, 10 \mathrm{~min}$ )
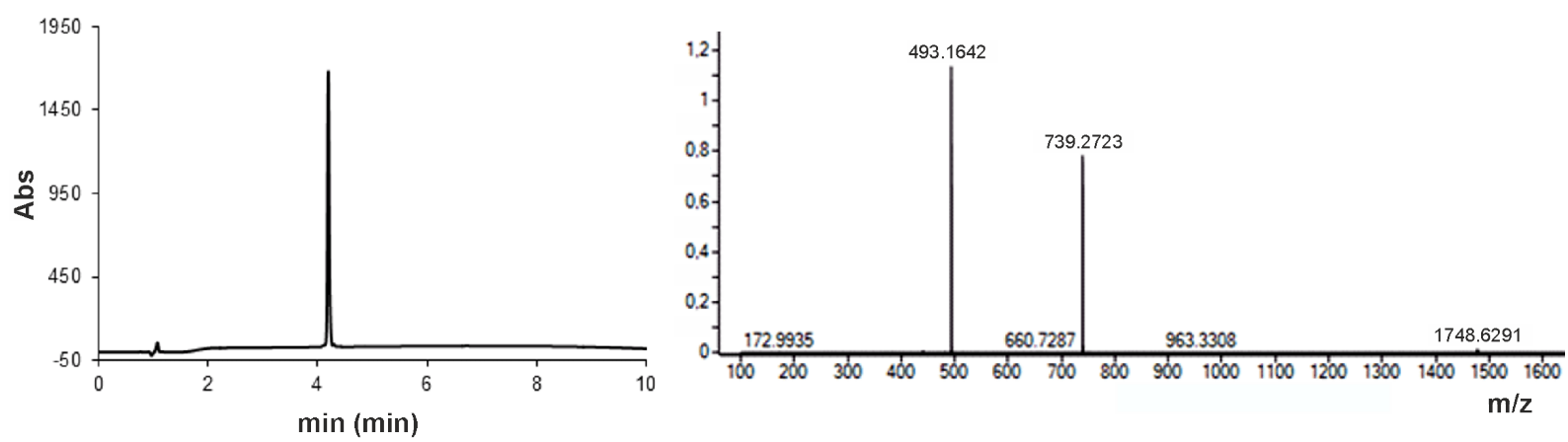

C10: Ac-A-S-T-E-E-K-Nal ${ }^{\mathrm{u}}-\mathrm{R}^{\mathrm{u}}-\mathrm{L}^{\mathrm{u}}-\mathrm{Q}^{\mathrm{u}}-\mathrm{R}-\mathrm{I}-\mathrm{A}-\mathrm{NH}_{2}$

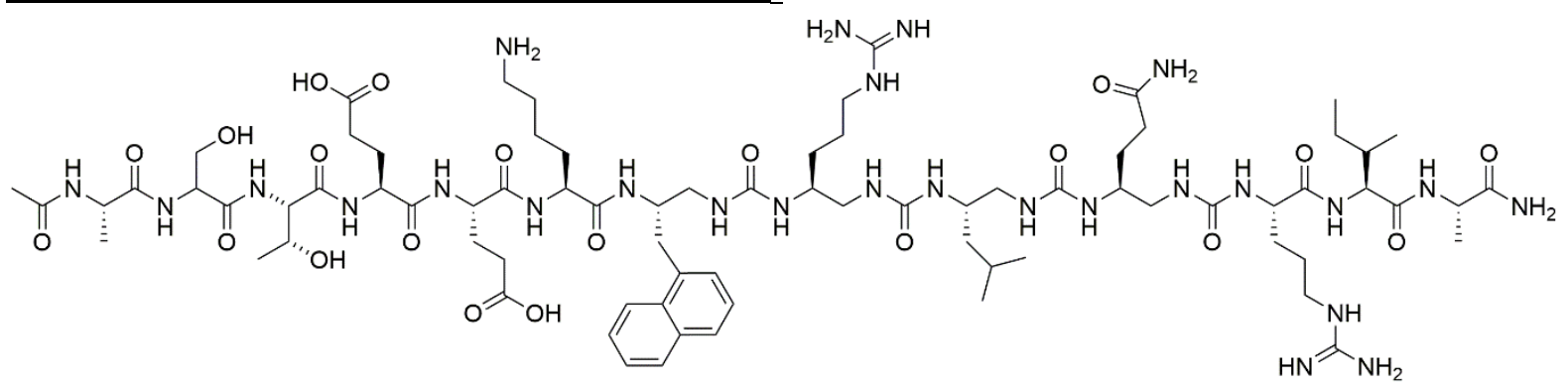

Overall yield yield after HPLC purification: $6 \%$.

ESI-MS (ESI+): $\mathrm{m} / z$ calculated for $\mathrm{C}_{77} \mathrm{H}_{130} \mathrm{~N}_{26} \mathrm{O}_{21} 1757.03[\mathrm{M}+\mathrm{H}]^{+}$; found $1756.87[\mathrm{M}+\mathrm{H}]^{+}, 879.00$ $[\mathrm{M}+2 \mathrm{H}]^{2+}, 586.40[\mathrm{M}+3 \mathrm{H}]^{3+}$; RP-HPLC $t_{\mathrm{R}} 4.11 \mathrm{~min}$; (linear gradient, 10-100\% B, $10 \mathrm{~min}$ )
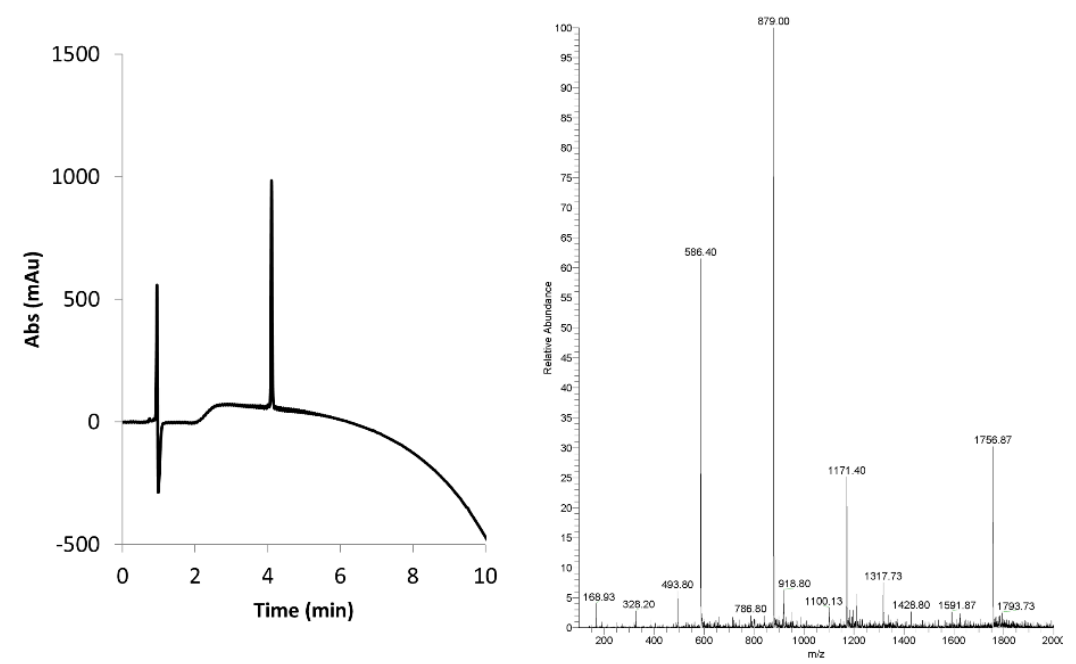


\section{Isothermal Titration Calorimetry}
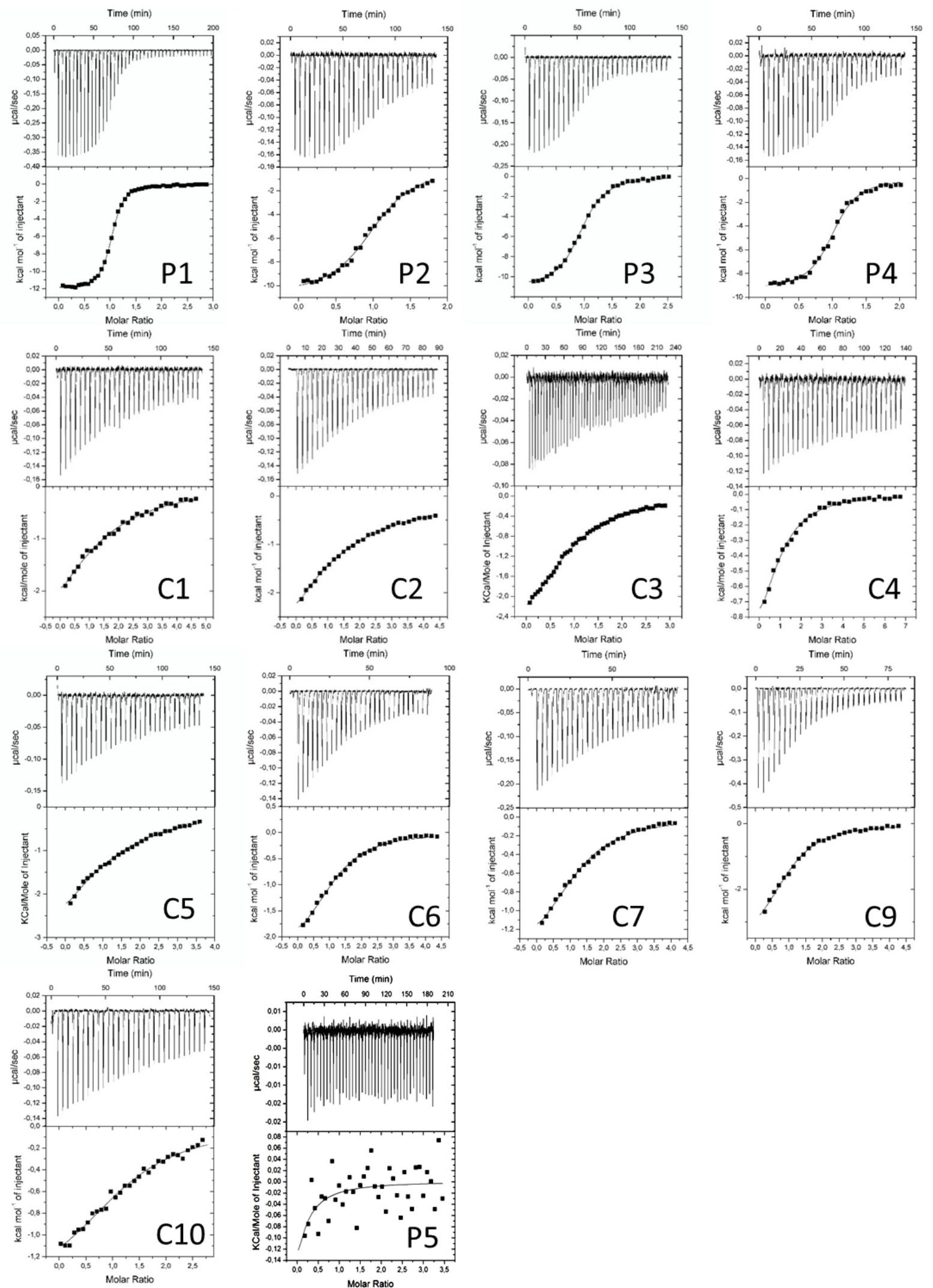

Figure S2. ITC thermograms and data fitting for the indicated peptides/chimera with hASF1A(1-156) 


\section{NMR studies $-{ }^{1} \mathrm{H}-{ }^{15} \mathrm{~N}$ HSQC}
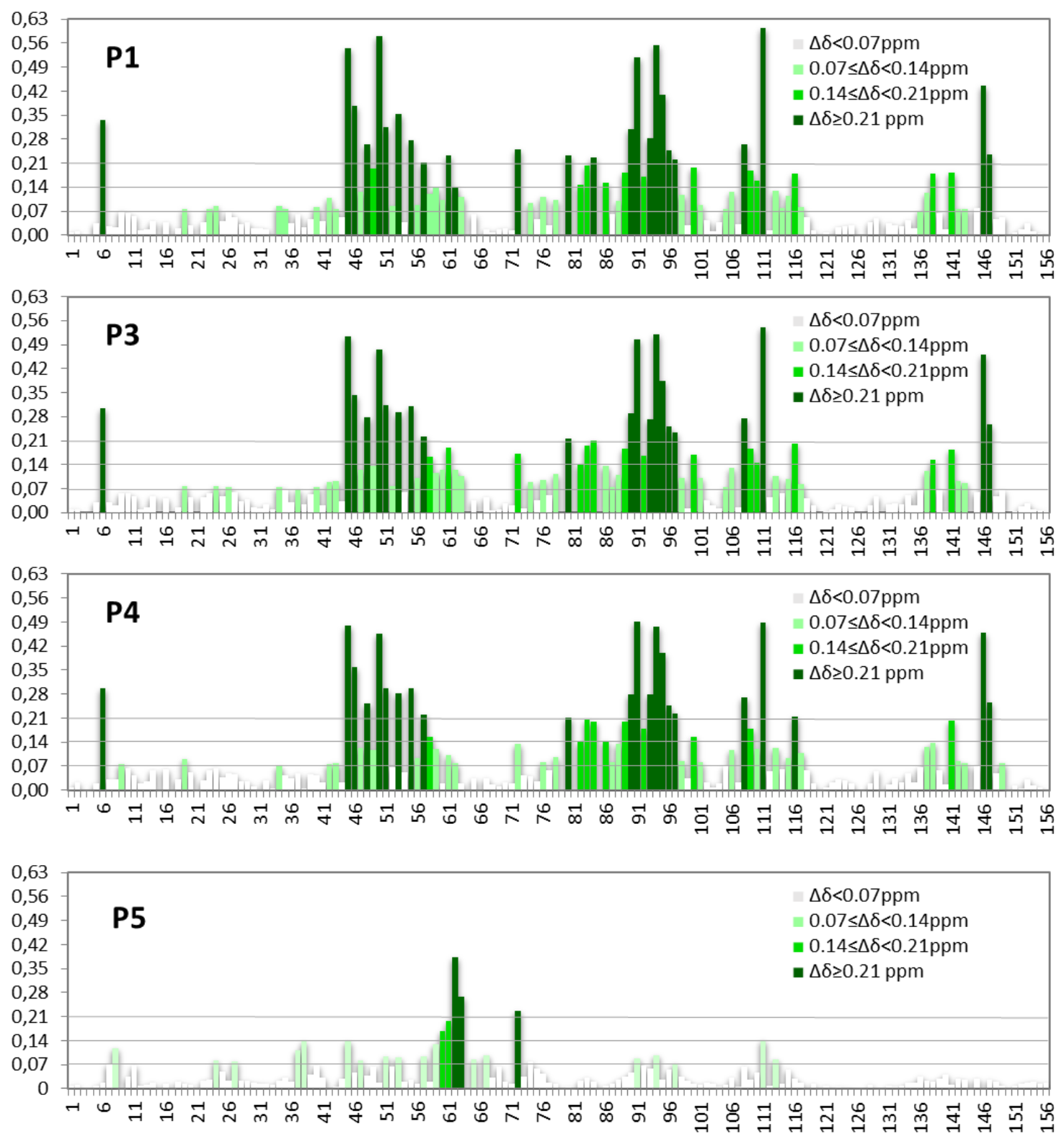

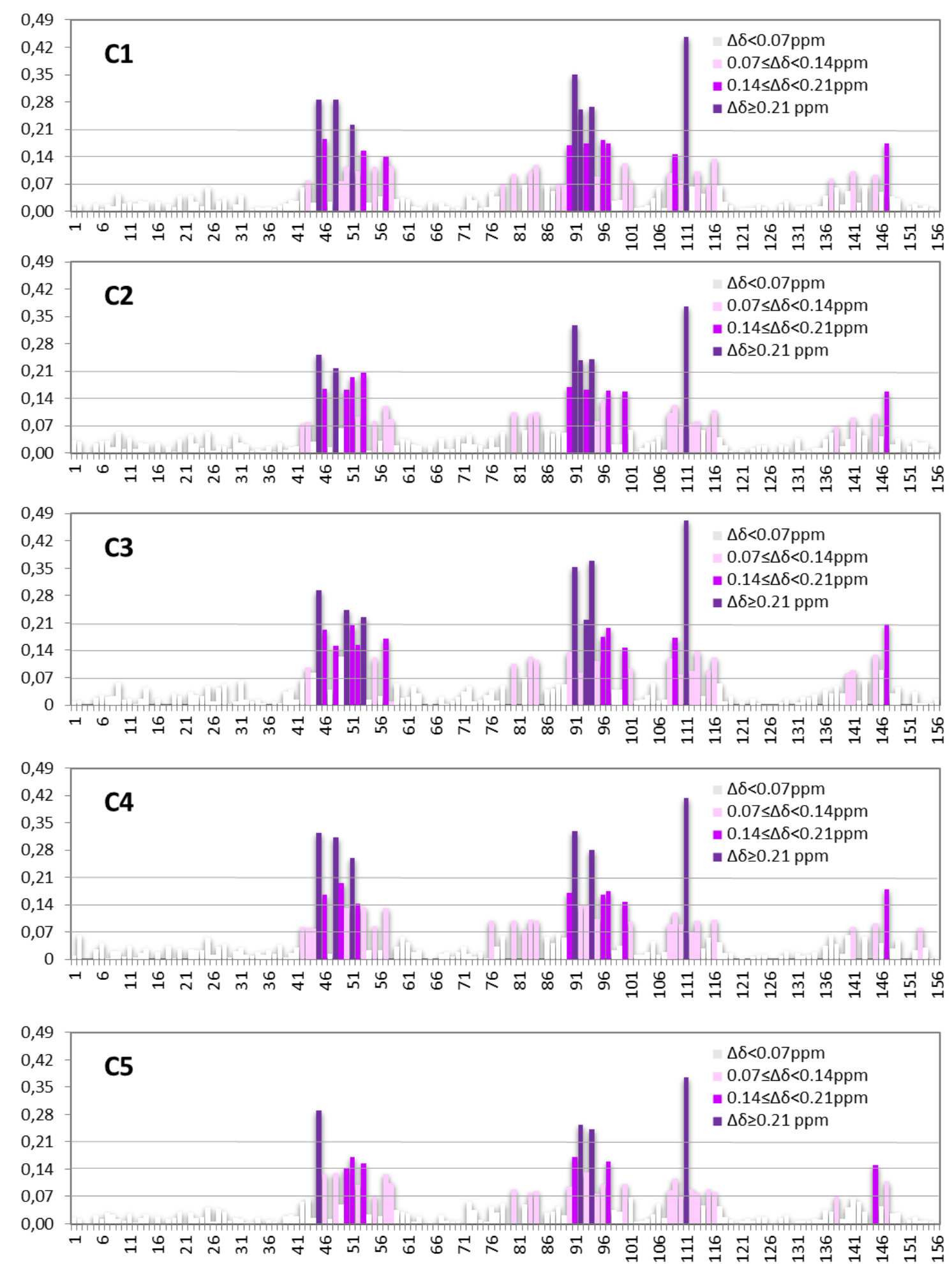

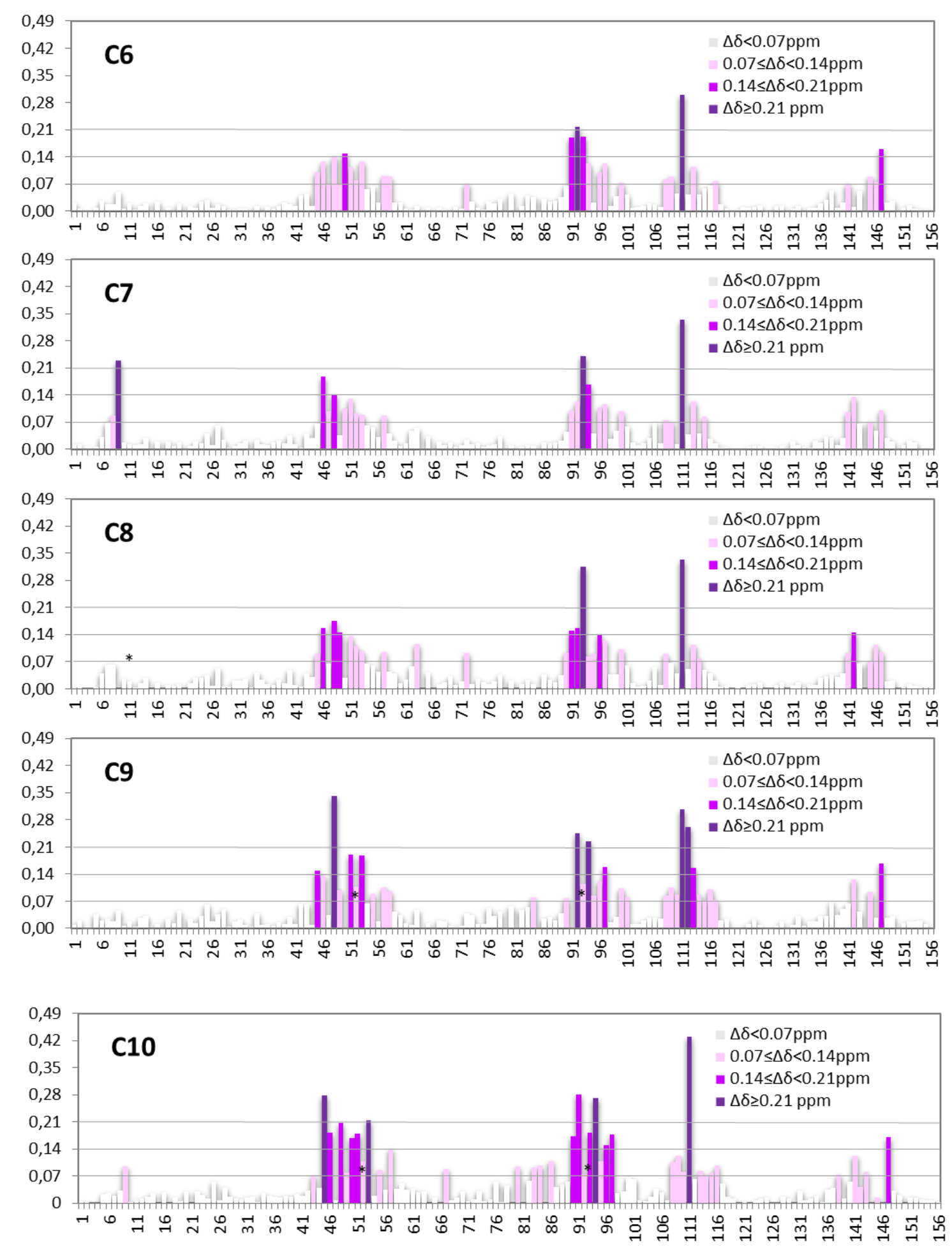

Figure S3. Chemical shift variation after addition of an excess of the indicated peptide/chimera. Stars indicate the disappearing of the signal due to chemical exchange. Chemical shift changes of residues are highlighted with the following color code (in magenta or green): dark color $\Delta \delta>0.21$, medium color $0.21<\Delta \delta<0.14$, light color $0.14<\Delta \delta<0.07$, gray $\Delta \delta<0.07$. 

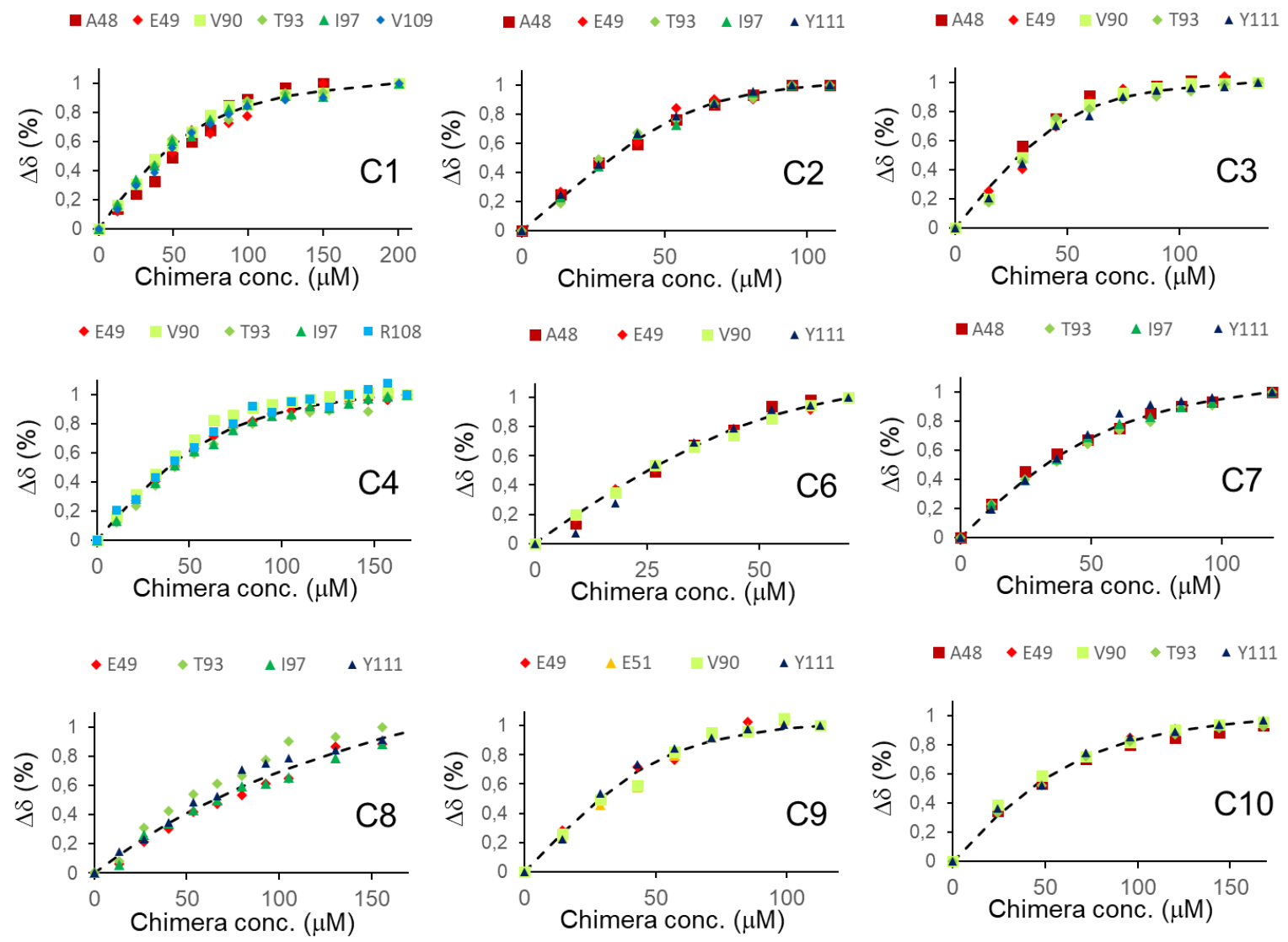

Figure S4. NMR titration curves upon addition of the indicated chimera. Experimental values for the indicated residues are shown. The curve corresponding to the mean $K_{D}$ value is presented with a dashed line. 


\section{Crystallization, data collection and structure determination}

Table S2 : Data collection and statistical refinement of the crystal structures of ASF1A(1-156) in complex with the inhibitory chimer $\mathbf{C 2}$.

\begin{tabular}{|c|c|}
\hline & hASF1A(1-156)-C2 \\
\hline \multicolumn{2}{|l|}{ Data collection } \\
\hline Space group & $P 1$ \\
\hline \multicolumn{2}{|l|}{ Cell dimensions } \\
\hline$a, b, c(\AA)$ & $36.73,51.28,56.08$ \\
\hline$\alpha, \beta, \gamma\left(^{\circ}\right)$ & $112.38,104.87,101.190$ \\
\hline Resolution $(\AA ̊)$ & $48.291-1.798$ (1.91-1.798)* \\
\hline$R_{\text {merge }}$ & $8.4(66.6)^{*}$ \\
\hline$I / \sigma I$ & $9.4(2.14)^{*}$ \\
\hline Complefteness (\%) & $96.1(70.5)^{*}$ \\
\hline Redundancy & $3.9(2.6)^{*}$ \\
\hline \multicolumn{2}{|l|}{ Refinement } \\
\hline Resolution $(\AA ̊)$ & 48.291-1.798 \\
\hline No. unique reflections & 31049 \\
\hline$R_{\text {work }} / R_{\text {free }}(\%)$ & $17.64 / 20.72$ \\
\hline \multicolumn{2}{|l|}{ No. atoms } \\
\hline Protein & 2576 \\
\hline Ligand/ion & 369 \\
\hline Water & 180 \\
\hline \multicolumn{2}{|l|}{$B$-factors } \\
\hline Protein & 35.2 \\
\hline Ligand/ion & 47.1 \\
\hline Water & 44.3 \\
\hline \multicolumn{2}{|l|}{ R.m.s. deviations } \\
\hline Bond lengths $(\AA ̊)$ & 0.010 \\
\hline Bond angles $\left({ }^{\circ}\right)$ & 1.10 \\
\hline
\end{tabular}

*Values in parentheses are for highest-resolution shell. 

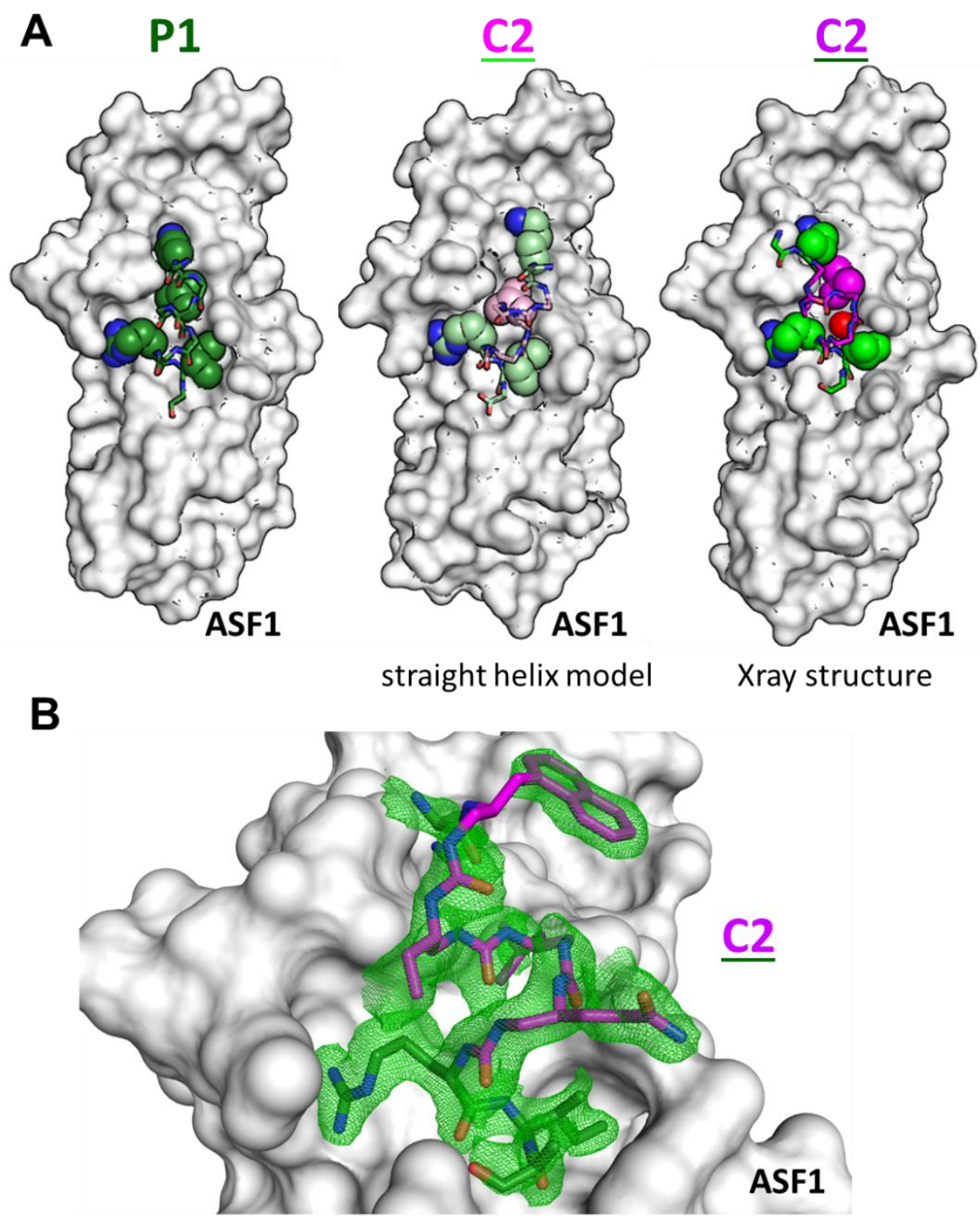

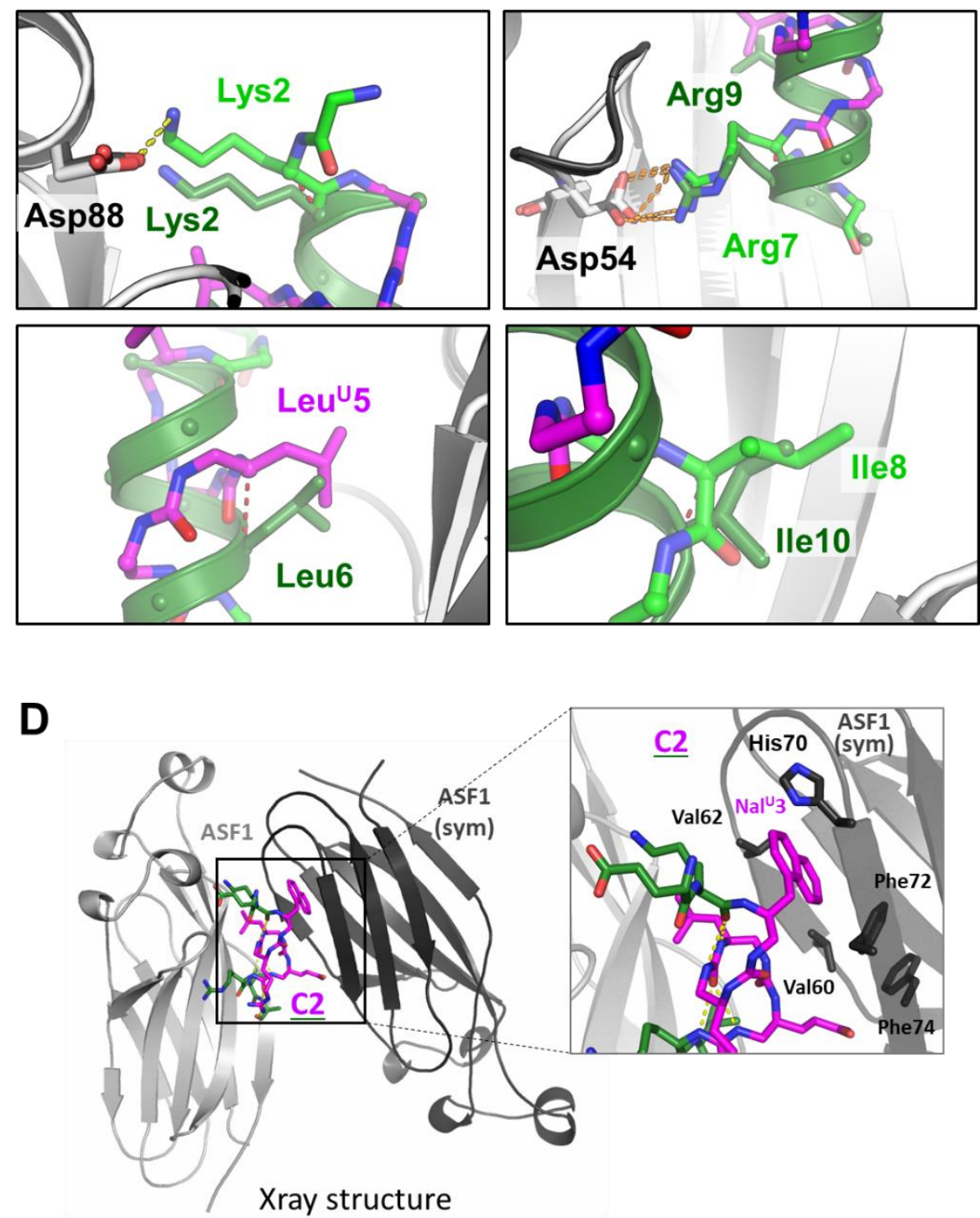

Figure S5. X-ray structure of the complex ASF1-C2. A) Overview of the structure of the complex. ASF1 is shown with a gray surface. P1, modeled $\mathbf{C 2}$ and experimental $\mathbf{C 2}$ conformations are shown in sticks in the left, middle and right panels respectively. The four anchor residues side chains are labeled and shown as spheres. The color code is the same as in Fig. 4. B) Electron density map ( $|\mathrm{Fo}|-|\mathrm{Fc}|$ omit map for the chimera) contoured at $2.8 \sigma$ presented with green mesh. The structure of $\mathbf{C 2}$ obtained after the final refinement is shown as sticks, ASF1 as a gray surface. C) Overlay of $\mathbf{P 1}$ and $\mathbf{C 2}$ bound to ASF1 (C2 alpha aminoacids in light green and ureido residues groups in pink and P1 in dark green). ASF1 bound to P1 is in black and ASF1 bound to $\mathbf{C 2}$ in gray. Each panel is centered on one anchor residue as indicated. Hydrogen bonds are shown with orange dashed lines. D) Left panel, crystal packing induced interaction of $\mathbf{C} 2$ with a second ASF1 molecule engaging the $\mathrm{Nal}^{\mathrm{U}} 3$ side chain. Right panel, zoomed view of this second interface. ASF1 residues in contact with $\mathrm{Nal}^{\mathrm{U}} 3$ side chain are highlighted. 